
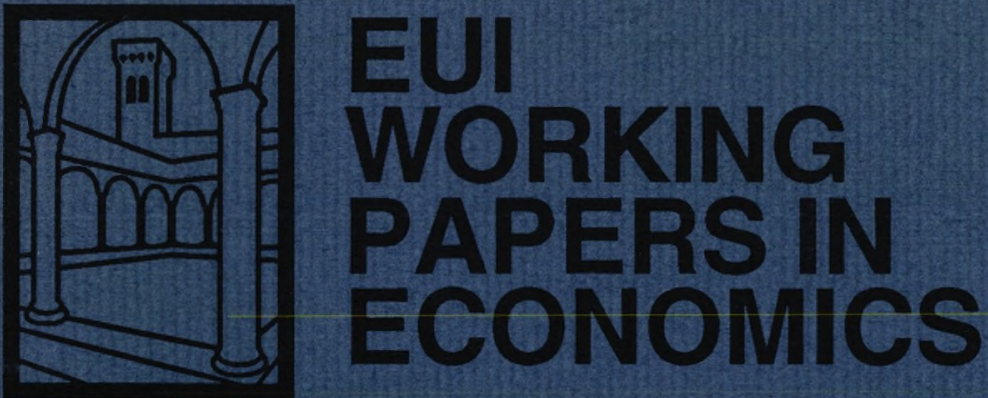

EUI Working Paper ECO No. 94/15

Oligopoly Limit Pricing: Strategic

Substitutes, Strategic Complements

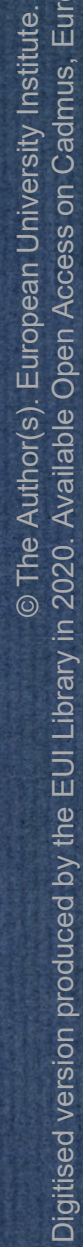

Stephen Martin

WF

330

EUR 
European University Library

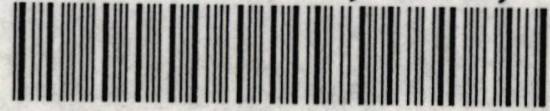

30001001584236 
EUROPEAN UNIVERSITY INSTITUTE, FLORENCE

ECONOMICS DEPARTMENT

EUI Working Paper ECO No. 94/15

Oligopoly Limit Pricing: Strategic

Substitutes, Strategic Complements

STEPHEN MARTIN 
All rights reserved.

No part of this paper may be reproduced in any form without permission of the author.

(c) Stephen Martin

Printed in Italy in April 1994

European University Institute

Badia Fiesolana

I - 50016 San Domenico (FI)

Italy 


\title{
Oligopoly Limit Pricing: Strategic Substitutes, Strategic Complements
}

\author{
Stephen Martin* \\ Department of Economics \\ European University Institute \\ 50016 San Domenico di Fiesole \\ Florence, Italy \\ martin@datacomm.iue.it
}

January 28, 1994

\begin{abstract}
Conditions are outlined under which it is a sequential equilibrium for firms to forego current profit to reduce the likelihood of entry, if firms are uncertain about rivals' costs. The assumptions about out-of-equilibrium beliefs that sustain such equilibria are more plausible if firms produce strategic substitutes than if firms produce strategic complements.
\end{abstract}

JEL Codes: D43, L13

${ }^{*}$ I am grateful to anonymous referees, to Svend Albaek, and to seminar participants at the September 1993 ASSET meetings and at IGIER for comments on earlier versions of this paper. Responsibility for errors is my own. 


\section{Contents}

1 Introduction 1

2 Preliminaries 2

2.1 General setup . . . . . . . . . . . . . . . . . . 2

2.2 Solution concept . . . . . . . . . . . . . . . . 2

3 Pooling Equilibria 3

3.1 Preconditions for pooling to limit entry . . . . . . . . . . . . . 3

3.2 Strategic substitutes: high-output pooling equilibrium .... 5

3.2.1 Behavior of the potential entrant . . . . . . . . . 6

3.2.2 Behavior of low-cost incumbents . . . . . . . . . . 6

3.2.3 Behavior of high-cost incumbents . . . . . . . . . . . 6

3.2 .4 Linear examples . . . . . . . . . . . . . . . . . . 8

3.3 Low-price pooling equilibrium . . . . . . . . . . . . . . 9

3.3.1 Behavior of the entrant . . . . . . . . . . . . 10

3.3.2 Behavior of high-cost incumbents, case $2(\mathrm{a}) \ldots . . .10$

3.3.3 Behavior of high-cost incumbents, case 2(b) . . . . . . . 11

3.3.4 Behavior of low-cost incumbents, case 2(a). . . . . . 11

3.3.5 A linear example ... . . . . . . . . . . 13

4 Separating Equilibrium 14

4.1 Entrant's post-separation payoffs . . . . . . . . . . . . . . 14

4.2 Strategic substitutes . . . . . . . . . . . . . . . . . 15

4.2 .1 Case $\mathrm{S} 2 \ldots \ldots \ldots 16 \ldots$

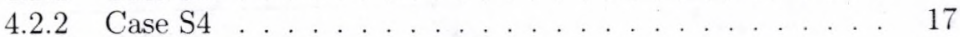

4.2 .3 A linear example . . . . . . . . . . . . . . . 18

4.3 Strategic complements . . . . . . . . . . . . . . . . . 19

4.3 .1 Case S2 . . . . . . . . . . . . . . . . . . . 19

4.3.2 Case S4 . . . . . . . . . . . . . . . . . . . . . . . 21

4.3.3 A linear example ................ . . 22

5 Disequilibrium Beliefs and the Plausibility of Equilibria $\quad 22$

6 Conclusion $\quad 23$

7 References $\quad 25$ 


\section{Introduction}

In the words of Bain (1949, p. 449), limit pricing occurs when

established sellers persistently ...[forego] prices high enough to maximize the industry profit for fear of thereby attracting new entry to the industry and thus reducing the demands for their outpuis and their own profits.

The implications of limit pricing for market performance are mixed. Because incumbents forego some economic profit, market performance is better than it would be without the threat of entry. But limit pricing allows incumbents to exercise some market power over the long run.

Milgrom and Roberts' (1982) model of monopoly limit pricing traces its ancestry to Bain's literary analysis. From their work springs a proliferation of models of monopoly and more recently oligopoly limit pricing. ${ }^{1}$ A central topic of this literature is the analysis of circumstances, if any, under which noncooperative limit pricing is an equilibrium strategy when there are multiple incumbents.

Bagwell and Ramey (1991) model noncooperative entry deterrence in duopoly when incumbents' costs depend on an industry cost parameter. Because incumbents' costs are either both high or both low, plausible pooling equilibria fail to exist. In equilibrium an entrant can infer the true value of the industry cost parameter by observing incumbents prices.

In this paper, I explore an alternative specification. in which unit costs may differ across firms. It is clear that such differences occur in real world markets. ${ }^{2}$ Results show that if an entrant's uncertainty about incumbents' costs is firm-specific, then there are conditions under which incumbents, in sequential equilibrium, noncooperatively give up some current profit to deter some or all future entry. This is so even if incumbents have high cost and each incumbent knows that the other has high cost. But whether firms' products are strategic substitutes or strategic complements is seen to be critical to the plausibility of the disequilibrium beliefs that sustain entry-limiting and other equilibria.

\footnotetext{
${ }^{1}$ For references, see Martin (1993, Chapter 4) or Bagwell and Ramey (1991, pp. 155-156).

${ }^{2}$ Consider, for example, the world automobile industry.
} 


\section{Preliminaries}

\subsection{General setup}

In the first period of a two-period market, there are two incumbents. A potential entrant observes first-period actions and decides whether or not to come into the market in the second period.

Each firm's constant unit cost is either high $\left(c_{H}\right)$ or low $\left(c_{L}\right){ }^{3}$ Unit costs may differ across firms. At the beginning of the game, each firm knows its own unit cost, but not the unit costs of its rivals. Each firm has prior beliefs about rivals' cost types. Prior beliefs are common knowledge. Following Harsanyi [1967-68], this makes it possible to model the game as one of complete but imperfect information.

If entry occurs, the entrant pays a fixed and sunk entry cost $K$ (the value of which is common knowledge). The entrant breaks even by staying out of the market.

\subsection{Solution concept}

I examine conditions for specified actions and beliefs to constitute a sequential equilibrium. In sequential equilibrium, each firm's strategy maximizes its expected payoff, given the equilibrium behavior of other firms and beliefs about out-of-equilibrium behavior. ${ }^{4}$ Equilibrium beliefs must be consistent with equilibrium behavior, as implied by Bayes' Law. Beliefs about out-of-equilibrium behavior are not restricted by the requirement of consistency with Bayes' Law, and will be specified below on a case-by-case basis.

In pooling equilibrium, incumbents of either cost type play the same action in the first period. No knowledge about cost types is gained by observing first-period actions, and prior beliefs are carried forward from the first period to the second. In separating equilibrium, incumbents of different cost types play different actions in the first period, and observation of first-period actions reveals incumbents' cost types. In either type of equilibrium, if only a low-cost entrant would find it profitable to come into the market, then the fact of entry reveals the entrant's cost type. If an entrant of either cost type would find entry profitable, then incumbents carry prior beliefs about the entrant's cost type forward from the first to the second period.

\footnotetext{
${ }^{3}$ The assumption that the values of high unit cost and low unit cost are the same for all firms can be relaxed without altering the nature of the results.

${ }^{4}$ Formally, an incumbent's strategy is an ordered triple, giving its first period action, its second-period action if entry occurs, and its second period action if entry does not occur. The entrant's strategy specifies whether or not it enters and, if it enters, its second-period action.
} 


\section{Pooling Equilibria}

\subsection{Preconditions for pooling to limit entry}

The extent to which a pooling strategy can limit entry depends on the relation between the entrant's expected post-entry profit and sunk entry cost $K$. If incumbents pool in the first period, three cases may be distinguished:

(1) Free and easy entry: sunk entry $\operatorname{cost} K$ is so low that a high-cost entrant expects a positive net profit after entry if each incumbent's cost type is known only to itself;

(2) Some entrant limitation possible: sunk entry cost $K$ takes intermediate values; a low-cost entrant expects a positive net profit after entry, if each incumbent's cost type is known only to itself, but a high - cost entrant does not. Two subcases may be distinguished:

(a) for smaller values of sunk entry cost $K$, if a high-cost incumbent defects from pooling equilibrium in the first period. revealing its cost type, it becomes profitable for a high-cost entrant to come into the market;

(b) for larger values of entry cost $K$, a high-cost incumbent can defect from pooling equilibrium in the first period, revealing its cost type, without making entry profitable for a high-cost potential entrant;

(3) Complete entry limitation possible: sunk entry cost $K$ takes higher values; if each incumbent's cost type is known only to itself, a low-cost entrant expects a negative profit after entry. Two subcases may be distinguished:

(a) for smaller values of sunk entry cost $K$, if a high-cost incumbent defects from pooling equilibrium in the first period, revealing its cost type, a low-cost entrant expects a positive post-entry profit and a high-cost entrant expects a negative profit after entry;

(b) blockaded entry: for larger values of entry cost $K$, a high-cost incumbent can defect from pooling behavior in the first period. revealing its cost type, without making it profitable for a low-cost entrant to come into the market.

To determine the ranges of $K$ that define these different cases, one must examine equilibrium payoffs in the one-period game that would be played in the second period if entry occurs but each firm knows only its own cost type. The natural generalization of Nash equilibrium such markets is to require that 
each firm's noncooperative equilibrium action maximize its own expected profit, taking the equilibrium actions of rivals of different cost types as given. ${ }^{5}$

If entry occurs and each firm knows only its own cost type, the game that is played has 6 notional players: a high-cost firm 1 , a low-cost firm 1 , a highcost firm 2, a low-cost firm 2, a high-cost entrant, and a low-cost entrant. Let the subscripts 1 and 2 designate the first and second incumbent, respectively, while the subscript 3 refers to the entrant. To describe prior beliefs, write

$$
u_{i j}=\text { firm } i \text { 's prior probability that firm } j \text { 's costs are high, }
$$

for $i, j=1,2,3$ and $j \neq i$. For notational compactness, write $v_{i j}=1-u_{i j}$.

The high-cost entrant's expected payoff in this 6-player game (before allowing for the cost of entry) can be written ${ }^{6}$

$$
\pi_{3 H}\left(u_{12}, u_{13}, u_{21}, u_{23}, u_{31}, u_{32}\right) .
$$

The first two arguments in (2) indicate firm 1's prior beliefs, the next two indicate firm 2's prior beliefs, and the last two give the entrant's prior beliefs. This notation will be used throughout the paper.

Then if

$$
\pi_{3 H}\left(u_{12}, u_{13}, u_{21}, u_{23}, u_{31}, u_{32}\right)>K .
$$

a high-cost entrant expects a positive net profit after entry. This puts the game in case 1: incumbents cannot prevent entry by pooling.

On the other hand, if ${ }^{7}$

$$
\pi_{3 L}\left(u_{12}, 0, u_{21}, 0, u_{31}, u_{32}\right)>K \geq \pi_{3 H}\left(u_{12}, u_{13}, u_{21}, u_{23}, u_{31}, u_{32}\right),
$$

a known low-cost entrant expects a positive profit competing against incumbents whose cost types are not common knowledge. This is the condition for the game to be in case 2: if incumbents pool in the first period, a high-cost entrant will stay out of the market, but a low-cost entrant will come in. In case 2 , the fact of entry reveals that the entrant has low unit cost.

Finally, if

$$
K \geq \pi_{3 L}\left(u_{12}, 0, u_{21}, 0, u_{31}, u_{32}\right),
$$

a known low-cost entrant expects a net loss competing against incumbents whose cost types are not common knowledge. If condition (5) is met, the game is in case 3: if incumbents pool in the first period, entry does not occur.

\footnotetext{
${ }^{5}$ This is the approach of Saloner's [1987] model of duopoly with one-sided uncertainty about firm costs.

${ }^{6}$ For explicit solutions for the various payoffs in linear quantity-setting and price-setting models, see the Appendix.

${ }^{7} \mathrm{I}$ adopt the convention that if a potential entrant expects to break even, it stays out of the market.
} 
Making due allowance for the fact that they model a market with a single incumbent, Milgrom and Roberts (1982) consider a situation that corresponds to case 2. Detailed discussion in this paper is also limited to case 2. Results for case 3, which are logically parallel to those for case 2, are contained in an Appendix that is available on request from the author.

\subsection{Strategic substitutes: high-output pooling equilib- rium}

For concreteness, consider a market in which firms set quantities and produce a homogeneous product. Qualitatively, the results obtained hold provided the outputs of different firms are strategic substitutes. ${ }^{8}$ Let $q_{L}$ be noncooperative (Cournot) equilibrium duopoly output if both incumbents are known to have low cost. I seek conditions under which the following pooling entry-limiting collection of strategies and beliefs is a sequential equilibrium:

High-output pooling, case 2:

(a) incumbents each produce $q_{L}$ in period 1;

(b) a high-cost potential entrant stays out in period 2;

(c) a low-cost potential entrant enters in period 2;

(d) if entry does not occur, then in the second period incumbents produce their equilibrium outputs in the duopoly game with unknown cost types;

(e) incumbents and the entrant carry prior beliefs about incumbents' cost types forward from the first to the second period; if entry occurs, the entrant is revealed as having low cost, while each incumbent's cost type is known only to itself, and each player produces the secord-period output that maximizes its expected payoff, given beliefs.

Out-of-equilibrium beliefs are not restricted by the requirements of sequential equilibrium. Assume that if an incumbent produces any output other than $q_{L}$. in period 1 , rivals believe that it has high cost.

Incumbents' payoffs are the sums of their payoffs in the two periods.

\footnotetext{
${ }^{8}$ That is, that an increase in the choice variable of one firm, here taken to be output. decreases the marginal profitability of other firms; see Bulow et al. [1985].
} 


\subsubsection{Behavior of the potential entrant}

In equilibrium, the potential entrant acquires no information about incumbents' cost types by observing first-period output. The pooling strategy calls for the potential entrant to come in if its expected post-entry profit is positive, otherwise to stay out, and to maximize expected profit if it does come in. Given its beliefs, the entrant maximizes its expected payoff by behaving in this way.

\subsubsection{Behavior of low-cost incumbents}

If a low-cost incumbent produces any output other than $q_{L}$ in period 1 , it reduces its expected first-period payoff and portrays itself as a high-cost firm to the other incumbent and to the entrant. Because products are strategic substitutes, this induces the other incumbent to produce more in period 2 than if the pooling strategy were followed. It does not reduce, and may increase, the probability of entry. First-period defection therefore reduces the expected second-period payoff as well as the expected first-period payoff. It follows that a low-cost incumbent would not wish to defect from the strategy outlined above.

\subsubsection{Behavior of high-cost incumbents}

If incumbent $1 H$ pools in the first period, its expected equilibrium payoff is

$$
\pi_{1 H}\left(q_{L}\right)+u_{13} \pi_{1 H}\left(u_{12}, u_{21}\right)+v_{13} \pi_{1 H}\left(u_{12}, 0, u_{21}, 0, u_{31}, u_{32}\right) .
$$

The first term is the equilibrium payoff of a high-cost firm that produces output $q_{L}$ in the first period. The second term is the second-period payoff of firm $1 H$ if the entrant has high cost and stays out of the market, weighted by firm $1 \mathrm{H}$ 's prior probability that the entrant has high cost. The third term is firm $1 H$ 's the second-period payoff if the entrant has low cost and comes into the market, weighted by firm $1 H$ 's prior probability that the entrant has low cost. (Because the game is in stage 2 , the fact that the entrant comes into the market reveals that the entrant has low cost; thus the second and fourth arguments in the third term are zero.)

Case 2(a) Firm 1H's defection payoff depends on whether the game is in case 2 (a) or case 2(b). In case 2(a), defection implies that entry becomes profitable for a high-cost entrant. The defecting firm $1 H$ 's payoff is

$$
\pi_{1 H}^{b r}\left(q_{L}\right)+\pi_{1 H}\left(u_{12}, u_{13}, 1, u_{23}, 1, u_{32}\right) .
$$

Given out-of-equilibrium beliefs, any defection by firm 1 in the first period convinces rivals that firm 1 has high cost. This being the case, if firm $1 H$ defects, it will produce its best-response output to the equilibrium output of 
the other firm. This is the first term in (7). Then in the second period, firm 1 's cost type is common knowledge, while each other firm's cost type is known only to itself.

In case $2(\mathrm{a})$, firm $1 H$ will pool if $(6)$ is greater than or equal to (7), a condition that can be written

$$
\begin{gathered}
u_{13}\left[\pi_{1 H}\left(u_{12}, u_{21}\right)-\pi_{1 H}\left(u_{12}, 1\right)\right] \\
+v_{13}\left[\pi_{1 H}\left(u_{12}, 0, u_{21}, 0, u_{31}, u_{32}\right)-\pi_{1 H}\left(u_{12}, u_{13}, 1, u_{23}, 1, u_{32}\right)\right] \\
+u_{13}\left[\pi_{1 H}\left(u_{12}, 1\right)-\pi_{1 H}\left(u_{12}, u_{13}, 1, u_{23}, 1, u_{32}\right)\right] \geq \pi_{1 H}^{b r}\left(q_{L}\right)-\pi_{1 H}\left(q_{L}\right)
\end{gathered}
$$

The right-hand side gives the first-period increase in profit from defection. The first and second terms on the left show the impact of cost-type revelation on firm $1 H$ 's second-period payoffs, in the cases in which the entrant has high and low costs, respectively, weighted by the corresponding prior probabilities. The third term on the left shows the impact of entry by a firm of unknown cost type on firm $1 H$ 's second-period profit, when firm $1 H$ 's cost type is common knowledge.

The second term on the left in (8) can be written as the difference between two components. The first,

$$
\pi_{1 H}\left(u_{12}, 0, u_{21}, 0, u_{31}, u_{32}\right)-\pi_{1 H}\left(u_{12}, 0,1,0,1, u_{32}\right),
$$

is a pure cost revelation effect: it gives firm $1 H$ 's lost profit competing against firm 2 of unknown cost type and a known low-cost entrant because it reveals itself as having high cost. The second,

$$
\pi_{1 H}\left(u_{12}, u_{13}, 1, u_{23}, 1, u_{32}\right)-\pi_{1 H}\left(u_{12}, 0,1,0,1, u_{32}\right),
$$

is firm $1 H$ 's expected gain in profit competing against an entrant of unknown cost type rather than a known low-cost entrant. When products are strategic substitutes, firm $1 H$ has a greater expected profit if there is some probability that firm 3 has high cost than if it is known that firm 3 has low cost. Expressions (9) and (10) are both positive; their difference, the net effect of cost type revelation on firm $1 H$ 's second-period payoff if the entrant has low cost, can be positive or negative.

Case 2(b) In case 2(b), defection does not alter the probability of entry. Firm $1 H$ 's expected defection payoff is

$$
\pi_{1 H}^{b r}\left(q_{L}\right)+u_{13} \pi_{1 H}\left(u_{12}, 1\right)+v_{13} \pi_{1 H}\left(u_{12}, 0,1,0,1, u_{32}\right) .
$$

The condition for firm $1 H$ to pool if the game is in case 2(b) is

$$
u_{13}\left[\pi_{1 H}\left(u_{12}, u_{21}\right)-\pi_{1 H}\left(u_{12}, 1\right)\right]
$$




\begin{tabular}{|l|c|c|}
\hline Payoff Difference & $(\mathbf{1})$ & $\mathbf{( 2 )}$ \\
\hline$\pi_{1 H}\left(u_{12}, u_{21}\right)-\pi_{1 H}\left(u_{12}, 1\right)$ & 0.5033 & 0.0000 \\
\hline$\pi_{1 H}\left(u_{12}, 0, u_{21}, 0, u_{31}, u_{32}\right)-\pi_{1 H}\left(u_{12}, 0,1,0,1, u_{32}\right)$ & 0.4094 & 0.1825 \\
\hline$\pi_{1 H}\left(u_{12}, u_{13}, 1, u_{23}, 1, u_{32}\right)-\pi_{1 H}\left(u_{12}, 0,1,0,1, u_{32}\right)$ & 0.4094 & 0.4656 \\
\hline$\pi_{1 H}\left(u_{12}, 1\right)-\pi_{1 H}\left(u_{12}, u_{13}, 1, u_{23}, 1, u_{32}\right)$ & 3.1944 & 3.4055 \\
\hline$\pi_{1 H}^{b r}\left(q_{L}\right)-\pi_{1 H}\left(q_{L}\right)$ & 0.2500 & 0.2500 \\
\hline
\end{tabular}

Table 1: Firm $1 H$ Pooling Condition, Strategic Substitutes; (1) $a=10, c_{L}=1$, $c_{H}=2, u_{12}=u_{21}=0.4, u_{13}=u_{23}=0.5, u_{31}=u_{32}=0.6$; (2) $u_{12}=u_{21}=1$, otherwise as for (1).

$$
+v_{13}\left[\pi_{1 H}\left(u_{12}, 0, u_{21}, 0, u_{31}, u_{32}\right)-\pi_{1 H}\left(u_{12}, 0,1,0,1, u_{32}\right)\right] \geq \pi_{1 H}^{b r}\left(q_{L}\right)-\pi_{1 H}\left(q_{L}\right) .
$$

Since defection does not alter the probability of entry, the incentive to separate depends on a tradeoff between lost second-period profit due to cost-type revelation and the first-period gain from defection.

Given that the entrant and low-cost incumbents maximize their expected payoffs by pooling, the results of this section may be summarized as

Theorem 1: For firms producing strategic substitutes, high-output pooling is a sequential equilibrium if a high-cost incumbent's second-period expected lost profit due to cost type revelation and entry (if any) outweighs the first-period profit gained by defecting.

It is only in case 2(a) that high-output pooling involves entry-limiting behavior.

\subsubsection{Linear examples}

Let the product be homogeneous and the demand curve linear,

$$
p=a-Q
$$

Let $a=10, c_{L}=1$, and $c_{H}=2$. Case 2 (by pooling, incumbents can preclude entry by a high-cost firm) holds if $3.90 \leq K<6.76$. Case 2(a) (firstperiod defection from pooling equilibrium means that entry becomes profitable for a high-cost entrant) occurs for $3.90 \leq K<4.20$. The high-output pooling equilibrium calls for incumbents to produce $q_{L}=3$.

First, let $u_{12}=u_{21}=0.4, u_{13}=u_{23}=0.5$, and $u_{31}=u_{32}=0.6 .^{9}$ Then condition (8) becomes (see Table 1)

\footnotetext{
${ }^{9} \mathrm{I}$ have imposed a limited symmetry of prior beliefs, to reduce the number of entries in the tables. BASIC computer programs that evaluate stability conditions for general parameter values are available on request.
} 


$$
\frac{1}{2}(0.5033)+\frac{1}{2}(0.4094-0.4094)+\frac{1}{2}(3.1944) \geq \frac{1}{4} .
$$

The first two terms on the left are cost type revelation effects. These terms alone are greater than the gain from defection (the right hand side), which means that firm $1 H$ would be willing to pool in case $2(\mathrm{~b})$. The third term on the left is expected lost profit due to entry; it is an order of magnitude greater than the cost type revelation effects, and sufficient to ensure pooling in its own right.

Now let $u_{12}=u_{21}=1$, keeping all other parameters of the example unchanged. This is the situation in which each incumbent believes with certainty that the other has high cost. It illustrates incentives to pool if incumbents have high cost and, because they have competed in the same market for some time, know each other's cost type. Condition (8) becomes

$$
\frac{1}{2}(0.0000)+\frac{1}{2}(0.1825-0.4656)+\frac{1}{2}(3.4054) \geq \frac{1}{4}
$$

The first term on the left is zero: if firm 2 believes that firm 1 has high cost, then firm $1 H$ loses nothing by confirming this belief. The second term is negative: for these parameter values, (10) is greater in magnitude than (9). Nonetheless, expected lost profit due to induced entry dominates the first period gain from defection. High-cost incumbents will pool on $q_{L}$ in case 2(a). but not in case $2(\mathrm{~b})$.

\subsection{Low-price pooling equilibrium}

Suppose now that firms set price, supplying differentiated varieties that are strategic complements. Let $p_{L}$ be the noncooperative (Bertrand) equilibrium duopoly price if both incumbents are known to have low cost. Consider the following low-price pooling entry-limiting collection of strategies and beliefs:

Low-price pooling, case 2:

(a) incumbents each set price $p_{L}$ in period 1 ;

(b) a high-cost potential entrant stays out in period 2:

(c) a low-cost potential entrant enters in period 2;

(d) if entry does not occur, then in the second period incumbents set their equilibrium prices in the duopoly game with unknown cost types:

(e) incumbents and the entrant carry prior beliefs about incumbents cost types forward from the first to the second period; if entry occurs. the 
entrant is revealed as having low cost, while each incumbent's cost type is known only to itself, and each player sets the second-period price that maximizes its expected payoff, given beliefs.

If an incumbent sets any price other than $p_{L}$ in period 1 , rivals believe that it has high cost.

Incumbents' payoffs are the sums of their payoffs in the two periods.

\subsubsection{Behavior of the entrant}

In equilibrium, the entrant acquires no information about incumbents' cost types by observing first-period price. The strategy outlined above calls for the entrant to come in if expected profit from entry is positive, and otherwise to stay out. Given its beliefs, the entrant maximizes its expected payoff by behaving in this way.

\subsubsection{Behavior of high-cost incumbents, case 2(a)}

When firms set price and defection by a high-cost incumbent would make it profitable for a high-cost entrant to come into the market, the condition for a high-cost incumbent to pool on $p_{L}$ in the first period is

$$
\begin{gathered}
u_{13}\left[\pi_{1 H}\left(u_{12}, 1\right)-\pi_{1 H}\left(u_{12}, u_{13}, 1, u_{23}, 1, u_{32}\right)\right] \geq \pi_{1 H}^{b r}\left(p_{L}\right)-\pi_{1 H}\left(p_{L}\right) \\
+u_{13}\left[\pi_{1 H}\left(u_{12}, 1\right)-\pi_{1 H}\left(u_{12}, u_{21}\right)\right] \\
+v_{13}\left[\pi_{1 H}\left(u_{12}, u_{13}, 1, u_{23}, 1, u_{32}\right)-\pi_{1 H}\left(u_{12}, 0, u_{21}, 0, u_{31}, u_{32}\right)\right]
\end{gathered}
$$

The term on the left is the pure entry effect of defection on firm $1 H$ 's profit; the first term on the right is the first-period gain from defection. The remaining terms on the right are cost-type revelation effects. When produce varieties that are strategic complements, a firm has a higher second-period profit if rivals believe that it has high cost, holding the number of rivals constant. If a high--cost incumbent defects, thus revealing its cost type, rivals charge higher prices in the second period than they would if they thought there was some possibility that the incumbent had low cost. With upward sloping reaction functions, this allows the defecting firm to charge a higher equilibrium second-period price. When firms produce varieties that are strategic complements, entry deterrence effects and cost-type revelation effects influence high-cost incumbents' incentives in opposite directions. ${ }^{10}$

It is apparent from the left-hand side of (16) that if $u_{13}$ is sufficiently small - if firm 1 thinks it very likely that the entrant has low cost - a high-cost firm 1 will defect from the low-price pooling equilibrium. If $u_{13}$ is low, firm 1 believes entry is likely to occur whether it pools or not. In this case, firm $1 H$ is able to set a higher price in period 2 if it defects and reveals its cost type.

\footnotetext{
${ }^{10}$ See Bulow et al. [1985, p. 506].
} 


\subsubsection{Behavior of high-cost incumbents, case 2(b)}

When firms produce varieties that are strategic complements, if a high-cost incumbent can defect without making it profitable for a high cost cntrint to come into the market, then it will always find it profitable to defect from the low-price pooling strategy.

The intuition behind this result is straightforward. Defection increases the high-cost incumbent's first-period payoff. By revealing that it has high cost, the defecting firm leads second-period rivals (whether this is the other incumbent or the other incumbent and the low-cost entrant) to set higher prices than they would if they thought there was some probability that the defecting firm had low cost. Since defection does not affect the likelihood of entry, firstperiod defection raises the high-cost incumbent's payoff in both the first and the second periods.

\subsubsection{Behavior of low-cost incumbents, case 2(a)}

If firm $1 L$ pools on $p_{L}$ in the first period, its expected equilibrium payoff is

$$
\pi_{1 L}^{b r}\left(p_{L}\right)+u_{13} \pi_{1 L}\left(u_{12}, u_{21}\right)+v_{13} \pi_{1 L}\left(u_{12}, 0, u_{21}, 0, u_{31}, u_{32}\right) .
$$

$p_{L}$ is firm $1 L$ 's best-response price if firm 2 sets price $p_{L}$ (which is firm 2 's equilibrium action). This explains the first term in (17). In equilibrium entry does not occur with probability $u_{13}$, incumbents play a duopoly game in which cost types are not common knowledge in the second period, and firm $1 \mathrm{~L}$ has the payoff given by the second term in (17). Equilibrium entry occurs with probability $v_{13}$, firm $1 L$ 's prior probability that the entrant has low cost, leading to a second-period game in which the entrant is known to have low cost while each incumbent's cost type is known only to itself. The resulting payoff is the third term in (17).

If firm $1 L$ defects by a negligible amount from the pooling price $p_{L}$ in the first period, it reduces its first-period payoff by a negligible amount. Given the assumed nature of out-of-equilibrium beliefs, this leads the other incumbent and the entrant to believe that firm 1 has high cost.

The assumption that a small defection from $p_{L}$ leads rivals to believe that firm $1 L$ has high cost minimizes the opportunity cost to firm $1 L$, in terms of first-period lost profit, of defection. With other specifications of out - ofequilibrium beliefs (for example, that if rivals observe a disequilibrium price, they infer that the firm has the cost type for which the observed price is most profitable) it would be more costly for a low-cost incumbent to defect. If a low-cost incumbent would pool under the assumption made here, it would also pool under assumptions about out-of-equilibrium beliefs that imply a greater cost of defection. 
By masquerading as a high-cost firm, firm $1 L$ induces rivals to charge higher prices in the second period. This allows firm $1 L$ to charge a higher second-period price, and to earn a greater second-period profit, than would otherwise be possible. But the masquerade creates the possibility that a highcost potential entrant will come into the market.

If firm $1 L$ defects slightly from price $p_{L}$ in period 1 , its defection payoff is slightly less than

$$
\pi_{1 L}^{b r}\left(p_{L}\right)+\pi_{1 L}\left(u_{12}, u_{13}, 1, u_{23}, 1, u_{32}\right) .
$$

The arguments in the second term indicate that firms 2 and 3 incorrectly believe that firm 1 has high cost, while rivals' cost types are known only to themselves. Firm $1 L$ charges its best-response price to rivals' actions.

Comparing payoffs (17) and (18), firm $1 L$ will prefer to pool on $p_{L}$ in the first period if

$$
\begin{gathered}
u_{13}\left[\pi_{1 L}\left(u_{12}, 1\right)-\pi_{1 L}\left(u_{12}, u_{13}, 1, u_{23}, 1, u_{32}\right)\right] \geq u_{13}\left[\pi_{1 L}\left(u_{12}, 1\right)-\pi_{1 L}\left(u_{12}, u_{21}\right)\right] \\
+v_{13}\left[\pi_{1 L}\left(u_{12}, u_{13}, 1, u_{23}, 1, u_{32}\right)-\pi_{1 L}\left(u_{12}, 0, u_{21}, 0, u_{31}, u_{32}\right)\right]
\end{gathered}
$$

The term on the left gives the low-cost defector's expected lost profit due to entry. The terms on the right are masquerade effects. The first term is firm $1 L$ 's profit increase from convincing a single rival, firm 2, that it has high cost (weighted by $u_{13}$ ). The second term combines two effects, both of which tend to increase firm $1 L$ 's second-period payoff: convincing two rivals that it has high cost and creating the possibility that entry is by a high-cost firm.

As with (16), it is apparent from (19) that if $u_{13}$ is sufficiently small, firm $1 L$ will prefer not to pool.

Considering the incentives of high-cost and low-cost incumbents, the results of this section may be summarized as

Theorem 2: For firms producing strategic complements, low-price pooling is a sequential equilibrium (a) if a high-cost incumbent's second-period expected lost profit due to induced entry of a high-cost entrant outweighs the first-period gain from defection and the second-period gain from revealing its cost type, and (b) if a low-cost incumbent's second-period expected lost profit due to induced entry of a high-cost entrant outweighs the second-period gain from masquerading as a high-cost firm.

For firms producing varieties that are strategic complements, cost-type revelation is not enough to ensure pooling on low prices. If it is an equilibrium to pool on $p_{L}$, it is because the profit to be gained by deterring entry is sufficiently great. 


\begin{tabular}{|l|c|c|}
\hline Payoff Difference & $(\mathbf{1})$ & $\mathbf{( 2 )}$ \\
\hline$\pi_{1 H}\left(u_{12}, 1\right)-\pi_{1 H}\left(u_{12}, u_{13}, 1, u_{23}, 1, u_{32}\right)$ & 3.6135 & 3.8513 \\
\hline$\pi_{1 H}^{b r}\left(p_{L}\right)-\pi_{1 H}\left(p_{L}\right)$ & 0.3906 & 0.3906 \\
\hline$\pi_{1 H}\left(u_{12}, 1\right)-\pi_{1 H}\left(u_{12}, u_{21}\right)$ & 0.1366 & 0 \\
\hline$\pi_{1 H}\left(u_{12}, u_{13}, 1, u_{23}, 1, u_{32}\right)-\pi_{1 H}\left(u_{12}, 0, u_{21}, 0, u_{31}, u_{32}\right)$ & 0.5001 & 0.4643 \\
\hline
\end{tabular}

Table 2: Firm $1 H$ Pooling Condition, Strategic Complements; (1) $a=10$, $c_{L}=1, c_{H}=2, u_{12}=u_{13}=u_{21}=u_{31}=u_{32}=\theta=0.6$; (2) $u_{12}=u_{21}=1$. otherwise as for (1).

\subsubsection{A linear example}

Let the linear inverse demand curve for firm 1's variety be

$$
p_{1}=a-q_{1}-\theta q_{2}
$$

if there are two firms, or

$$
p_{1}=a-q_{1}-\theta q_{2}-\theta q_{3}
$$

if there are three firms, with corresponding expressions for firm 2 and the entrant.

The parameter $\theta$ governs demand relationships among varieties. For $0<$ $\theta<1$, products of different producers are imperfect substitutes in demand. if $\theta=0$, demands for the different varieties are independent. If $\theta=1$, the different varieties are perfect substitutes. ${ }^{11}$

Let $a=10, c_{L}=1$, and $\theta=0.6$. If it were known that both incumbents had low cost, noncooperative equilibrium prices in a one-period game would be

$$
p_{L}=c_{L}+\frac{1-\theta}{2-\theta}\left(a-c_{L}\right)=3.57 \text {. }
$$

Now let $c_{H}=2$, and $u_{12}=u_{13}=u_{21}=u_{31}=u_{32}=0.6$. Case 2 (by pooling, incumbents can preclude entry by a high-cost firm) holds if $3.98 \leq \mathrm{K}<$ 6.92. Case 2(a) (first-period defection from pooling equilibrium means that entry becomes profitable for a high-cost entrant) holds for $3.98 \leq K<4.26$.

The elements of the high-cost firm pooling condition (16) are shown in Table 2 and (23). If a high-cost incumbent defects from the pooling equilibrium. it gains 0.3906 . In the second period, cost-type revelation gains the defecting firm 0.1366 if the entrant has high cost, 0.5001 if the entrant has low cost. But if entry becomes profitable for a high-cost entrant because defection reveals that one firm has high cost, lost profit is 3.6135. Condition (16) becomes

$$
\frac{3}{5}(3.6135) \geq 0.3906+\frac{3}{5}(0.1366)+\frac{2}{5}(0.5001),
$$

\footnotetext{
${ }^{11}$ Allowing for differences in notation, this is the Spence (1976) model of demand for differentiated products. Prices and quantities must be nonnegative (Majerus. 1987).
} 


\begin{tabular}{|l|c|c|}
\hline Payoff Difference & $(\mathbf{1})$ & $(\mathbf{2})$ \\
\hline$\pi_{1 L}\left(u_{12}, 1\right)-\pi_{1 L}\left(u_{12}, u_{13}, 1, u_{23}, 1, u_{32}\right)$ & 4.2931 & 4.6521 \\
\hline$\pi_{1 L}\left(u_{12}, 1\right)-\pi_{1 L}\left(u_{12}, u_{21}\right)$ & 0.1675 & 0 \\
\hline$\pi_{1 L}\left(u_{12}, u_{13}, 1, u_{23}, 1, u_{32}\right)-\pi_{1 L}\left(u_{12}, 0, u_{21}, 0, u_{31}, u_{32}\right)$ & 0.6723 & 0.5259 \\
\hline
\end{tabular}

Table 3: Firm $1 L$ Pooling Condition, Strategic Complements; Parameters as for Table 2 .

which evidently is satisfied.

Table 3 and (24) show the elements of condition (19), the low-cost incumbent pooling condition. Once again, expected lost profit due to entry dominates expected gains from cost-type revelation.

$$
\frac{3}{5}(4.2931) \geq \frac{3}{5}(0.1675)+\frac{2}{5}(0.6723)
$$

For these parameter values, pooling on $p_{L}$ is a sequential equilibrium.

The second columns of Tables 2 and 3 show the elements of the pooling conditions if $u_{12}=u_{21}=1$ and $u_{13}=u_{23}=u_{31}=u_{32}=\theta=0.6$. For these parameter values, incumbents will pool on low prices even if each is convinced that the other has high costs.

\section{Separating Equilibrium}

\subsection{Entrant's post-separation payoffs}

To analyze incumbents' incentives to separate in the first period, it is necessary to relate the entrant's second period payoff to incumbents' cost types. A profitmaximizing potential entrant will come into the market only if its expected payoff exceeds entry cost $K$. As shown in the Appendix, the entrant's payoffs against incumbents of alternative cost types can be ranked as follows:

$$
\begin{gathered}
\pi_{3 L}(1,0,1,0,1,1)>\pi_{3 L}(0,0,1,0,1,0)>\pi_{3 L}(0,0,0,0,0,0) \\
\geq \pi_{3 H}\left(1, u_{13}, 1, u_{23}, 1,1\right)>\pi_{3 H}\left(0, u_{13}, 1, u_{23}, 1,0\right)>\pi_{3 H}\left(0, u_{13}, 0, u_{23}, 0,0\right) .
\end{gathered}
$$

The first term is the payoff of a known low-cost entrant if both incumbents are known to have high cost. The first and second inequalities state that the low-cost entrant's expected profit is lower if one incumbent has high cost while the second has low cost, and is lower still if both incumbents are known to have low cost.

If entrants of either cost type would come into the market, then in the second period, the entrant's cost type is not known. The fourth term represents the payoff of a high-cost entrant of unknown cost type if both incumbents are 
known to have high cost. ${ }^{12}$ Such an entrant's expected payoff is lower if one incumbent is known to have low cost (the fourth inequality) and lower still if both incumbents are known to have low cost (the fifth inequality).

Incentives to separate in the first period vary depending on the relation between entry cost $K$ and the payoffs ranked in (25). For concreteness, I will discuss two of the seven possible cases. The first, S2, holds if a low-cost entrant will come into the market if both incumbents are known to have high cost. but not if at least one incumbent is known to have low cost:

$$
\pi_{3 L}(1,0,1,0,1,1)>K \geq \pi_{3 L}(0,0,1,0,1,0)
$$

The second, S4, holds if a known low-cost entrant will come into the market if it is common knowledge that both incumbents have low cost, while a high-cost entrant will stay out of the market if it is common knowledge that both incumbents have high cost:

$$
\pi_{3 L}(0,0,0,0,0,0)>K \geq \pi_{3 H}\left(1, u_{13}, 1, u_{23}, 1,1\right) .
$$

These cases give typical results. The remaining five cases are discussed in the Appendix.

\subsection{Strategic substitutes}

In no-distortion equilibrium, ${ }^{13}$ in the first period incumbents play their noncooperative equilibrium action from a one-period game in which the rival's cost type is unknown, thus revealing their cost types. ${ }^{14}$ For quantity-setting firms producing varieties that are strategic substitutes, this becomes:

Nash output separation:

(a) incumbents produce their equilibrium outputs from a one period game with rival's cost type unknown in period 1;

(b) the entrant comes into the market in the second period if and only if it expects a positive second-period payoff (net of entry cost $K$ );

\footnotetext{
${ }^{12}$ Comparing the third and the fourth terms, observe that $\pi_{3 L}(0,0,0,0,0,0) \geq$ $\pi_{3 H}(1,1,1,1,1,1) \geq \pi_{3 H}\left(1, u_{13}, 1, u_{23}, 1,1\right)$. In words, a known low-cost firm earns a greater profit competing against two known low-cost rivals than a known high-cost firm earns competing against two known high-cost rivals, and a known high-cost firm's expected payoff is lower if there is some probability that one of the two rivals has low cost.

${ }^{13}$ This terminology is due to Bagwell and Ramey [1991].

${ }^{14}$ The one-period quantity-setting and price-setting games are discussed in the Appendix. It may also be a sequential equilibrium for low-cost firms to expand output (respectively, lower price) so much that it is not profitable for high-cost firms to pool. This type of equilibrium is also discussed in the Appendix.
} 
(c) in the second period, the entrant knows incumbents' cost types;

(d) if only a low-cost entrant would earn a positive profit in the second period, then the fact of entry reveals that the entrant has low cost;

(e) if a high-cost entrant would find entry profitable, then incumbents carry prior beliefs about the entrant's cost type forward from the first period to the second;

(f) all firms noncooperatively maximize expected profit in the second period.

If an incumbent produces a disequilibrium output in the first period, rivals believe that it has high cost.

Incumbents' payoffs are the sums of their payoffs in the two periods.

Virtually by definition, a profit-maximizing potential entrant will wish to follow the above strategy.

For low-cost incumbents, the separation outputs are (in equilibrium) bestresponse outputs. Deviation would reduce the first-period payoff. It would lead rivals to believe that the deviating firm had high cost, and therefore to expand second-period output. Deviation might induce entry. Defection would therefore reduce first- and second-period payoffs. It follows that a low-cost incumbent would never want to deviate from the separating equilibrium.

It remains to consider the incentives of high-cost incumbents to separate.

\subsubsection{Case S2}

If firm $1 H$ separates, its expected payoff is

$$
\pi_{1 H}\left(u_{12}, u_{21}\right)+u_{12}\left[u_{13} \pi_{1 H}(1,1)+v_{13} \pi_{1 H}(1,0,1,0,1,1)\right]+v_{12} \pi_{1 H}(0,1)
$$

The first term is $1 H$ 's first-period payoff. If firm 2 has high cost, a low-cost entrant will come in, while a high-cost entrant will stay out; the second term gives the resulting expected payoff. If firm 2 has low cost, then entry does not occur; the third term gives the resulting expected payoff.

Given the nature of out-of-equilibrium beliefs, if firm $1 H$ defects at all, it will do so by producing firm $1 L$ 's separation output. This reduces its firstperiod payoff, but leads rivals to believe that firm 1 has low cost (so that entry does not occur). In case $\mathrm{S} 2$, firm $1 H$ 's expected defection payoff is

$$
\pi_{1 H}\left(q_{1 L}\right)+u_{12} \pi_{1 H}(1,0)+v_{12} \pi_{1 H}(0,0) .
$$

Firm 2 maximizes its second-period profit in the belief that firm 1 has low cost, and firm $1 H$ sets its best response output.

Comparing (28) and (29), firm $1 H$ will separate if

$$
\pi_{1 H}\left(u_{12}, u_{21}\right)-\pi_{1 H}\left(q_{1 L}\right) \geq u_{12} u_{13}\left[\pi_{1 H}(1,0)-\pi_{1 H}(1,1)\right]
$$




$$
+u_{12} v_{13}\left[\pi_{1 H}(1,0)-\pi_{1 H}(1,0,1,0,1,1)\right]+v_{12}\left[\pi_{1 H}(0,0)-\pi_{1 H}(0,1)\right] .
$$

The term on the left is the first-period loss of profit from mimicking a lowcost firm. The first and third terms on the right are mastyurade effects: firm $1 H$ 's increased second-period profit competing against a misinformed high-cost and low-cost firm 2, respectively. The second term on the left is a pure entry effect: the profit that would otherwise be lost if a known low-cost entrant came into a market with two known high-cost incumbents. All terms on the left are weighted by the appropriate probabilities. The incremental profit to be gained by discouraging entry is an incentive to defect from separating behavior.

If condition (30) is satisfied, firm $1 H$ will separate in the first period; a corresponding condition will ensure that firm $2 \mathrm{H}$ would separate. The profit to be preserved by limiting entry is an inducement to defect from the no-distortion strategy.

\subsubsection{Case $\mathrm{S} 4$}

If firm $1 H$ separates, its payoff is

$$
\begin{gathered}
\pi_{1 H}\left(u_{12}, u_{21}\right)+u_{12}\left[u_{13} \pi_{1 H}(1,1)+v_{13} \pi_{1 H}(1.0 .1,0.1 .1)\right] \\
+v_{12}\left[u_{13} \pi_{1 H}(0,1)+v_{13} \pi_{1 H}(0,0,1,0,1,0)\right] .
\end{gathered}
$$

In equilibrium, a low-cost entrant comes into the market and a high cost entrant stays out of the market.

If firm $1 H$ defects, rivals believe it has low cost. Once again, a low-cost entrant comes into the market and a high-cost entrant stays out of the market. Firm $1 H$ 's defection payoff is

$$
\begin{gathered}
\pi_{1 H}\left(q_{1 L}\right)+u_{12}\left[u_{13} \pi_{1 H}(1,0)+v_{13} \pi_{1 H}(1,0.0,0.0 .1)\right] \\
+v_{12}\left[u_{13} \pi_{1 H}(0,0)+v_{13} \pi_{1 H}(0,0,0,0,0.0)\right] .
\end{gathered}
$$

Comparing (31) and (32), the most profitable action for firm $1 H$ is to separate if

$$
\begin{gathered}
\pi_{1 H}\left(u_{12}, u_{21}\right)-\pi_{1 H}\left(q_{1 L}\right) \geq \\
u_{12} u_{13}\left[\pi_{1 H}(1,0)-\pi_{1 H}(1,1)\right]+u_{12} v_{13}\left[\pi_{1 H}(1,0,0,0,0,1)-\pi_{1 H}(1,0,1.0,1.1)\right] \\
+v_{12} u_{13}\left[\pi_{1 H}(0,0)-\pi_{1 H}(0,1)\right]+v_{12} v_{13}\left[\pi_{1 H}(0,0,0,0,0,0)-\pi_{1 H}(0,0,1,0,1,0)\right] .
\end{gathered}
$$

The term on the left is firm 1H's first-period lost profit if it mimics a low-cost firm. The terms on the right are masquerade effects: firm $1 H$ earns a greater profit in period 2 if rivals mistakenly believe it has low cost. But if entry cost places the game in case S4, defection by a high-cost incumbent does not alter the entry decision, with the result that entry deterrence does not affect the high-cost incumbent's incentives to separate. 


\begin{tabular}{|l|l|}
\hline Payoff Difference & \\
\hline$\pi_{1 H}\left(u_{12}, u_{21}\right)-\pi_{1 H}\left(q_{1 L}\right)$ & 2.2500 \\
\hline$\pi_{1 H}(1,0)-\pi_{1 H}(1,1)$ & 2.2500 \\
\hline$\pi_{1 H}(0,0)-\pi_{1 H}(1,0,1,0,1,1)$ & 5.6875 \\
\hline$\pi_{1 H}(0,0)-\pi_{1 H}(0,1)$ & 1.2500 \\
\hline
\end{tabular}

Table 4: Firm $1 H$ Separation Condition, Strategic Substitutes, Case S2; $a=$ $10, c_{L}=1, c_{H}=4$

In each of the seven cases of entry conditions, either the possibility of entry deterrence does not arise, and therefore does not affect a high-cost incumbent's incentives to separate, or the expected profit to be gained by deterring entry is an incentive to defect from the separating strategy. While it can be a sequential equilibrium for incumbents to separate on their equilibrium outputs from a oneperiod game, such an equilibrium does not involve entry deterrence.

Theorem 3: For firms producing strategic substitutes, first-period separation on equilibrium outputs from a one-period game with rival's cost type unknown is a sequential equilibrium strategy if a high-cost incumbent's first-period expected lost profit from mimicking a low-cost firm exceeds expected second-period incremental profit from masquerading as a low-cost firm and deterring entry (if any).

\subsubsection{A linear example}

Table 4 shows the elements of the case S2 high-cost incumbent separation condition (30) for the linear demand example. While the profit to be gained by imitating a low-cost firm and discouraging entry is large, given the parameters of the example, for low values of $u_{12}$, the separation condition is satisfied. For example, if $u_{12}=u_{21}=0.2, u_{13}=u_{23}=0.5$, condition (30) becomes

$$
2.25 \geq\left(\frac{1}{5}\right)\left(\frac{1}{2}\right)(2.25)+\left(\frac{1}{5}\right)\left(\frac{1}{2}\right)(5.6875)+\frac{4}{5}(1.25) ;
$$

a high-cost incumbent will prefer to separate if it believes that its rival has low cost. On the other hand, if incumbents each believe the other has high cost, $u_{12}=u_{21}=1$, the condition (30) fails:

$$
2.25<(1)\left(\frac{1}{2}\right)(2.25)+(1)\left(\frac{1}{2}\right)(5.6875)+(0)(1.25) .
$$

\subsection{Strategic complements}

If firms produce varieties that are strategic complements, the following is a no-distortion collection of strategies and beliefs: 
Nash price separation:

(a) incumbents set their equilibrium prices from a one-period game with rival's cost type unknown in period 1 ;

(b) the entrant comes into the market in the second period if and only if it expects a positive second-period payoff (net of entry cost $K$ );

(c) in the second period, the entrant knows incumbents' cost types;

(d) if only a low-cost entrant would earn a positive profit in the second period, then the fact of entry reveals that the entrant has low cost;

(e) if a high-cost entrant would find entry profitable, then incumbents carry prior beliefs about the entrant's cost type forward from the first period to the second;

(f) all firms noncooperatively maximize expected profit in the second period.

If an incumbent sets a disequilibrium price in the first period, rivals believe that it has high cost.

Incumbents' payoffs are the sums of their payoffs in the two periods.

\subsubsection{Case S2}

If firm $1 H$ separates, its payoff is

$$
\pi_{1 H}\left(u_{12}, u_{21}\right)+u_{12}\left[u_{13} \pi_{1 H}(1,1)+v_{13} \pi_{1 H}(1,0,1,0,1,1)\right]+v_{12} \pi_{1 H}(0,1) .
$$

If firm 2 has high cost, a low-cost entrant comes into the market, while a high-cost entrant stays out. This explains the second term in (36). If firm 2 has low cost, entry does not occur; this explains the third term in (36).

If firm $1 H$ defects at all from the separating equilibrium, it will set firm $1 L$ 's separation price. Entry will not occur, and firm 2 will incorrectly believe that firm 1 has low cost. This induces firm 2 to set a lower price than it otherwise would in period 2; this tends to reduce firm $1 H$ 's payoff. Firm $1 H$ 's expected defection profit is

$$
\pi_{1 H}\left(p_{1 L}\right)+u_{12} \pi_{1 H}(1,0)+v_{12} \pi_{1 H}(0,0) .
$$

Comparing (36) and (37), firm $1 H$ will separate if

$$
\begin{gathered}
\pi_{1 H}\left(u_{12}, u_{21}\right)-\pi_{1 H}\left(p_{1 L}\right)+u_{12} u_{13}\left[\pi_{1 H}(1,1)-\pi_{1 H}(1,0)\right] \\
+v_{12}\left[\pi_{1 H}(0,1)-\pi_{1 H}(0,0)\right] \geq u_{12} v_{13}\left[\pi_{1 H}(1,0)-\pi_{1 H}(1,0,1,0,1,1)\right]
\end{gathered}
$$


When firms produce varieties that are strategic complements, a highcost firm reduces its second-period payoff if it masquerades as a low-cost firm. The expected gain in profit from deterring entry is an incentive for high-cost incumbents not to separate. Examining the right-hand side of (38), firm $1 H$ will separate if $u_{12}$ or $v_{13}$ is sufficiently small. If firm $1 H$ thinks it very likely that firm 2 has low cost, it expects the entrant to stay out, and it is in firm $1 H$ 's interest to reveal its cost type. The same applies if $v_{13}$ is sufficiently small-if firm 1 thinks it very likely that the entrant has high cost.

If the game is in case $\mathrm{S} 2$ and firm $1 L$ separates, entry does not occur. Firm $1 L$ 's expected second-period payoff is

$$
u_{12} \pi_{1 L}(1,0)+v_{12} \pi_{1 L}(0,0) .
$$

If firm $1 L$ deviates slightly from its separating price, it will slightly reduce its first-period payoff and convince rivals that it has high cost. This induces rivals to set higher prices in the second period. A low-cost entrant will come into the market if firm 2 has high cost; firm $1 L$ 's expected second-period defection profit is

$$
u_{12}\left[u_{13} \pi_{1 L}(1,1)+v_{13} \pi_{1 L}(1,0,1,0,1,1)\right]+v_{12} \pi_{1 L}(0,1)
$$

Firm $1 L$ will separate if

$$
\begin{gathered}
u_{12} v_{13}\left[\pi_{1 L}(1,0)-\pi_{1 L}(1,0,1,0,1,1)\right] \geq \\
u_{12} u_{13}\left[\pi_{1 L}(1,1)-\pi_{1 L}(1,0)\right]+v_{12}\left[\pi_{1 L}(0,1)-\pi_{1 L}(0,0)\right]
\end{gathered}
$$

The term on the left is the profit lost by a known low-cost firm 1 if firm 2 has high cost and a low-cost entrant comes into the market. The terms on the right are masquerade effects, showing firm $1 L$ 's increases in second-period profit from misleading rivals about its cost type.

Examining the left-hand side of (41), if firm 1 thinks firm 2 is very likely to have low cost $\left(u_{12}\right.$ near zero) or that the entrant is very likely to have high cost $\left(v_{13}\right.$ near zero) - firm $1 L$ will defect from the separating strategy. In either case, it believes entry is unlikely to occur, and will profit by misleading the other incumbent as to its cost type. On the other hand, if firm $1 L$ is willing to separate in case $\mathrm{S} 2$, it is because expected lost profit due to entry dominates masquerade effects.

\subsubsection{Case $\mathrm{S} 4$}

If the game is in case $\mathrm{S} 4$ and firm $1 H$ mimics a low-cost firm, it reduces its firstand second-period payoffs (rivals will set lower prices in the second period). It does not alter the probability of entry: in case $\mathrm{S} 4$, a low-cost entrant will come into the market in the second period, while a high-cost entrant will stay out. 


\begin{tabular}{|l|l|}
\hline Payoff Difference & \\
\hline$\pi_{1 H}\left(u_{12}, u_{21}\right)-\pi_{1 H}\left(p_{1 L}\right)$ & 0.3906 \\
\hline$\pi_{1 H}(1,1)-\pi_{1 H}(1,0)$ & 0.3494 \\
\hline$\pi_{1 H}(0,1)-\pi_{1 H}(0,0)$ & 0.3239 \\
\hline$\pi_{1 H}(1,0)-\pi_{1 H}(1,0,1,0,1,1)$ & 3.8652 \\
\hline
\end{tabular}

Table 5: Firm $1 H$ Separation Condition, Strategic Complements, Case S2; $a=$ $10, c_{L}=1, c_{H}=2, \theta=0.6$

\begin{tabular}{|l|l|}
\hline Payoff Difference & \\
\hline$\pi_{1 L}(1,0)-\pi_{1 L H}(1,0,1,0,1,1)$ & 4.6161 \\
\hline$\pi_{1 L}(1,1)-\pi_{1 L}(1,0)$ & 0.4267 \\
\hline$\pi_{1 L}(0,1)-\pi_{1 L}(0,0)$ & 0.4012 \\
\hline
\end{tabular}

Table 6: Firm $1 L$ Separation Condition, Strategic Complements, Case S2; $a=$ $10, c_{L}=1, c_{H}=2, \theta=0.6$

It follows that firm $1 H$ will always be willing to separate if the game is in case S4.

Contrariwise, a low-cost incumbent will always wish to set a disequilibrium price, leading rivals to believe that it has high cost. This will increase its second-period payoff without altering the probability of entry. No distortion pricing is not an equilibrium in case $\mathrm{S} 4$.

In three of the seven possible cases, the entrant's decision is not affected by incumbents' first-period actions, with the result that low-cost incumbents are unwilling to separate. In the remaining cases, the possibility of deterring entry is an incentive for the high-cost incumbent to defect from the no-distortion path, while it is the only incentive for low-cost incumbents to separate.

Theorem 4: For firms producing strategic complements, first period separation on equilibrium prices from a one-period game with rival's cost type unknown is a sequential equilibrium strategy if a high-cost incumbents' first-period expected lost profit from mimicking a low-cost firm and from misleading rivals as to its cost type exceeds expected incremental profit from deterring entry, and if a low-cost incumbent's expected incremental profit from deterring entry (if any) exceeds its expected incremental profit from misleading rivals as to its cost type.

\subsubsection{A linear example}

Tables 5 and 6 give the elements of the case $\mathrm{S} 2$ high-cost incumbent and lowcost incumbent separation conditions, respectively, for a linear example. If 
$u_{12}=u_{13}=u_{21}=u_{23}=0.2,(38)$ and (41) become

$$
0.3906+\left(\frac{1}{5}\right)\left(\frac{1}{5}\right)(0.3494)+\left(\frac{4}{5}\right)(0.3239) \geq\left(\frac{1}{5}\right)\left(\frac{4}{5}\right)(3.8653)
$$

and

$$
\left(\frac{1}{5}\right)\left(\frac{4}{5}\right)(4.6161) \geq\left(\frac{1}{5}\right)\left(\frac{1}{5}\right)(0.4267)+\left(\frac{4}{5}\right)(0.4012)
$$

respectively, so that high-cost and low-cost incumbents will prefer to separate. But if $u_{12}=u_{13}=1$, high-cost incumbents will prefer to defect from the separating strategy:

$$
0.3906+(1)\left(\frac{1}{5}\right)(0.3494)+(0)(0.3239)<(1)\left(\frac{4}{5}\right)(3.8653) .
$$

\section{Disequilibrium Beliefs and the Plausibility of Equilibria}

The reader will be aware that multiple equilibria are the bane of models of oligopoly under conditions of imperfect information. The models presented here are no exception. Provided the conditions outlined above are met, the pooling and separating strategies examined above are sequential equilibria. It can also be a sequential equilibrium for firms to pool on high prices or for low-cost firms to separate by expanding output (lowering price) so much that high-cost firms are unwilling to mimic; these possibilities are discussed in the Appendix. Further, there may be mixed equilibria, in which one firm pools while the other separates.

These alternatives can all be sequential equilibria: equilibrium beliefs are consistent with equilibrium actions, and there is some set of disequilibrium beliefs that implies players maximize expected payoffs by acting as specified.

I broach here the subject of the relative plausibility of the disequilibrium beliefs that sustain the alternative equilibria. ${ }^{15}$ In this respect, the distinction between strategic substitutes and strategic complements is fundamental.

Consider pooling on high outputs by firms producing strategic substitutes. This is a sequential equilibrium if any disequilibrium output is taken as an indication that the offending firm has high cost. And if players hold this belief, then it is never a first-best strategy for a low-cost incumbent to set a disequilibrium output. The assumed disequilibrium beliefs are internally consistent with the incentives they create. It seems fair to regard this combination of equilibrium

\footnotetext{
${ }^{15}$ Binmore [1992, pp. 544-545] notes the fundamental lack of consensus among game theorists regarding refinements of Nash equilibrium. It is not my intention to contribute to this debate, but to elaborate on the nature of the disequilibrium beliefs that sustain the sequential equilibria of the models presented here.
} 
actions/beliefs and disequilibrium beliefs as (Cho and Kreps [1987, p. 203]) "a mode of self-enforcing behavior that is common knowledge among the players."

The same cannot be said if firms produce strategic complements. In that case, cost-type revelation effects give a low-cost incumbent some incentive to defect from a low-price pooling equilibrium. It is true that if beliefs about disequilibrium actions are as assumed and conditions like (19) are met, lowcost incumbents will not, on balance, wish to set disequilibrium prices. But since there are some cases in which low-cost incumbents would wish to set disequilibrium prices, the belief that disequilibrium prices identify a firm as having high cost is not quite as self-evident as when firms produce strategic complements.

The situation is similar for the equilibria in which firms separate in the first period by following actions from the one-period game. When firms produce strategic substitutes, the incentives that stem from entry deterrence and the incentives that stem from cost-type revelation work in the same direction; this implies that mean low-cost incumbents will never wish to defect from the separating equilibrium. Beliefs about disequilibrium actions and equilibrium incentives are consistent; for firms that produce strategic substitutes, the nodistortion equilibrium can be regarded as plausible. But when firms produce strategic complements, there are some circumstances in which low-cost incumbents will never wish to separate.

Nor does not appear that any of these equilibria are "focal" in the sense of Bagwell and Ramey [1991]. ${ }^{16}$ By pooling, incumbents can impede some or all (in Case 3 ) entry; this may be thought to make the pooling strategy attractive from incumbents' points of view. But on strictly theoretical grounds, the alternative sequential equilibria analyzed here are all equally peccable or impeccable.

\section{Conclusion}

In the model developed here, unit costs may differ across firms. One class of equilibria has incumbents pool on high output (low price). If entry cost is such that incumbents' first-period actions affect the entry decision, then the expected profit from entry deterrence is an incentive for incumbents to pool and deter entry. The high output/low price pooling equilibrium is oligopoly limit pricing, in the sense of Bain.

If firms produce strategic substitutes, entry deterrence effects and costtype revelation effects work in the same direction: a high-cost incumbent may reduce the probability of entry if it conceals its cost type, and it induces secondperiod rivals to produce lower second-period outputs if they think it may have

\footnotetext{
${ }^{16}$ They [1991, p. 160] define an equilibrium class as focal "provided that other equilibria with plausible belief specifications do not exist."
} 
low cost. If firms produce strategic complements, entry deterrence effects and revelation effects work in opposite directions. A high-cost firm may reduce the probability of entry if it conceals its cost type, but it will induce rivals to set higher second-period prices if it reveals its cost type. For this reason, the conditions to sustain pooling equilibrium are more severe, and the beliefs about disequilibrium actions that sustain pooling equilibrium less plausible, if firms produce strategic complements than if they produce strategic substitutes.

There are other equilibria in which incumbents separate in the first period. In such equilibria, the profit to be gained by deterring entry is typically an incentive for one type of firm to separate, but an incentive for the other type of firm to defect from the separating strategy. These are at most partially entry-limiting equilibria. When firms produce varieties that are strategic complements, low-cost incumbents will not separate unless there is the possibility that their action reduces the likelihood of entry. 


\section{$7 \quad$ References}

Bagwell, Kyle and Ramey, Garey "Oligopoly limit pricing." Rand Journal of Economics, Volume 22, Number 2, Summer 1991, pp. 155-72.

Bain, Joe S. "A note on pricing in monopoly and oligopoly," American Economic Review Volume 39, Number 1, March 1949, pp. 448-469.

Binmore, Ken Fun and Games. Lexington, Massachusetts: D.C. Heath, 1992.

Bulow, Jeremy, Geankoplos, John and Klemperer, Paul D. "Multimarket oligopoly: strategic substitutes and strategic complements," Journal of Political Economy Volume 93, 1985, pp. 488-511.

Cho, In-Koo and Kreps, David M. "Signaling games and stable equilibria," Quarterly Journal of Economics Volume 102, Issue 2, May 1987, pp. 179221.

Harrington, Joseph E. Jr. "Limit pricing when the potential entrant is uncertain of its cost function," Econometrica Volume 54, 1986, pp. 429-437.

Harsanyi, John C. "Games with Incomplete Information Played by 'Bayesian' Players, I-III," Management Science Volume 14, Number 3, November 1967, pp. 159-82; Volume 14, Number 5, January 1968. pp. 320-34; Volume 14, Number 7, March 1968, pp. 486-502; reprinted in Harsanyi, John C. Papers in Game Theory. Dordrecht: D. Reidel Publishing Company, 1982, pp. 115-70.

Majerus, David W. "Price vs. Quantity Competition in Oligopoly Supergames," Economics Letters Volume 27, 1988, pp. 293-7.

Martin, Stephen Advanced Industrial Economics. London: Basil Blackwell, 1993.

Milgrom, Paul and Roberts, John "Limit pricing and entry under incomplete information," Econometrica Volume 50, Number 2. March 1982. pp. 44366.

Saloner, Garth "Predation, Mergers, and Incomplete Information," Rand Journal of Economics, Volume 18, Number 2, Summer 1987. pp. 165-86.

Spence, A. Michael "Product Differentiation and Welfare," American Economic Review Volume 66, Number 2, May 1976, pp. 407-14. 


\title{
Oligopoly Limit Pricing: Strategic Substitutes, Strategic Complements Appendix
}

\author{
Stephen Martin \\ Department of Economics \\ European University Institute \\ 50016 San Domenico di Fiesole \\ Florence, Italy \\ martin@datacomm.iue.it \\ January 28, 1994
}




\section{Contents}

1 Quantity-Setting Firms 31

1.1 Duopoly ........................ 31

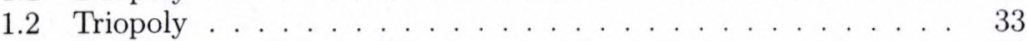

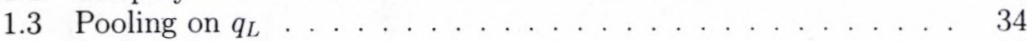

1.3.1 Case 2 . . . . . . . . . . . . . . . . . . . 34

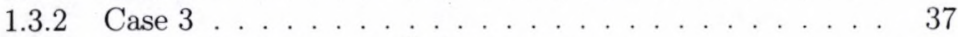

1.4 Separating equilibrium: payoffs from entry . . . . . . . . . 39

1.5 Separation by L-firm output expansion . . . . . . . . . . . . . . 40

1.5.1 High-cost incumbents . . . . . . . . . . . . . . . 40

1.5.2 Low-cost incumbents . . . . . . . . . . . . . . . . . 43

1.5.3 Linear example . . . . . . . . . . . . . . . . . . . . . . 46

1.6 Separation on Nash duopoly outputs . . . . . . . . . . . . . . 47

1.6.1 High-cost incumbents . . . . . . . . . . . . . 47

2 Price-Setting Firms $\quad 50$

2.1 Duopoly . . . . . . . . . . . . . . . . . . 50

2.2 Triopoly . . . . . . . . . . . . . . . . . . . . . . 53

2.3 Pooling on $p_{L} \ldots \ldots \ldots \ldots \ldots \ldots$

2.3 .1 Boundaries of Case $2 \ldots \ldots \ldots 5$

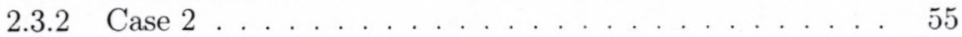

2.3.3 Linear example, Case 2(a) . . . . . . . . . . . . . . . . 56

2.3 .4 Case $3 \ldots \ldots \ldots . \ldots . \ldots . \ldots 57$

2.4 Pooling on $p_{H} \ldots \ldots \ldots \ldots \ldots$. . . . . . . . . . . . . . . . . 58

2.5 Separating equilibrium: payoffs from entry . . . . . . . . . 60

2.6 Separation by $\mathrm{L}$-firm price reduction . . . . . . . . . . . . . 61

2.6.1 High-cost incumbents . . . . . . . . . . . . 62

2.6.2 Low-cost incumbents . . . . . . . . . . . . . . . . . . . . 64

2.7 Separation on Nash duopoly prices . . . . . . . . . . . . . 67

2.7.1 High-cost incumbents . . . . . . . . . . . . . . . 67

2.7 .2 Low-cost incumbents . . . . . . . . . . . . . . 69

2.7.3 Linear example, case S2 . . . . . . . . . . 72 


\section{Quantity-Setting Firms}

\subsection{Duopoly}

Recall the notation

$$
\begin{aligned}
& u_{i j}=\text { firm } i \text { 's prior probability that firm j's costs are high. } \\
& v_{i j}=\text { firm } i \text { 's prior probability that firm } j \text { 's costs are low, }
\end{aligned}
$$

for $i, j=1,2,3$ and $i \neq j$.

With the linear demand curve

$$
p=a-Q .
$$

firm $1 L$ 's expected profit is

$$
\pi_{1 L}=\left(a_{L}-q_{1 L}-u_{12} q_{2 H}-v_{12} q_{2 L}\right) q_{1 L},
$$

where $a_{L}=a-c_{L}$. Maximizing (2) with respect to $q_{1 L}$ gives the equation of firm $1 L$ 's reaction function,

$$
2 q_{1 L}+u_{12} q_{2 H}+v_{12} q_{2 L}=a_{L}
$$

Note that (2) and (3) together imply that anywhere along $1 L$ 's reaction function, and in particular in equilibrium,

$$
\pi_{1 L}=q_{1 L}^{2}
$$

In like manner, one obtains the equations of the other 3 reaction functions,

$$
\begin{aligned}
2 q_{1 H}+u_{12} q_{2 H}+v_{12} q_{2 L} & =a_{H} . \\
u_{21} q_{1 H}+v_{21} q_{1 L}+2 q_{2 L} & =a_{L} . \\
u_{21} q_{1 H}+v_{21} q_{1 L}+2 q_{2 H} & =a_{H} .
\end{aligned}
$$

(where $a_{H}=a-c_{H}$ ).

Duopoly equilibrium for a single-period game can be illustrated graphically. Define the output each firm expects to see from the other as

$$
\begin{aligned}
& q_{1}\left(u_{21}\right)=u_{21} q_{1 H}+v_{21} q_{1 L} \\
& q_{2}\left(u_{12}\right)=u_{12} q_{2 H}+v_{12} q_{2 L}
\end{aligned}
$$

Now multiply (5) by $u_{21},(3)$ by $v_{21}$, and add to obtain

$$
2 q_{1}\left(u_{21}\right)+q_{2}\left(u_{12}\right)=u_{21} a_{H}+v_{21} a_{L}=a\left(u_{21}\right)
$$


In like manner, from (6) and (7) one obtains

$$
q_{1}\left(u_{21}\right)+2 q_{2}\left(u_{12}\right)=u_{12} a_{H}+v_{12} a_{L}=a\left(u_{12}\right)
$$

(10) and (11) have the form of conventional quantity reaction functions for the linear model. They can be graphed, as in Figure A1, to illustrate equilibrium expected outputs $q_{1}^{*}\left(u_{21}\right)$ and $q_{2}^{*}\left(u_{12}\right)$.

\section{Insert Figure $\mathrm{A} 1$ about here}

Now graph (10) and the reaction functions of firms $1 L(3)$ and $1 H(5)$ together, as in Figure A2. The reaction function with equation (10) is bounded below by the reaction function of firm $1 H$, and above by the reaction function of firm $1 L$. The equilibrium outputs of firms $1 H$ and $1 L$ can be read off the graph at the intersection of the respective reaction functions with the equilibrium expected output of firm $2, q_{2}^{*}\left(u_{12}\right)$. In like manner, the equilibrium outputs of firms $2 H$ and $2 L$ are found at the intersections of their reaction functions with the vertical line showing $q_{1}^{*}\left(u_{21}\right)$. Figure A3 shows duopoly equilibrium outputs for all four notional players.

\section{Insert Figure A2 about here Insert Figure A3 about here}

For the pooling equilibrium discussed in the text, in the first period incumbents produce their equilibrium outputs from the one-period game. For the separating equilibrium discussed in the text, in the first period incumbents produce the outputs given by the intersection of the L-firm reaction functions.

To find an explicit solution to the system of equations of the reaction functions, subtract (5) from (3) to obtain

$$
q_{1 L}=q_{1 H}+\frac{1}{2}\left(a_{L}-a_{H}\right)=q_{1 H}+\frac{1}{2}\left(c_{H}-c_{L}\right)
$$

Similarly, from (6) and (7),

$$
q_{2 L}=q_{2 H}+\frac{1}{2}\left(a_{L}-a_{H}\right)=q_{2 H}+\frac{1}{2}\left(c_{H}-c_{L}\right)
$$

Substitute from (13) into (3) to eliminate $q_{2 H}$ and from (12) into (6) to eliminate $q_{1 H}$. The result is a system of two equations in $q_{1 L}$ and $q_{2 L}$,

$$
\left(\begin{array}{ll}
2 & 1 \\
1 & 2
\end{array}\right)\left(\begin{array}{l}
q_{1 L} \\
q_{2 L}
\end{array}\right)=a_{L}\left(\begin{array}{l}
1 \\
1
\end{array}\right)+\frac{1}{2}\left(\begin{array}{l}
u_{12} \\
u_{21}
\end{array}\right)\left(c_{H}-c_{L}\right),
$$

which yields expressions for the equilibrium outputs of the low-cost firms,

$$
q_{1 L}=\frac{1}{3}\left[a_{L}+\frac{2 u_{12}-u_{21}}{2}\left(c_{H}-c_{L}\right)\right]
$$




$$
q_{2 L}=\frac{1}{3}\left[a_{L}+\frac{2 u_{21}-u_{12}}{2}\left(c_{H}-c_{L}\right)\right]
$$

In like manner, one obtains expressions for the equilibrium outputs of high-cost firms,

$$
\begin{aligned}
& q_{1 H}=\frac{1}{3}\left[a_{H}-\frac{2 v_{12}-v_{21}}{2}\left(c_{H}-c_{L}\right)\right] \\
& q_{2 H}=\frac{1}{3}\left[a_{H}-\frac{2 v_{21}-v_{12}}{2}\left(c_{H}-c_{L}\right)\right]
\end{aligned}
$$

Here and throughout, I restrict the discussion to the case in which equilibrium outputs are nonnegative.

Using (4) and the corresponding relationships for other players, equilibrium payoffs are

$$
\begin{aligned}
& \pi_{1 L}\left(u_{12}, u_{21}\right)=\frac{1}{9}\left[a_{L}+\frac{2 u_{12}-u_{21}}{2}\left(c_{H}-c_{L}\right)\right]^{2} \\
& \pi_{2 L}\left(u_{12}, u_{21}\right)=\frac{1}{9}\left[a_{L}+\frac{2 u_{21}-u_{12}}{2}\left(c_{H}-c_{L}\right)\right]^{2} \\
& \pi_{1 H}\left(u_{12}, u_{21}\right)=\frac{1}{9}\left[a_{H}-\frac{2 v_{12}-v_{21}}{2}\left(c_{H}-c_{L}\right)\right]^{2} \\
& \pi_{2 H}\left(u_{12}, u_{21}\right)=\frac{1}{9}\left[a_{H}-\frac{2 v_{21}-v_{12}}{2}\left(c_{H}-c_{L}\right)\right]^{2}
\end{aligned}
$$

\subsection{Triopoly}

A game of three players, each with its cost type known only to itself, must be analyzed to determine the limits of case 1 , case 2, and case 3 . Following the same procedure as in the duopoly case, the equations of reaction functions if there are 3 firms are

$$
\begin{aligned}
& 2 q_{1 L}+u_{12} q_{2 H}+v_{12} q_{2 L}+u_{13} q_{3 H}+v_{13} q_{3 L}=a_{L} . \\
& 2 q_{1 H}+u_{12} q_{2 H}+v_{12} q_{2 L}+u_{13} q_{3 H}+v_{13} q_{3 L}=a_{H} . \\
& 2 q_{2 L}+u_{21} q_{1 H}+v_{21} q_{1 L}+u_{23} q_{3 H}+v_{23} q_{3 L}=a_{L} . \\
& 2 q_{2 H}+u_{21} q_{1 H}+v_{21} q_{1 L}+u_{23} q_{3 H}+v_{23} q_{3 L}=a_{H} . \\
& 2 q_{3 L}+u_{31} q_{1 H}+v_{31} q_{1 L}+u_{32} q_{2 H}+v_{32} q_{2 L}=a_{L} . \\
& 2 q_{3 H}+u_{31} q_{1 H}+v_{31} q_{1 L}+u_{32} q_{2 H}+v_{32} q_{2 L}=a_{H} .
\end{aligned}
$$

(12) and (13) continue to hold; in addition, from (27) and (28) one obtains

$$
q_{3 L}=q_{3 H}+\frac{1}{2}\left(a_{L}-a_{H}\right)=q_{1 H}+\frac{1}{2}\left(c_{H}-c_{L}\right)
$$


Using (12), (13), and (29) to eliminate the outputs of high-cost firms from (23), (25), and (27) yields a system of 3 equations in $q_{1 L}, q_{2 L}$, and $q_{3 L}$ :

$$
\left(\begin{array}{lll}
2 & 1 & 1 \\
1 & 2 & 1 \\
1 & 1 & 2
\end{array}\right)\left(\begin{array}{l}
q_{1 L} \\
q_{2 L} \\
q_{3 L}
\end{array}\right)=a_{L}\left(\begin{array}{l}
1 \\
1 \\
1
\end{array}\right)+\frac{1}{2}\left(\begin{array}{l}
u_{12}+u_{13} \\
u_{21}+u_{23} \\
u_{31}+u_{32}
\end{array}\right)\left(c_{H}-c_{L}\right)
$$

Write the coefficient matrix on the left as $I_{3}+J_{3} J_{3}^{\prime}$, where $I$ is the identity matrix, $J$ is a column vector of ones, and subscripts indicate dimension. Then using

$$
\left(I_{3}+J_{3} J_{3}^{\prime}\right)^{-1}=I_{3}-\frac{1}{4} J_{3} J_{3}^{\prime},
$$

one obtains equilibrium outputs of low-cost firms,

$$
\begin{aligned}
& q_{1 L}=\frac{1}{4}\left[a_{L}+\frac{3\left(u_{12}+u_{13}\right)-\left(u_{21}+u_{23}+u_{31}+u_{32}\right)}{2}\left(c_{H}-c_{L}\right)\right] \\
& q_{2 L}=\frac{1}{4}\left[a_{L}+\frac{3\left(u_{21}+u_{23}\right)-\left(u_{12}+u_{13}+u_{31}+u_{32}\right)}{2}\left(c_{H}-c_{L}\right)\right] \\
& q_{3 L}=\frac{1}{4}\left[a_{L}+\frac{3\left(u_{31}+u_{32}\right)-\left(u_{12}+u_{13}+u_{21}+u_{23}\right)}{2}\left(c_{H}-c_{L}\right)\right]
\end{aligned}
$$

In like manner, equilibrium outputs of high-cost firms are

$$
\begin{aligned}
& q_{1 H}=\frac{1}{4}\left[a_{H}-\frac{3\left(v_{12}+v_{13}\right)-\left(v_{21}+v_{23}+v_{31}+v_{32}\right)}{2}\left(c_{H}-c_{L}\right)\right] \\
& q_{2 H}=\frac{1}{4}\left[a_{H}-\frac{3\left(v_{21}+v_{23}\right)-\left(v_{12}+v_{13}+v_{31}+v_{32}\right)}{2}\left(c_{H}-c_{L}\right)\right] \\
& q_{3 H}=\frac{1}{4}\left[a_{H}-\frac{3\left(v_{31}+v_{32}\right)-\left(v_{12}+v_{13}+v_{21}+v_{23}\right)}{2}\left(c_{H}-c_{L}\right)\right]
\end{aligned}
$$

Equilibrium payoffs (for firm 3, subtracting entry cost) are the squares of equilibrium outputs.

\subsection{Pooling on $q_{L}$}

\subsubsection{Case 2}

If

$$
\begin{gathered}
\pi_{3 H}\left(u_{12}, u_{13}, u_{21}, u_{23}, u_{31}, u_{32}\right)-K= \\
\frac{1}{16}\left[a_{H}-\frac{3\left(v_{31}+v_{32}\right)-\left(v_{12}+v_{13}+v_{21}+v_{23}\right)}{2}\left(c_{H}-c_{L}\right)\right]^{2}-K
\end{gathered}
$$


is positive, pooling cannot limit entry. If (38) is nonpositive but

$$
\begin{gathered}
\pi_{3 L}\left(u_{12}, 0, u_{21}, 0, u_{31}, u_{32}\right)-K= \\
\frac{1}{16}\left[a_{L}+\frac{3\left(u_{31}+u_{32}\right)-\left(u_{12}+u_{21}\right)}{2}\left(c_{H}-c_{L}\right)\right]^{2}-K
\end{gathered}
$$

is positive, then a low-cost entrant would come into the market after firstperiod pooling, while a high-cost entrant would stay out. This is case 2 . If (39) is nonpositive, the game falls in case 3 ; incumbents can limit all entry by pooling in the first period.

If entry costs place the game in case 2 and a high - cost incumbent defects from the pooling equilibrium, revealing its cost type, then a high-cost entrant's payoff would be

$$
\begin{gathered}
\pi_{3 H}\left(u_{12}, u_{13}, 1, u_{23}, 1, u_{32}\right)-K= \\
\frac{1}{16}\left[a_{H}-\frac{3 v_{32}-\left(v_{12}+v_{13}+v_{23}\right)}{2}\left(c_{H}-c_{L}\right)\right]^{2}-K .
\end{gathered}
$$

If (40) is positive, the game is in case 2(a); otherwise, it is in case 2(b).

As noted in the text, low-cost firms and entrants will always adhere to the pooling strategy. In case $2(\mathrm{a})$, firm $1 H$ will pool if

$$
\begin{gathered}
u_{13}\left[\pi_{1 H}\left(u_{12}, u_{21}\right)-\pi_{1 H}\left(u_{12}, 1\right)\right] \\
+v_{13}\left[\pi_{1 H}\left(u_{12}, 0, u_{21}, 0, u_{31}, u_{32}\right)-\pi_{1 H}\left(u_{12}, u_{13}, 1, u_{23}, 1, u_{32}\right)\right] \\
+u_{13}\left[\pi_{1 H}\left(u_{12}, 1\right)-\pi_{1 H}\left(u_{12}, u_{13}, 1, u_{23}, 1, u_{32}\right)\right] \geq \pi_{1 H}^{b r}\left(q_{L}\right)-\pi_{1 H}\left(q_{L}\right)
\end{gathered}
$$

This is equation (8) of the text.

In case $2(\mathrm{~b})$, firm $1 H$ will pool if

$$
u_{13}\left[\pi_{1 H}\left(u_{12}, u_{21}\right)-\pi_{1 H}\left(u_{12}, 1\right)\right]
$$

$+v_{13}\left[\pi_{1 H}\left(u_{12}, 0, u_{21}, 0, u_{31}, u_{32}\right)-\pi_{1 H}\left(u_{12}, 0,1,0,1, u_{32}\right)\right] \geq \pi_{1 H}^{b_{r}}\left(q_{L}\right)-\pi_{1 H}\left(q_{L}\right)$.

This is equation (12) of the text.

Let us begin by evaluating the first-period gain from defection.

$$
\pi_{1 H}^{b r}\left(q_{L}\right)-\pi_{1 H}\left(q_{L}\right)
$$

for the linear model.

Firm $1 H$ 's best response payoff is

$$
\pi_{1 H}^{b r}\left(q_{L}\right)=\left[a_{H}-q_{1 H}^{b r}-q_{L}\right] q_{1 H}^{b r}=\left(q_{1 H}^{b r}\right)^{2} .
$$

using $a-q_{1 H}^{b r}-q_{L}=q_{1 H}^{b r}$ from the equation of the reaction function. 
Then firm $1 H$ 's first-period pooling payoff can be written

$$
\begin{gathered}
\pi_{1 H}\left(q_{L}\right)=\left[a_{H}-q_{L}-q_{L}\right] q_{L} \\
=\left[a_{H}-q_{1 H}^{b r}-q_{L}-\left(q_{L}-q_{1 H}^{b r}\right)\right]\left[q_{1 H}^{b r}+\left(q_{L}-q_{1 H}^{b r}\right)\right] \\
=\left[q_{1 H}^{b r}-\left(q_{L}-q_{1 H}^{b r}\right)\right]\left[q_{1 H}^{b r}+\left(q_{L}-q_{1 H}^{b r}\right)\right] \\
=\left(q_{1 H}^{b r}\right)^{2}-\left(q_{L}-q_{1 H}^{b r}\right)^{2} \\
=\pi_{1 H}^{b r}\left(q_{L}\right)-\left(q_{L}-q_{1 H}^{b r}\right)^{2} .
\end{gathered}
$$

Hence

$$
\pi_{1 H}^{b r}\left(q_{L}\right)-\pi_{1 H}\left(q_{L}\right)=\left(q_{L}-q_{1 H}^{b r}\right)^{2} .
$$

Finally, from the equation of firm $1 H$ 's reaction function, $q_{1 H}^{b r}=(1 / 2)\left(a_{H^{-}}\right.$ $q_{L}$ ), and recalling $q_{L}=a_{L} / 3$,

$$
q_{L}-q_{1 H}^{b r}=\frac{3}{2} q_{L}-\frac{1}{2} a_{H}=\frac{1}{2}\left(a_{L}-a_{H}\right)=\frac{1}{2}\left(c_{H}-c_{L}\right) .
$$

Now turn to the impact of cost type revelation on the defecting firm's profits, terms which appear in both (41) and (42). Using (17) or equivalently $(21)$

$$
\begin{gathered}
\pi_{1 H}\left(u_{12}, u_{21}\right)-\pi_{1 H}\left(u_{12}, 1\right)=q_{1 H}^{2}\left(u_{12}, u_{21}\right)-q_{1 H}^{2}\left(u_{12}, 1\right) \\
=\left[q_{1 H}\left(u_{12}, u_{21}\right)+q_{1 H}\left(u_{12}, 1\right)\right]\left[q_{1 H}\left(u_{12}, u_{21}\right)-q_{1 H}\left(u_{12}, 1\right)\right] \\
=\frac{v_{21}}{9}\left[a_{H}-\frac{4 v_{12}-v_{21}}{4}\left(c_{H}-c_{L}\right)\right]\left(c_{H}-c_{L}\right) \geq 0 .
\end{gathered}
$$

In like manner, using (35)

$$
\begin{gathered}
\pi_{1 H}\left(u_{12}, 0, u_{21}, 0, u_{31}, u_{32}\right)-\pi_{1 H}\left(u_{12}, 0,1,0,1, u_{32}\right) \\
=q_{1 H}^{2}\left(u_{12}, 0, u_{21}, 0, u_{31}, u_{32}\right)-q_{1 H}^{2}\left(u_{12}, 0,1,0,1, u_{32}\right) \\
=\frac{v_{21}+v_{31}}{16}\left[a_{H}-\frac{4+6 v_{12}-\left(v_{21}+v_{31}+2 v_{32}\right)}{4}\left(c_{H}-c_{L}\right)\right]\left(c_{H}-c_{L}\right) \geq 0 .
\end{gathered}
$$

When quantity-setting firms produce strategic substitutes, a firm's rivals expand second-period output if it becomes known that the firm has high cost, compared with the situation in which there is some probability that the firm has low cost. This cost revelation effect reduces the defecting high-cost firm's second-period payoffs.

Similarly

$$
\begin{aligned}
& \pi_{1 H}\left(u_{12}, u_{13}, 1, u_{23}, 1, u_{32}\right)-\pi_{1 H}\left(u_{12}, 0,1,0,1, u_{32}\right) \\
= & q_{1 H}^{2}\left(u_{12}, u_{13}, 1, u_{23}, 1, u_{32}\right)-q_{1 H}^{2}\left(u_{12}, 0,1,0,1, u_{32}\right)
\end{aligned}
$$




$$
=\frac{3 u_{13}-u_{23}}{16}\left[a_{H}-\frac{2+6 v_{12}+3 v_{13}-\left(v_{23}+2 v_{32}\right)}{4}\left(c_{H}-c_{L}\right)\right]\left(c_{H}-c_{L}\right) \geq 0 .
$$

The entry effect, which appears only in case 2(a), is

$$
\pi_{1 H}\left(u_{12}, 1\right)-\pi_{1 H}\left(u_{12}, u_{13}, 1, u_{23}, 1, u_{32}\right)
$$

$=\left[q_{1 H}\left(u_{12}, 1\right)+q_{1 H}\left(u_{12}, u_{13}, 1, u_{23}, 1, u_{32}\right)\right]\left[q_{1 H}\left(u_{12}, 1\right)-q_{1 H}\left(u_{12}, u_{13}, 1, u_{23}, 1, u_{32}\right)\right]$.

This shows the change in profit of a known high-cost firm 1 if an entrant of unknown cost type comes into the market. Examining the terms in the second brackets on the right,

$$
\begin{gathered}
q_{1 H}\left(u_{12}, 1\right)=\frac{1}{3}\left[a_{H}-v_{12}\left(c_{H}-c_{L}\right)\right] \\
q_{1 H}\left(u_{12}, u_{13}, 1, u_{23}, 1, u_{32}\right)=\frac{1}{4}\left[a_{H}-\frac{3 v_{12}+3 v_{13}-\left(v_{23}+v_{32}\right)}{2}\left(c_{H}-c_{L}\right)\right] .
\end{gathered}
$$

The normal case is that

$$
\begin{gathered}
q_{1 H}\left(u_{12}, 1\right)-q_{1 H}\left(u_{12}, u_{13}, 1, u_{23}, 1, u_{32}\right) \\
=\frac{1}{12} a_{H}+\left[\frac{v_{12}}{24}+\frac{3 v_{13}-\left(v_{23}+v_{32}\right)}{8}\right]\left(c_{H}-c_{L}\right)
\end{gathered}
$$

is positive: we expect entry to reduce incumbents' equilibrium outputs and profits. But this is not a necessary result. If $u_{12}=u_{13}=1$ and $u_{23}=u_{32}=0$, then firm 1 is known to have high cost, firm 1 believes both rivals have high cost, and firms 2 and 3 each believe the other has low cost. Then (53) may be positive. In particular

$$
\begin{gathered}
q_{1 H}(1,1)=\frac{1}{3} a_{H}=\frac{1}{3}\left(a-c_{H}\right), \\
q_{1 H}(1,1,1,0,1,0)=\frac{1}{4} a_{L}=\frac{1}{4}\left(a-c_{L}\right),
\end{gathered}
$$

and if $a_{L} / 4>a_{H} / 3$, firm $1 H$ would expect greater output and profit with entry than without entry. With downward-sloping quantity reaction functions, and believing its rivals to have high cost, firm $1 H$ would expand output. Firms 2 and 3 , each believing the other to have low cost, will reduce output.

\subsubsection{Case 3}

If entry costs place the game in case 3 and a high-cost entrant defects from the pooling equilibrium, revealing its cost type, a low-cost entrant's payoff is

$$
\pi_{3 L}\left(u_{12}, 0,1,0,1, u_{32}\right)=\frac{1}{16}\left[a_{L}+\frac{2+3 u_{32}-u_{12}}{2}\left(c_{H}-c_{L}\right)\right]^{2}-K
$$


If this is positive, then the game is in case $3(\mathrm{a})$ : defection by a high-cost incumbent will induce entry by a low-cost potential entrant. If (55) is nonpositive, then a high-cost incumbent can defect without inducing entry; this is case 3(b).

The high-output pooling strategy requires an entrant to come into the market if it expects a positive post-entry profit and to stay out otherwise. If incumbents pool in the first period, the entrant expects a negative post-entry profit, and will maximize its payoff by staying out of the market.

If a low-cost incumbent defects, it reduces its first-period payoff and rivals infer that it has high cost. This leads the other incumbent to expand secondperiod output. It may (in case 3(a)) induce entry. Both consequences have the effect of reducing the defecting low-cost firm's second-period payoff. A low-cost incumbent would therefore be willing to pool on $q_{L}$ in the first period.

Now turn to the incentives of a high-cost incumbent. If firm $1 \mathrm{H}$ pools on $q_{L}$ in the first period, its expected equilibrium payoff is

$$
\pi_{1 H}\left(q_{L}\right)+\pi_{1 H}\left(u_{12}, u_{21}\right) .
$$

If firm $1 H$ defects from the pooling equilibrium, its expected payoff is

$$
\pi_{1 H}^{b r}\left(q_{L}\right)+u_{13} \pi_{1 H}\left(u_{12}, 1\right)+v_{13} \pi_{1 H}\left(u_{12}, 0,1,0,1, u_{32}\right)
$$

if the game is in case $3(\mathrm{a})$ and

$$
\pi_{1 H}^{b r}\left(q_{L}\right)+\pi_{1 H}\left(u_{12}, 1\right)
$$

if the game is in case $3(\mathrm{~b})$.

Comparing pooling and defection payoffs, in case $3(\mathrm{a})$ the incumbent will pool if

$$
\begin{gathered}
\pi_{1 H}\left(u_{12}, u_{21}\right)-\pi_{1 H}\left(u_{12}, 1\right)+v_{13}\left[\pi_{1 H}\left(u_{12}, 1\right)-\pi_{1 H}\left(u_{12}, 0,1,0,1, u_{32}\right)\right] \\
\geq \pi_{1 H}^{b r}\left(q_{L}\right)-\pi_{1 H}\left(q_{L}\right) .
\end{gathered}
$$

In case $3(\mathrm{~b})$, the incumbent will pool if

$$
\pi_{1 H}\left(u_{12}, u_{21}\right)-\pi_{1 H}\left(u_{12}, 1\right) \geq \pi_{1 H}^{b r}\left(q_{L}\right)-\pi_{1 H}\left(q_{L}\right)
$$

The right-hand side of $(60)$ is the first-period gain from defection. The left-hand side is the second-period lost profit due to cost type revelation. The additional term that appears on the left-hand side in (59) is the lost secondperiod profit if entry occurs, weighted by the prior probability that the entrant has low cost.

For the linear example, the first-period gain from defection is given by (46) and (47). The revelation effect is given by (48). In contrast to the result 
for case 2(a), in case 3(a) entry always results in lower output and profit for the defecting high-cost firm:

$$
\begin{gathered}
\pi_{1 H}\left(u_{12}, 1\right)-\pi_{1 H}\left(u_{12}, 0,1,0,1, u_{32}\right) \\
=\left[q_{1 H}\left(u_{12}, 1\right)+q_{1 H}\left(u_{12}, 0,1,0,1, u_{32}\right)\right]\left[q_{1 H}\left(u_{12}, 1\right)-q_{1 H}\left(u_{12}, 0,1,0,1, u_{32}\right)\right] . \\
q_{1 H}\left(u_{12}, 1\right) \text { is given by }(52) ; \\
q_{1 H}\left(u_{12}, 0,1,0,1, u_{32}\right)=\frac{1}{4}\left[a_{H}-\frac{3 v_{12}+1+u_{32}}{2}\left(c_{H}-c_{L}\right)\right] .
\end{gathered}
$$

Then

$$
q_{1 H}\left(u_{12}, 1\right)-q_{1 H}\left(u_{12}, 0,1,0,1, u_{32}\right)=\frac{a_{H}}{12}+\left(\frac{v_{12}}{24}+\frac{1+u_{32}}{8}\right)\left(c_{H}-c_{L}\right)>0 .
$$

In case 3(a), if entry occurs at all, it is known that the entrant has low cost. With downward sloping reaction functions, this induces incumbents to restrict output.

\subsection{Separating equilibrium: payoffs from entry}

To determine incumbents' separating and defection payoffs, we need to specify the relationship between entry costs and expected payoffs for entrants of different cost types. Entrants' payoffs can be ranked as follows:

$$
\begin{gathered}
\pi_{3 L}(1,0,1,0,1,1)>\pi_{3 L}(0,0,1,0,1,0)>\pi_{3 L}(0,0,0,0,0,0) \\
\geq \pi_{3 H}\left(1, u_{13}, 1, u_{23}, 1,1\right)>\pi_{3 H}\left(0, u_{13}, 1, u_{23}, 1,0\right)>\pi_{3 H}\left(0, u_{13}, 0, u_{23}, 0,0\right) .
\end{gathered}
$$

To establish these inequalities for quantity-setting firms, it is sufficient to show that the corresponding relationships hold for outputs. Evaluating (34) and (37) for alternative beliefs,

$$
\begin{gathered}
q_{3 L}(1,0,1,0,1,1)=\frac{1}{4}\left[a_{L}+2\left(c_{H}-c_{L}\right)\right] \\
q_{3 L}(0,0,1,0,1,0)=\frac{1}{4}\left[a_{L}+\left(c_{H}-c_{L}\right)\right] \\
q_{3 L}(0,0,0,0,0,0)=\frac{1}{4} a_{L} \\
q_{3 H}\left(1, u_{13}, 1, u_{23}, 1,1\right)=\frac{1}{4}\left[a_{H}-\frac{u_{13}+u_{23}-2}{2}\left(c_{H}-c_{L}\right)\right] \\
q_{3 H}\left(0, u_{13}, 1, u_{23}, 1,0\right)=\frac{1}{4}\left[a_{H}-\frac{u_{13}+u_{23}}{2}\left(c_{H}-c_{L}\right)\right]
\end{gathered}
$$




$$
q_{3 H}\left(0, u_{13}, 0, u_{23}, 0,0\right)=\frac{1}{4}\left[a_{H}-\frac{u_{23}+u_{13}+2}{2}\left(c_{H}-c_{L}\right)\right]
$$

The only pairwise comparison that is not immediate is between (67) and (68); for this, by subtraction,

$$
q_{3 L}(0,0,0,0,0,0)-q_{3 H}\left(1, u_{13}, 1, u_{23}, 1,1\right)=\frac{u_{13}+u_{23}}{8}\left(c_{H}-c_{L}\right) \geq 0,
$$

with equality holding only if $u_{13}=u_{23}=0$.

\subsection{Separation by $\mathrm{L}$-firm output expansion}

It can be a sequential equilibrium for low-cost incumbents to separate by producing outputs so great that their (notional) high-cost counterparts would not find it profitable to imitate. Consider the following collection of strategies and beliefs:

(a) firms $1 L$ and $2 L$ produce outputs $q_{1 \lambda}>q_{1 L}$ and $q_{2 \lambda}>q_{2 L}$, respectively, in period 1 ;

(b) firms $1 H$ and $2 H$ produce their best-response outputs $q_{1 h}$ and $q_{2 h}$, respectively, in period 1 ;

(c) incumbents' cost types are revealed by observing first-period outputs;

(d) the potential entrant comes into the market in the second period if it expects a positive second-period profit, net of entry cost;

(e) if the fact of entry does not reveal the entrant's cost type, incumbents carry forward prior beliefs from the first period to the second; all firms maximize expected profit in the second period;

If firm 1 produces any output other than $q_{1 \lambda}$ (firm 2 produces any output other than $q_{2 \lambda}$ ), rivals infer that it has high cost.

It is clear that the entrant maximizes its expected payoff by behaving as indicated, given that other players behave as indicated.

\subsubsection{High-cost incumbents}

The inequalities (64) define the seven ranges of entry cost that must be considered to examine incumbents' incentives to separate. Firm $1 H$ 's separation and defection payoffs for the seven ranges, and the conditions for firm $1 \mathrm{H}$ to separate, are: 
Case S1 $K>\pi_{3 L}(1,0,1,0,1,1)$

Separation payoff:

$$
\pi_{1 H}\left(q_{1 h}\right)+u_{12} \pi_{1 H}(1,1)+v_{12} \pi_{1 H}(0,1) .
$$

Defection payoff:

$$
\pi_{1 H}\left(q_{1 \lambda}\right)+u_{12} \pi_{1 H}(1,0)+v_{12} \pi_{1 H}(0,0) .
$$

Condition for $1 H$ to separate:

$$
\pi_{1 H}\left(q_{1 h}\right)-\pi_{1 H}\left(q_{1 \lambda}\right) \geq u_{12}\left[\pi_{1 H}(1,0)-\pi_{1 H}(1,1)\right]+v_{12}\left[\pi_{1 H}(0,0)-\pi_{1 H}(0,1)\right] .
$$

Case S2 $\pi_{3 L}(1,0,1,0,1,1)>K \geq \pi_{3 L}(0,0,1,0,1,0)$

Separation payoff:

$$
\pi_{1 H}\left(q_{1 h}\right)+u_{12}\left[u_{13} \pi_{1 H}(1,1)+v_{13} \pi_{1 H}(1,0,1,0,1,1)\right]+v_{12} \pi_{1 H}(0,1) .
$$

Defection payoff:

$$
\pi_{1 H}\left(q_{1 \lambda}\right)+u_{12} \pi_{1 H}(1,0)+v_{12} \pi_{1 H}(0.0) .
$$

Condition for $1 H$ to separate:

$$
\begin{gathered}
\pi_{1 H}\left(q_{1 h}\right)-\pi_{1 H}\left(q_{1 \lambda}\right) \geq u_{12} u_{13}\left[\pi_{1 H}(1,0)-\pi_{1 H}(1,1)\right] \\
+v_{12}\left[\pi_{1 H}(0,0)-\pi_{1 H}(0,1)\right]+u_{12} v_{13}\left[\pi_{1 H}(1,0)-\pi_{1 H}(1,0,1,0,1,1)\right] .
\end{gathered}
$$

Case S3 $\pi_{3 L}(0,0,1,0,1,0)>K \geq \pi_{3 L}(0,0,0,0,0,0)$

Separation payoff:

$$
\begin{gathered}
\pi_{1 H}\left(q_{1 h}\right)+u_{12}\left[u_{13} \pi_{1 H}(1,1)+v_{13} \pi_{1 H}(1,0,1,0,1,1)\right] \\
+v_{12}\left[u_{13} \pi_{1 H}(0,1)+v_{13} \pi_{1 H}(0,0,1,0,1,0)\right] .
\end{gathered}
$$

Defection payoff:

$$
\pi_{1 H}\left(q_{1 \lambda}\right)+u_{12}\left[u_{13} \pi_{1 H}(1,0)+v_{13} \pi_{1 H}(1,0,0,0,0,1)\right]+v_{12} \pi_{1 H}(0,0) .
$$

Condition for $1 H$ to separate:

$$
\begin{gathered}
\pi_{1 H}\left(q_{1 h}\right)-\pi_{1 H}\left(q_{1 \lambda}\right) \geq \\
+u_{12} u_{13}\left[\pi_{1 H}(1,0)-\pi_{1 H}(1,1)\right]+u_{12} v_{13}\left[\pi_{1 H}(1,0,0,0,0,1)-\pi_{1 H}(1,0,1,0,1,1)\right] \\
+v_{12} u_{13}\left[\pi_{1 H}(0,0)-\pi_{1 H}(0,1)\right]+v_{12} v_{13}\left[\pi_{1 H}(0,0)-\pi_{1 H}(0,0,1,0,1,0)\right]
\end{gathered}
$$


Case S4 $\pi_{3 L}(0,0,0,0,0,0)>K \geq \pi_{3 H}\left(1, u_{13}, 1, u_{23}, 1,1\right)$

Separation payoff:

$$
\begin{gathered}
\pi_{1 H}\left(q_{1 h}\right)+u_{12}\left[u_{13} \pi_{1 H}(1,1)+v_{13} \pi_{1 H}(1,0,1,0,1,1)\right] \\
+v_{12}\left[u_{13} \pi_{1 H}(0,1)+v_{13} \pi_{1 H}(0,0,1,0,1,0)\right] .
\end{gathered}
$$

Defection payoff:

$$
\begin{gathered}
\pi_{1 H}\left(q_{1 \lambda}\right)+u_{12}\left[u_{13} \pi_{1 H}(1,0)+v_{13} \pi_{1 H}(1,0,0,0,0,1)\right] \\
+v_{12}\left[u_{13} \pi_{1 H}(0,0)+v_{13} \pi_{1 H}(0,0,0,0,0,0)\right] .
\end{gathered}
$$

Condition for $1 H$ to separate:

$$
\pi_{1 H}\left(q_{1 h}\right)-\pi_{1 H}\left(q_{1 \lambda}\right) \geq
$$

$$
\begin{aligned}
& u_{12} u_{13}\left[\pi_{1 H}(1,0)-\pi_{1 H}(1,1)\right]+u_{12} v_{13}\left[\pi_{1 H}(1,0,0,0,0,1)-\pi_{1 H}(1,0,1,0,1,1)\right] \\
+ & v_{12} u_{13}\left[\pi_{1 H}(0,0)-\pi_{1 H}(0,1)\right]+v_{12} v_{13}\left[\pi_{1 H}(0,0,0,0,0,0)-\pi_{1 H}(0,0,1,0,1,0)\right] .
\end{aligned}
$$

Case S5 $\pi_{3 H}\left(1, u_{13}, 1, u_{23}, 1,1\right)>K \geq \pi_{3 H}\left(0, u_{13}, 1, u_{23}, 1,0\right)$

Separation payoff:

$\pi_{1 H}\left(q_{1 h}\right)+u_{12} \pi_{1 H}\left(1, u_{13}, 1, u_{23}, 1,1\right)+v_{12}\left[u_{13} \pi_{1 H}(0,1)+v_{13} \pi_{1 H}(0,0,1,0,1,0)\right]$.

Defection payoff:

$$
\begin{gathered}
\pi_{1 H}\left(q_{1 \lambda}\right)+u_{12}\left[u_{13} \pi_{1 H}(1,0)+v_{13} \pi_{1 H}(1,0,0,0,0,1)\right] \\
+v_{12}\left[u_{13} \pi_{1 H}(0,0)+v_{13} \pi_{1 H}(0,0,0,0,0,0)\right] .
\end{gathered}
$$

Condition for $1 H$ to separate:

$$
\begin{gathered}
\pi_{1 H}\left(q_{1 h}\right)-\pi_{1 H}\left(q_{1 \lambda}\right) \geq u_{12} u_{13}\left[\pi_{1 H}(1,0)-\pi_{1 H}\left(1, u_{13}, 1, u_{23}, 1,1\right)\right] \\
+u_{12} v_{13}\left[\pi_{1 H}(1,0,0,0,0,1)-\pi_{1 H}\left(1, u_{13}, 1, u_{23}, 1,1\right)\right]
\end{gathered}
$$

$+v_{12} u_{13}\left[\pi_{1 H}(0,0)-\pi_{1 H}(0,1)\right]+v_{12} v_{13}\left[\pi_{1 H}(0,0,0,0,0,0)-\pi_{1 H}(0,0,1,0,1,0)\right]$.

Case S6 $\pi_{3 H}\left(0, u_{13}, 1, u_{23}, 1,0\right)>K \geq \pi_{3 H}\left(0, u_{13}, 0, u_{23}, 0,0\right)$

Separation payoff:

$$
\pi_{1 H}\left(q_{1 h}\right)+u_{12} \pi_{1 H}\left(1, u_{13}, 1, u_{23}, 1,1\right)+v_{12} \pi_{12}\left(0, u_{13}, 1, u_{23}, 1,0\right) .
$$

Defection payoff:

$$
\pi_{1 H}\left(q_{1 \lambda}\right)+u_{12} \pi_{1 H}\left(1, u_{13}, 0, u_{23}, 0,1\right)+v_{12}\left[u_{13} \pi_{1 H}(0,0)+v_{13} \pi_{1 H}(0,0,0,0,0,0)\right] .
$$

Condition for $1 H$ to separate:

$$
\begin{gathered}
\pi_{1 H}\left(q_{1 h}\right)-\pi_{1 H}\left(q_{1 \lambda}\right) \geq u_{12}\left[\pi_{1 H}\left(1, u_{13}, 0, u_{23}, 0,1\right)-\pi_{1 H}\left(1, u_{13}, 1, u_{23}, 1,1\right)\right] \\
+v_{12} u_{13}\left[\pi_{1 H}(0,0)-\pi_{1 H}\left(0, u_{13}, 1, u_{23}, 1,0\right)\right] \\
+v_{12} v_{13}\left[\pi_{1 H}(0,0,0,0,0,0)-\pi_{12}\left(0, u_{13}, 1, u_{23}, 1,0\right)\right] .
\end{gathered}
$$


Case S7 $\pi_{3 H}\left(0, u_{13}, 0, u_{23}, 0,0\right)>K$

Separation payoff:

$\pi_{1 H}\left(q_{1 h}\right)+u_{12} \pi_{1 H}\left(1, u_{13}, 1, u_{23}, 1,1\right)+v_{12} \pi_{1 H}\left(0, u_{13}, 1 . u_{23}, 1,0\right)$.

Defection payoff:

$\pi_{1 H}\left(q_{1 \lambda}\right)+u_{12} \pi_{1 H}\left(1, u_{13}, 0, u_{23}, 0,1\right)+v_{12} \pi_{1 H}\left(0, u_{13}, 0, u_{23}, 0,0\right)$.

Condition for $1 H$ to separate:

$$
\begin{gathered}
\pi_{1 H}\left(q_{1 h}\right)-\pi_{1 H}\left(q_{1 \lambda}\right) \geq u_{12}\left[\pi_{1 H}\left(1, u_{13}, 0, u_{23}, 0,1\right)-\pi_{1 H}\left(1, u_{13}, 1, u_{23}, 1,1\right)\right] \\
+v_{12}\left[\pi_{1 H}\left(0, u_{13}, 0, u_{23}, 0,0\right)-\pi_{1 H}\left(0, u_{13}, 1, u_{23}, 1,0\right)\right] .
\end{gathered}
$$

In cases $\mathrm{S} 1, \mathrm{~S} 4$, and $\mathrm{S} 7$, the potential entrant's decision is not affected by action of the high-cost incumbent, with the result that the possibility of entry or entry deterrence does not affect the incentives of the high cost incumbent. In the remaining cases, the possibility of deterring entry is an incentive to defect from the separating strategy. For high-cost incumbents, separation is not entry-limiting behavior.

\subsubsection{Low-cost incumbents}

Case $\mathbf{S} 1 K>\pi_{3 L}(1,0,1,0,1,1)$

Separation payoff:

$$
\pi_{1 L}\left(q_{1 \lambda}, q_{2 \lambda}\right)+u_{12} \pi_{1 L}(1,0)+v_{12} \pi_{1 L}(0,0) .
$$

Defection payoff:

$$
\pi_{1 L}^{b r}\left(q_{1 \lambda}, q_{2 \lambda}\right)+u_{12} \pi_{1 L}(1,1)+v_{12} \pi_{1 L}(0,1) .
$$

Condition for $1 L$ to separate:

$$
\begin{gathered}
u_{12}\left[\pi_{1 L}(1,0)-\pi_{1 L}(1,1)\right]+v_{12}\left[\pi_{1 L}(0,0)-\pi_{1 L}(0,1)\right] \geq \\
\pi_{1 L}^{b r}\left(q_{1 \lambda}, q_{2 \lambda}\right)-\pi_{1 L}\left(q_{1 \lambda}, q_{2 \lambda}\right)
\end{gathered}
$$

Case S2 $\pi_{3 L}(1,0,1,0,1,1)>K \geq \pi_{3 L}(0,0,1,0,1.0)$

Separation payoff:

$$
\pi_{1 L}\left(q_{1 \lambda}, q_{2 \lambda}\right)+u_{12} \pi_{1 L}(1,0)+v_{12} \pi_{1 L}(0.0) .
$$

Defection payoff:

$$
\pi_{1 L}^{b r}\left(q_{1 \lambda}, q_{2 \lambda}\right)+u_{12}\left[u_{13} \pi_{1 L}(1,1)+v_{13} \pi_{1 L}(1,0,1,0,1,1)\right]+v_{12} \pi_{1 L}(0,1) .
$$

Condition for $1 L$ to separate:

$$
\begin{gathered}
u_{12} u_{13}\left[\pi_{1 L}(1,0)-\pi_{1 L}(1,1)\right]+u_{12} v_{13}\left[\pi_{1 L}(1,0)-\pi_{1 L}(1.0 .1,0.1 .1)\right] \\
+v_{12}\left[\pi_{1 L}(0,0)-\pi_{1 L}(0,1)\right] \geq \pi_{1 L}^{b r}\left(q_{1 \lambda}, q_{2 \lambda}\right)-\pi_{1 L}\left(q_{1 \lambda} \cdot q_{2 \lambda}\right) .
\end{gathered}
$$


Case S3 $\pi_{3 L}(0,0,1,0,1,0)>K \geq \pi_{3 L}(0,0,0,0,0,0)$

Separation payoff:

$$
\pi_{1 L}\left(q_{1 \lambda}, q_{2 \lambda}\right)+u_{12}\left[u_{13} \pi_{1 L}(1,0)+v_{13} \pi_{1 L}(1,0,0,0,0,1)\right]+v_{12} \pi_{1 L}(0,0) .
$$

Defection payoff:

$$
\begin{gathered}
\pi_{1 L}^{b r}\left(q_{1 \lambda}, q_{2 \lambda}\right)+u_{12}\left[u_{13} \pi_{1 L}(1,1)+v_{13} \pi_{1 L}(1,0,1,0,1,1)\right] \\
+v_{12}\left[u_{13} \pi_{1 L}(0,1)+v_{13} \pi_{1 L}(0,0,1,0,1,0)\right] .
\end{gathered}
$$

Condition for $1 L$ to separate:

$$
\begin{gathered}
u_{12} u_{13}\left[\pi_{1 L}(1,0)-\pi_{1 L}(1,1)\right]+u_{12} v_{13}\left[\pi_{1 L}(1,0,0,0,0,1)-\pi_{1 L}(1,0,1,0,1,1)\right] \\
+v_{12} u_{13}\left[\pi_{1 L}(0,0)-\pi_{1 L}(0,1)\right]+v_{12} v_{13}\left[\pi_{1 L}(0,0)-\pi_{1 L}(0,0,1,0,1,0)\right] \\
\geq \pi_{1 L}^{b r}\left(q_{1 \lambda}, q_{2 \lambda}\right)-\pi_{1 L}\left(q_{1 \lambda}, q_{2 \lambda}\right) .
\end{gathered}
$$

Case $\mathbf{S} 4 \pi_{3 L}(0,0,0,0,0,0)>K \geq \pi_{3 H}\left(1, u_{13}, 1, u_{23}, 1,1\right)$

Separation payoff:

$$
\begin{gathered}
\pi_{1 L}\left(q_{1 \lambda}, q_{2 \lambda}\right)+u_{12}\left[u_{13} \pi_{1 L}(1,0)+v_{13} \pi_{1 L}(1,0,0,0,0,1)\right] \\
+v_{12}\left[u_{13} \pi_{1 L}(0,0)+v_{13} \pi_{1 L}(0,0,0,0,0,0)\right] .
\end{gathered}
$$

Defection payoff:

$$
\begin{gathered}
\pi_{1 L}^{b r}\left(q_{1 \lambda}, q_{2 \lambda}\right)+u_{12}\left[u_{13} \pi_{1 L}(1,1)+v_{13} \pi_{1 L}(1,0,1,0,1,1)\right] \\
+v_{12}\left[u_{13} \pi_{1 L}(0,1)+v_{13} \pi_{1 L}(0,0,1,0,1,0)\right] .
\end{gathered}
$$

Condition for $1 L$ to separate:

$$
\begin{gathered}
u_{12} u_{13}\left[\pi_{1 L}(1,0)-\pi_{1 L}(1,1)\right]+u_{12} v_{13}\left[\pi_{1 L}(1,0,0,0,0,1)-\pi_{1 L}(1,0,1,01,1)\right](104) \\
+v_{12} u_{13}\left[\pi_{1 L}(0,0)-\pi_{1 L}(0,1)\right]+v_{12} v_{13}\left[\pi_{1 L}(0,0,0,0,0,0)-\pi_{1 L}(0,0,1,0,1,0)\right] \\
\geq \pi_{1 L}^{b r}\left(q_{1 \lambda}, q_{2 \lambda}\right)-\pi_{1 L}\left(q_{1 \lambda}, q_{2 \lambda}\right) .
\end{gathered}
$$


Case S5 $\pi_{3 H}\left(1, u_{13}, 1, u_{23}, 1,1\right)>K \geq \pi_{3 H}\left(0, u_{13}, 1, u_{23}, 1,0\right)$ Separation payoff:

$$
\begin{gathered}
\pi_{1 L}\left(q_{1 \lambda}, q_{2 \lambda}\right)+u_{12}\left[u_{13} \pi_{1 L}(1,0)+v_{13} \pi_{1 L}(1,0,0,0,0,1)\right] \\
+v_{12}\left[u_{13} \pi_{1 L}(0,0)+v_{13} \pi_{1 L}(0,0,0,0,0,0)\right]
\end{gathered}
$$

Defection payoff:

$$
\begin{aligned}
& \left.\pi_{1 L}^{b r}\left(q_{1 \lambda}, q_{2 \lambda}\right)+u_{12} \pi_{1 L}\left(1, u_{13}, 1, u_{23}, 1,1\right)\right] \\
+ & v_{12}\left[u_{13} \pi_{1 L}(0,1)+v_{13} \pi_{1 L}(0,0,1,0,1,0)\right] .
\end{aligned}
$$

The condition for firm $1 L$ to pool is

$$
\begin{gathered}
u_{12} u_{13}\left[\pi_{1 L}(1,0)-\pi_{1 L}\left(1, u_{13}, 1, u_{23}, 1,1\right)\right] \\
+u_{12} v_{13}\left[\pi_{1 L}(1,0,0,0,0,1)-\pi_{1 L}\left(1, u_{13}, 1, u_{23}, 1,1\right)\right] \\
+v_{12} u_{13}\left[\pi_{1 L}(0,0)-\pi_{1 L}(0,1)\right]+v_{12} v_{13}\left[\pi_{1 L}(0,0,0,0,0,0)-\pi_{1 L}(0,0,1,0,1,0)\right] \\
\geq \pi_{1 L}^{b r}\left(q_{1 \lambda}, q_{2 \lambda}\right)-\pi_{1 L}\left(q_{1 \lambda}, q_{2 \lambda}\right) .
\end{gathered}
$$

Case S6 $\pi_{3 H}\left(0, u_{13}, 1, u_{23}, 1,0\right)>K \geq \pi_{3 H}\left(0, u_{13}, 0, u_{23}, 0,0\right)$

Separation payoff:

$$
\begin{aligned}
& \pi_{1 L}\left(q_{1 \lambda}, q_{2 \lambda}\right)+u_{12} \pi_{1 L}\left(1, u_{13}, 0, u_{23}, 0.1\right) \\
+ & v_{12}\left[u_{13} \pi_{1 L}(0,0)+v_{13} \pi_{1 L}(0,0,0,0,0,0)\right] .
\end{aligned}
$$

Defection payoff:

$\pi_{1 L}^{b r}\left(q_{1 \lambda}, q_{2 \lambda}\right)+u_{12} \pi_{1 L}\left(1, u_{13}, 1, u_{23}, 1,1\right)+v_{12} \pi_{1 L}\left(0, u_{13}, 1, u_{23}, 1,0\right)$.

Condition for $1 L$ to separate:

$$
\begin{gathered}
u_{12}\left[\pi_{1 L}\left(1, u_{13}, 0, u_{23}, 0,1\right)-\pi_{1 L}\left(1, u_{13}, 1 . u_{23} .1 .1\right)\right] \\
+v_{12} u_{13}\left[\pi_{1 L}(0,0)-\pi_{1 L}\left(0, u_{13}, 1, u_{23}, 1,0\right)\right]
\end{gathered}
$$

$+v_{12} v_{13}\left[\pi_{1 L}(0,0,0,0,0,0)-\pi_{1 L}\left(0, u_{13}, 1, u_{23}, 1,0\right)\right] \geq \pi_{1 L}^{b r}\left(q_{1 \lambda} \cdot q_{2 \lambda}\right)-\pi_{1 L}\left(q_{1 \lambda}, q_{2 \lambda}\right)$.

Case S7 $\pi_{3 H}\left(0, u_{13}, 0, u_{23}, 0,0\right)>K$

Separation payoff:

$$
\pi_{1 L}\left(q_{1 \lambda}, q_{2 \lambda}\right)+u_{12} \pi_{1 L}\left(1, u_{13}, 0, u_{23}, 0,1\right)+v_{12} \pi_{1 L}\left(0, u_{13}, 0, u_{23}, 0,0\right)
$$

Defection payoff:

$$
\pi_{1 L}^{b r}\left(q_{1 \lambda}, q_{2 \lambda}\right)+u_{12} \pi_{1 L}\left(1, u_{13}, 1, u_{23}, 1,1\right)+v_{12} \pi_{1 L}\left(0, u_{13}, 1, u_{13}, 1,0\right) .
$$

Condition for $1 L$ to separate:

$$
\begin{gathered}
u_{12}\left[\pi_{1 L}\left(1, u_{13}, 0, u_{23}, 0,1\right)-\pi_{1 L}\left(1, u_{13}, 1, u_{23} .1,1\right)\right] \\
+v_{12}\left[\pi_{1 L}\left(0, u_{13}, 0, u_{23}, 0,0\right)-\pi_{1 L}\left(0, u_{13}, 1, u_{13}, 1,0\right)\right] \geq \pi_{1 L}^{b r}\left(q_{1 \lambda}, q_{2 \lambda}\right)-\pi_{1 L}\left(q_{1 \lambda}, q_{2 \lambda}\right) .
\end{gathered}
$$


Separation by $\mathrm{L}$-firm output expansion: resumé In cases $\mathrm{S} 1, \mathrm{~S} 4$, and $\mathrm{S} 7$, the potential entrant's decision is not affected by action of the low-cost incumbent, with the result that the possibility of entry or entry deterrence does not affect the incentives of the low-cost incumbent. In the remaining cases, the possibility of deterring entry is an incentive to separate. For low-cost incumbents, separation by output expansion is entry-limiting behavior in four of the possible seven cases.

\subsubsection{Linear example}

I consider only case S2 here. If firms $1 L$ and $2 L$ expand output so that the high-cost firm separation conditions hold with equality (to expand output even more would lower own profit without altering rivals' behaviors), the high-cost incumbent separation conditions are (compare (77))

$$
\begin{gathered}
\pi_{1 H}\left(q_{1 h}\right)-\pi_{1 H}\left(q_{1 \lambda}\right)=u_{12} u_{13}\left[\pi_{1 H}(1,0)-\pi_{1 H}(1,1)\right] \\
+v_{12}\left[\pi_{1 H}(0,0)-\pi_{1 H}(0,1)\right]+u_{12} v_{13}\left[\pi_{1 H}(1,0)-\pi_{1 H}(1,0,1,0,1,1)\right]=R H S_{1 H}^{2} ; \\
\pi_{2 H}\left(q_{2 h}\right)-\pi_{2 H}\left(q_{2 \lambda}\right)=u_{21} u_{23}\left[\pi_{2 H}(0,1)-\pi_{2 H}(1,1)\right] \\
+v_{21}\left[\pi_{1 H}(0,0)-\pi_{2 H}(1,0)\right]+u_{21} v_{23}\left[\pi_{2 H}(0,1)-\pi_{2 H}(1,0,1,0,1,1)\right]=R H S_{2 H}^{2},
\end{gathered}
$$

where the terms $R H S_{1 H}$ and $R H S_{2 H}$ are defined for notational convenience.

To evaluate $\pi_{1 H}\left(q_{1 h}\right)-\pi_{1 H}\left(q_{1 \lambda}\right)$, write

$$
\begin{gathered}
\pi_{1 H}\left(q_{1 \lambda}\right)=\left[a_{H}-q_{1 \lambda}-u_{12} q_{2 h}-v_{12} q_{2 \lambda}\right] q_{1 \lambda} \\
=\left[a_{H}-q_{1 h}-u_{12} q_{2 h}-v_{12} q_{2 \lambda}-\left(q_{1 \lambda}-q_{1 h}\right)\right]\left[q_{1 h}+\left(q_{1 \lambda}-q_{1 h}\right)\right] \\
=\left[q_{1 h}-\left(q_{1 \lambda}-q_{1 h}\right)\right]\left[q_{1 h}+\left(q_{1 \lambda}-q_{1 h}\right)\right]
\end{gathered}
$$

(using the equation of $1 H$ 's reaction function)

$$
\begin{gathered}
=q_{1 h}^{2}-\left(q_{1 \lambda}-q_{1 h}\right)^{2} \\
=\pi_{1 H}\left(q_{1 h}\right)-\left(q_{1 \lambda}-q_{1 h}\right)^{2} .
\end{gathered}
$$

Hence

$$
\pi_{1 H}\left(q_{1 h}\right)-\pi_{1 H}\left(q_{1 \lambda}\right)=\left(q_{1 \lambda}-q_{1 h}\right)^{2},
$$

and in like manner

$$
\pi_{2 H}\left(q_{2 h}\right)-\pi_{2 H}\left(q_{2 \lambda}\right)=\left(q_{2 \lambda}-q_{2 h}\right)^{2} .
$$

The high-cost firm separation conditions (114) and (115) become

$$
q_{1 \lambda}-q_{1 h}=R H S_{1 H}
$$


and

$$
q_{2 \lambda}-q_{2 h}=R H S_{2 H}
$$

respectively.

$q_{1 h}$ and $q_{2 h}$ are best reply outputs. From the equations of the firm $1 H$, $2 H$ reaction functions, therefore, $q_{1 h}$ and $q_{2 h}$ are related to $q_{1 \lambda}$ and $q_{2 \lambda}$ via the system of equations

$$
\left(\begin{array}{cc}
2 & u_{12} \\
u_{21} & 2
\end{array}\right)\left(\begin{array}{l}
q_{1 h} \\
q_{2 h}
\end{array}\right)=a_{H}\left(\begin{array}{l}
1 \\
1
\end{array}\right)-\left(\begin{array}{cc}
0 & v_{12} \\
v_{21} & 0
\end{array}\right)\left(\begin{array}{l}
q_{1 \lambda} \\
q_{2 \lambda}
\end{array}\right)
$$

By subtraction,

$$
\left(\begin{array}{cc}
2 & u_{12} \\
u_{21} & 2
\end{array}\right)\left(\begin{array}{c}
q_{1 h}-q_{2 \lambda} \\
q_{2 h}-q_{2 \lambda}
\end{array}\right)=a_{H}\left(\begin{array}{l}
1 \\
1
\end{array}\right)-\left(\begin{array}{ll}
2 & 1 \\
1 & 2
\end{array}\right)\left(\begin{array}{l}
q_{1 \lambda} \\
q_{2 \lambda}
\end{array}\right) .
$$

Now substituting from (119) and (120), we obtain a system of two equations that determines the smallest values of $q_{1 \lambda}$ and $q_{2 \lambda}$ that high-cost incumbents will not be willing to mimic:

$$
\begin{aligned}
& \left(\begin{array}{ll}
2 & 1 \\
1 & 2
\end{array}\right)\left(\begin{array}{l}
q_{1 \lambda} \\
q_{2 \lambda}
\end{array}\right)=a_{H}\left(\begin{array}{l}
1 \\
1
\end{array}\right)+\left(\begin{array}{cc}
2 & u_{12} \\
u_{21} & 2
\end{array}\right)\left(\begin{array}{l}
R H S_{1 H} \\
R H S_{2 H}
\end{array}\right) . \\
& \left(\begin{array}{l}
q_{1 \lambda} \\
q_{2 \lambda}
\end{array}\right)=\frac{a_{H}}{3}\left(\begin{array}{l}
1 \\
1
\end{array}\right)+\frac{1}{3}\left(\begin{array}{cc}
4-u_{21} & -2 v_{12} \\
-2 v_{21} & 4-u_{12}
\end{array}\right)\left(\begin{array}{l}
R H S_{1 H} \\
R H S_{2 H}
\end{array}\right) .
\end{aligned}
$$

It remains to determine whether the $1 L$ separation condition, (98), and the corresponding condition for $2 L$, are satisfied.

\subsection{Separation on Nash duopoly outputs}

This is the separating equilibrium discussed in the text.

\subsubsection{High-cost incumbents}

The inequalities (64) define the seven ranges of entry cost that must be considered to examine incumbents' incentives to separate. Firm $1 H$ 's separation and defection payoffs for the seven ranges, and the conditions for firm $1 H$ to separate, are:

Case S1 $K>\pi_{3 L}(1,0,1,0,1,1)$

Separation payoff:

$$
\pi_{1 H}\left(u_{12}, u_{21}\right)+u_{12} \pi_{1 H}(1,1)+v_{12} \pi_{1 H}(0,1) .
$$


Defection payoff:

$$
\pi_{1 H}\left(q_{1 L}\right)+u_{12} \pi_{1 H}(1,0)+v_{12} \pi_{1 H}(0,0) .
$$

Condition for $1 H$ to separate:

$\pi_{1 H}\left(u_{12}, u_{21}\right)-\pi_{1 H}\left(q_{1 L}\right) \geq u_{12}\left[\pi_{1 H}(1,0)-\pi_{1 H}(1,1)\right]+v_{12}\left[\pi_{1 H}(0,0)-\pi_{1 H}(0,1)\right]$.

Case S2 $\pi_{3 L}(1,0,1,0,1,1)>K \geq \pi_{3 L}(0,0,1,0,1,0)$

Separation payoff:

$$
\pi_{1 H}\left(u_{12}, u_{21}\right)+u_{12}\left[u_{13} \pi_{1 H}(1,1)+v_{13} \pi_{1 H}(1,0,1,0,1,1)\right]+v_{12} \pi_{1 H}(0,1)
$$

Defection payoff:

$$
\pi_{1 H}\left(q_{1 L}\right)+u_{12} \pi_{1 H}(1,0)+v_{12} \pi_{1 H}(0,0) .
$$

Condition for $1 H$ to separate:

$$
\begin{gathered}
\pi_{1 H}\left(u_{12}, u_{21}\right)-\pi_{1 H}\left(q_{1 L}\right) \geq u_{12} u_{13}\left[\pi_{1 H}(1,0)-\pi_{1 H}(1,1)\right] \\
+v_{12}\left[\pi_{1 H}(0,0)-\pi_{1 H}(0,1)\right]+u_{12} v_{13}\left[\pi_{1 H}(1,0)-\pi_{1 H}(1,0,1,0,1,1)\right] .
\end{gathered}
$$

Case S3 $\pi_{3 L}(0,0,1,0,1,0)>K \geq \pi_{3 L}(0,0,0,0,0,0)$

Separation payoff:

$$
\begin{gathered}
\pi_{1 H}\left(u_{12}, u_{21}\right)+u_{12}\left[u_{13} \pi_{1 H}(1,1)+v_{13} \pi_{1 H}(1,0,1,0,1,1)\right] \\
+v_{12}\left[u_{13} \pi_{1 H}(0,1)+v_{13} \pi_{1 H}(0,0,1,0,1,0)\right]
\end{gathered}
$$

Defection payoff:

$$
\pi_{1 H}\left(q_{1 L}\right)+u_{12}\left[u_{13} \pi_{1 H}(1,0)+v_{13} \pi_{1 H}(1,0,0,0,0,1)\right]+v_{12} \pi_{1 H}(0,0) .
$$

Condition for $1 H$ to separate:

$$
\begin{gathered}
\pi_{1 H}\left(u_{12}, u_{21}\right)-\pi_{1 H}\left(q_{1 L}\right) \geq \\
+u_{12} u_{13}\left[\pi_{1 H}(1,0)-\pi_{1 H}(1,1)\right]+u_{12} v_{13}\left[\pi_{1 H}(1,0,0,0,0,1)-\pi_{1 H}(1,0,1,0,1,1)\right] . \\
+v_{12} u_{13}\left[\pi_{1 H}(0,0)-\pi_{1 H}(0,1)\right]+v_{12} v_{13}\left[\pi_{1 H}(0,0)-\pi_{1 H}(0,0,1,0,1,0)\right]
\end{gathered}
$$


Case $\mathbf{S} 4 \pi_{3 L}(0,0,0,0,0,0)>K \geq \pi_{3 H}\left(1, u_{13}, 1, u_{23}, 1,1\right)$

Separation payoff:

$$
\begin{gathered}
\pi_{1 H}\left(u_{12}, u_{21}\right)+u_{12}\left[u_{13} \pi_{1 H}(1,1)+v_{13} \pi_{1 H}(1,0,1,0,1,1)\right] \\
+v_{12}\left[u_{13} \pi_{1 H}(0,1)+v_{13} \pi_{1 H}(0,0,1,0,1,0)\right] .
\end{gathered}
$$

Defection payoff:

$$
\begin{gathered}
\pi_{1 H}\left(q_{1 L}\right)+u_{12}\left[u_{13} \pi_{1 H}(1,0)+v_{13} \pi_{1 H}(1,0,0,0,0,1)\right] \\
+v_{12}\left[u_{13} \pi_{1 H}^{b r}(0,0)+v_{13} \pi_{1 H}^{b r}(0,0,0,0,0,0)\right] .
\end{gathered}
$$

Condition for $1 H$ to separate:

$$
\begin{gathered}
\pi_{1 H}\left(u_{12}, u_{21}\right)-\pi_{1 H}\left(q_{1 L}\right) \geq \\
u_{12} u_{13}\left[\pi_{1 H}(1,0)-\pi_{1 H}(1,1)\right]+u_{12} v_{13}\left[\pi_{1 H}(1,0,0,0,0,1)-\pi_{1 H}(1,0,1,0,1,1)\right] \\
+v_{12} u_{13}\left[\pi_{1 H}(0,0)-\pi_{1 H}(0,1)\right]+v_{12} v_{13}\left[\pi_{1 H}(0,0,0,0,0,0)-\pi_{\mathrm{i} H}(0,0,1,0,1,0)\right] .
\end{gathered}
$$

Case S5 $\pi_{3 H}\left(1, u_{13}, 1, u_{23}, 1,1\right)>K \geq \pi_{3 H}\left(0, u_{13}, 1, u_{23}, 1,0\right)$

Separation payoff:

$$
\begin{array}{r}
\pi_{1 H}\left(u_{12}, u_{21}\right)+u_{12} \pi_{1 H}\left(1, u_{13}, 1, u_{23} .1 .1\right) \\
+v_{12}\left[u_{13} \pi_{1 H}(0,1)+v_{13} \pi_{1 H}(0,0,1,0,1,0)\right] .
\end{array}
$$

Defection payoff:

$$
\begin{gathered}
\pi_{1 H}\left(q_{1 L}\right)+u_{12}\left[u_{13} \pi_{1 H}(1,0)+v_{13} \pi_{1 H}(1,0,0,0,0,1)\right] \\
+v_{12}\left[u_{13} \pi_{1 H}(0,0)+v_{13} \pi_{1 H}(0,0,0,0,0,0)\right] .
\end{gathered}
$$

Condition for $1 H$ to separate:

$$
\begin{gathered}
\pi_{1 H}\left(u_{12}, u_{21}\right)-\pi_{1 H}\left(q_{1 L}\right) \geq u_{12} u_{13}\left[\pi_{1 H}(1,0)-\pi_{1 H}\left(1, u_{13}, 1, u_{23}, 1,1\right)\right] \\
+u_{12} v_{13}\left[\pi_{1 H}(1,0,0,0,0,1)-\pi_{1 H}\left(1, u_{13}, 1, u_{23}, 1,1\right)\right] \\
+v_{12} u_{13}\left[\pi_{1 H}(0,0)-\pi_{1 H}(0,1)\right]+v_{12} v_{13}\left[\pi_{1 H}(0,0,0.0,0,0)-\pi_{1 H}(0,0,1,0,1,0)\right] .
\end{gathered}
$$

Case S6 $\pi_{3 H}\left(0, u_{13}, 1, u_{23}, 1,0\right)>K \geq \pi_{3 H}\left(0, u_{13}, 0, u_{23}, 0.0\right)$

Separation payoff:

$$
\pi_{1 H}\left(u_{12}, u_{21}\right)+u_{12} \pi_{1 H}\left(1, u_{13}, 1, u_{23}, 1,1\right)+v_{12} \pi_{12}\left(0, u_{13}, 1, u_{23}, 1,0\right) .
$$

Defection payoff:

$\pi_{1 H}\left(q_{1 L}\right)+u_{12} \pi_{1 H}\left(1, u_{13}, 0, u_{23}, 0,1\right)+v_{12}\left[u_{13} \pi_{1 H}(0,0)+v_{13} \pi_{1 H}(0,0,0,0,0,0)\right]$

Condition for $1 H$ to separate:

$$
\pi_{1 H}\left(u_{12}, u_{21}\right)-\pi_{1 H}\left(q_{1 L}\right) \geq u_{12}\left[\pi_{1 H}\left(1, u_{13}, 0, u_{23}, 0,1\right)-\pi_{i H}\left(1 . u_{13}, 1, u_{23}, 1,1\right)\right]
$$

$$
+v_{12} u_{13}\left[\pi_{1 H}(0,0)-\pi_{1 H}\left(0, u_{13}, 1, u_{23}, 1,0\right)\right]
$$

$$
+v_{12} v_{13}\left[\pi_{1 H}(0,0,0,0,0,0)-\pi_{12}\left(0, u_{13}, 1, u_{23}, 1,0\right)\right] \text {. }
$$


Case S7 $\pi_{3 H}\left(0, u_{13}, 0, u_{23}, 0,0\right)>K$

Separation payoff:

$$
\pi_{1 H}\left(u_{12}, u_{21}\right)+u_{12} \pi_{1 H}\left(1, u_{13}, 1, u_{23}, 1,1\right)+v_{12} \pi_{1 H}\left(0, u_{13}, 1, u_{23}, 1,0\right) .
$$

Defection payoff:

$$
\pi_{1 H}\left(q_{1 L}\right)+u_{12} \pi_{1 H}\left(1, u_{13}, 0, u_{23}, 0,1\right)+v_{12} \pi_{1 H}\left(0, u_{13}, 0, u_{23}, 0,0\right)
$$

Condition for $1 H$ to separate:

$$
\begin{gathered}
\pi_{1 H}\left(u_{12}, u_{21}\right)-\pi_{1 H}\left(q_{1 L}\right) \geq u_{12}\left[\pi_{1 H}\left(1, u_{13}, 0, u_{23}, 0,1\right)-\pi_{1 H}\left(1, u_{13}, 1, u_{23}, 1,1\right)\right] \\
+v_{12}\left[\pi_{1 H}\left(0, u_{13}, 0, u_{23}, 0,0\right)-\pi_{1 H}\left(0, u_{13}, 1, u_{23}, 1,0\right)\right] .
\end{gathered}
$$

In cases S1, S4, and S7, the potential entrant's decision is not affected by action of the high-cost incumbent, with the result that the possibility of entry or entry deterrence does not affect the incentives of the high-cost incumbent. In the remaining cases, the possibility of deterring entry is an incentive to defect from the intuitive separating strategy. For high-cost incumbents, separation on equilibrium outputs from the one-period game is not entry-limiting behavior.

\section{Price-Setting Firms}

\subsection{Duopoly}

Inverting the equations of the inverse demand curves

$$
\begin{aligned}
& p_{1}-c_{1}=a-c_{1}-\theta q_{2}-q_{1} \\
& p_{2}-c_{2}=a-c_{2}-\theta q_{1}-q_{2},
\end{aligned}
$$

one obtains the equations of the demand curves

$$
\begin{aligned}
& q_{1}=\frac{\left(a-c_{1}\right)-\theta\left(a-c_{2}\right)+\theta\left(p_{2}-c_{2}\right)-\left(p_{1}-c_{1}\right)}{1-\theta^{2}} \\
& q_{2}=\frac{\left(a-c_{2}\right)-\theta\left(a-c_{1}\right)+\theta\left(p_{1}-c_{1}\right)-\left(p_{2}-c_{2}\right)}{1-\theta^{2}}
\end{aligned}
$$

The equations of the inverse demand curves are valid for nonnegative prices; the equations of the demand curves are valid for nonnegative quantities.

Firm $1 L$ 's expected profit is

$$
\pi_{1 L}=\bar{p}_{1 L}\left[u_{12}\left(\frac{a_{L}-\theta a_{H}+\theta \bar{p}_{2 H}-\bar{p}_{1 L}}{1-\theta^{2}}\right)+v_{12}\left(\frac{a_{L}-\theta a_{L}+\theta \bar{p}_{2 L}-\bar{p}_{1 L}}{1-\theta^{2}}\right)\right]
$$




$$
=\bar{p}_{1 L}\left[\frac{(1-\theta) a_{L}+\theta u_{12}\left(a_{L}-a_{H}\right)+u_{12} \theta \bar{p}_{2 H}+\theta v_{12} \bar{p}_{2 L}-\bar{p}_{1 L}}{1-\theta^{2}}\right],
$$

writing $\bar{p}_{1 L}=p_{1 L}-c_{L}, \bar{p}_{1 H}=p_{1 H}-c_{H}, \bar{p}_{2 L}=p_{2 L}-c_{L}, \bar{p}_{2 H}=p_{2 H}-c_{H}$, and $a_{L}=a-c_{L}$, and $a_{H}=a-c_{H}$.

Maximizing (150) with respect to $\bar{p}_{1 L}$ gives the equation of firm $1 L$ 's price reaction function,

$$
2 \bar{p}_{1 L}-u_{12} \theta \bar{p}_{2 H}-\theta v_{12} \bar{p}_{2 L}=(1-\theta) a_{L}+\theta u_{12}\left(a_{l}-a_{H}\right) .
$$

Observe that (151) implies

$$
(1-\theta) a_{L}+\theta u_{12}\left(a_{L}-a_{H}\right)+u_{12} \theta \bar{p}_{2 H}+\theta v_{12} \bar{p}_{2 L}-\bar{p}_{1 L}=\bar{p}_{1 L}
$$

It follows that anywhere along firm $1 L$ 's reaction function. and in particular in equilibrium,

$$
\pi_{1 L}=\frac{1}{1-\theta^{2}}\left(\bar{p}_{1 L}\right)^{2}
$$

Proceeding in the same way, one obtains the equations of the reaction functions of firms $1 H, 2 L$, and $2 H$ :

$$
\begin{aligned}
& 2 \bar{p}_{1 H}-u_{12} \theta \bar{p}_{2 H}-\theta v_{12} \bar{p}_{2 L}=(1-\theta) a_{H}-\theta v_{12}\left(a_{I}-a_{H}\right) \\
& 2 \bar{p}_{2 L}-u_{21} \theta \bar{p}_{1 H}-\theta v_{21} \bar{p}_{1 L}=(1-\theta) a_{L}+\theta u_{21}\left(a_{L}-a_{H}\right) \\
& 2 \bar{p}_{2 H}-u_{21} \theta \bar{p}_{1 H}-\theta v_{21} \bar{p}_{1 L}=(1-\theta) a_{H}-\theta v_{21}\left(a_{L}-a_{H}\right)
\end{aligned}
$$

The duopoly equilibrium can be illustrated graphically, in a way that parallels the quantity-setting case. Weighting (151) and (154) by $v_{21}$ and $u_{21}$ respectively and adding gives the equation of firm 1's expected (by firm 2) reaction function:

$$
2 \bar{p}_{1}\left(u_{21}\right)-\theta \bar{p}_{2}\left(u_{12}\right)=(1-\theta) a_{L}-\left(u_{21}-\theta u_{12}\right)\left(a_{L}-a_{H}\right)
$$

In like manner, one obtains the equation of firm 2's expected (by firm 1) reaction function,

$$
-\theta \bar{p}_{1}\left(u_{21}\right)+2 \bar{p}_{2}\left(u_{12}\right)=(1-\theta) a_{L}-\left(u_{12}-\theta u_{21}\right)\left(a_{L}-a_{H}\right)
$$

\section{Insert Figure 4 about here}

Graphing the two expected reaction functions, as in Figure 4, gives equilibrium expected prices. Matching the firm $1 L$ and $1 H$ reaction functions with firm 2's equilibrium expected net price, as in Figure 5, illustrates $\bar{p}_{1 L}$ and $\bar{p}_{1 H}$.

\section{Insert Figure 5 about here}


Figure 6 shows all four equilibrium net prices.

\section{Insert Figure 6 about here}

Comparing equilibrium prices net of marginal cost, note that $\bar{p}_{1 L}>\bar{p}_{1 H}$ and $\bar{p}_{2 L}>\bar{p}_{2 H}$, although the relative magnitudes of prices is the reverse. Lowcost firms charge lower prices and earn greater margins than the corresponding high-cost firms.

To obtain explicit expressions for equilibrium net prices, subtract (154) from (151) and (156) from (155) to obtain

$$
\bar{p}_{1 L}=\bar{p}_{1 H}+\frac{c_{H}-c_{L}}{2} ;
$$

and

$$
\bar{p}_{2 L}=\bar{p}_{2 H}+\frac{c_{H}-c_{L}}{2} .
$$

respectively.

Using (158) and (159), the system of four equations in four unknowns can be reduced to two subsystems each of two equations in two unknowns,

$$
\left(\begin{array}{cc}
2 & -\theta \\
-\theta & 2
\end{array}\right)\left(\begin{array}{l}
\bar{p}_{1 L} \\
\bar{p}_{2 L}
\end{array}\right)=(1-\theta) a_{L}+\frac{1}{2} \theta\left(\begin{array}{l}
u_{12} \\
u_{21}
\end{array}\right)\left(c_{H}-c_{L}\right)
$$

and

$$
\left(\begin{array}{cc}
2 & -\theta \\
-\theta & 2
\end{array}\right)\left(\begin{array}{l}
\bar{p}_{1 H} \\
\bar{p}_{2 H}
\end{array}\right)=(1-\theta) a_{H}-\frac{1}{2} \theta\left(\begin{array}{l}
v_{12} \\
v_{21}
\end{array}\right)\left(c_{H}-c_{L}\right) .
$$

Noncooperative equilibrium prices are

$$
\begin{aligned}
& \bar{p}_{1 L}=\frac{1-\theta}{2-\theta} a_{L}+\frac{\theta}{2}\left(\frac{2 u_{12}+\theta u_{21}}{4-\theta^{2}}\right)\left(c_{H}-c_{L}\right) \\
& \bar{p}_{2 L}=\frac{1-\theta}{2-\theta} a_{L}+\frac{\theta}{2}\left(\frac{\theta u_{12}+2 u_{21}}{4-\theta^{2}}\right)\left(c_{H}-c_{L}\right) \\
& \bar{p}_{1 H}=\frac{1-\theta}{2-\theta} a_{H}-\frac{\theta}{2}\left(\frac{2 v_{12}+\theta v_{21}}{4-\theta^{2}}\right)\left(c_{H}-c_{L}\right) \\
& \bar{p}_{2 H}=\frac{1-\theta}{2-\theta} a_{H}-\frac{\theta}{2}\left(\frac{\theta v_{12}+2 v_{21}}{4-\theta^{2}}\right)\left(c_{H}-c_{L}\right)
\end{aligned}
$$

Here and throughout I restrict attention to the case in which net prices are nonnegative (prices are not less than marginal costs).

Having found equilibrium prices, equilibrium payoffs are obtain using (153) and the corresponding relationships. 


\subsection{Triopoly}

Inverting the equations of the inverse demand curves

$$
\begin{aligned}
& p_{1}-c_{1}=a-c_{1}-q_{1}-\theta q_{2}-\theta q_{3} \\
& p_{2}-c_{2}=a-c_{2}-\theta q_{1}-q_{2}-\theta q_{3} \\
& p_{3}-c_{3}=a-c_{3}-\theta q_{1}-\theta q_{2}-q_{3},
\end{aligned}
$$

one obtains the equations of the demand curves

$$
\begin{aligned}
& q_{1}=\frac{(1+\theta) a_{1}-\theta\left(a_{2}+a_{3}\right)-(1+\theta) \bar{p}_{1}+\theta\left(\bar{p}_{2}+\bar{p}_{3}\right)}{(1-\theta)(1+2 \theta)} \\
& q_{2}=\frac{(1+\theta) a_{2}-\theta\left(a_{1}+a_{3}\right)-(1+\theta) \bar{p}_{2}+\theta\left(\bar{p}_{1}+\bar{p}_{3}\right)}{(1-\theta)(1+2 \theta)} \\
& q_{3}=\frac{(1+\theta) a_{3}-\theta\left(a_{1}+a_{2}\right)-(1+\theta) \bar{p}_{3}+\theta\left(\bar{p}_{1}+\bar{p}_{2}\right)}{(1-\theta)(1+2 \theta)}
\end{aligned}
$$

Firm $1 L$ 's expected profit satisfies

$$
\begin{gathered}
(1-\theta)(1+2 \theta) \pi_{1 L}=\bar{p}_{1 L}\left\{(1-\theta) a_{L}+\theta\left(u_{12}+u_{13}\right)\left(c_{H}-c_{L}\right)+\right. \\
\left.\theta\left[u_{12} \bar{p}_{2 H}+v_{12} \bar{p}_{2 L}+u_{13} \bar{p}_{3 H}+v_{13} \bar{p}_{3 L}\right]-(1+\theta) \bar{p}_{1 L}\right\}
\end{gathered}
$$

Maximizing (172) with respect to $\bar{p}_{1 L}$ gives the equation of firm $1 L$ 's price reaction function,

$$
\begin{gathered}
2(1+\theta) \bar{p}_{1 L}-\theta u_{12} \bar{p}_{2 H}-\theta v_{12} \bar{p}_{c_{L}}-\theta u_{13} \bar{p}_{3 H}-\theta v_{13} \bar{p}_{3 L}= \\
(1-\theta) a_{L}+\theta\left(u_{12}+u_{13}\right)\left(c_{H}-c_{L}\right)
\end{gathered}
$$

In like manner, one obtains the equations of the reaction functions of the other players:

$$
\begin{gathered}
2(1+\theta) \bar{p}_{1 H}-\theta u_{12} \bar{p}_{2 H}-\theta v_{12} \bar{p}_{2 L}-\theta u_{13} \bar{p}_{3 H}-\theta v_{13} \bar{p}_{3 L}= \\
(1-\theta) a_{H}-\theta\left(v_{12}+v_{13}\right)\left(c_{H}-c_{L}\right) \\
2(1+\theta) \bar{p}_{2 L}-\theta u_{21} \bar{p}_{1 H}-\theta v_{21} \bar{p}_{1 L}-\theta u_{23} \bar{p}_{3 H}-\theta v_{23} \bar{p}_{3 L}= \\
(1-\theta) a_{L}+\theta\left(u_{21}+u_{23}\right)\left(c_{H}-c_{L}\right) \\
2(1+\theta) \bar{p}_{2 H}-\theta u_{21} \bar{p}_{1 H}-\theta v_{21} \bar{p}_{1 L}-\theta u_{23} \bar{p}_{3 H}-\theta v_{23} \bar{p}_{3 L}= \\
(1-\theta) a_{H}-\theta\left(v_{21}+v_{23}\right)\left(c_{H}-c_{L}\right) \\
2(1+\theta) \bar{p}_{3 L}-\theta u_{31} \bar{p}_{1 H}-\theta v_{31} \bar{p}_{1 L}-\theta u_{32} \bar{p}_{2 H}-\theta v_{32} \bar{p}_{2 L}= \\
(1-\theta) a_{L}+\theta\left(u_{31}+u_{31}\right)\left(c_{H}-c_{L}\right)
\end{gathered}
$$




$$
\begin{gathered}
2(1+\theta) \bar{p}_{3 H}-\theta u_{31} \bar{p}_{1 H}-\theta v_{31} \bar{p}-\theta u_{32} \bar{p}_{2 H}-\theta v_{32} \bar{p}_{2 L}= \\
(1-\theta) a_{H}-\theta\left(v_{31}+v_{31}\right)\left(c_{H}-c_{L}\right)
\end{gathered}
$$

Observe that (172) and (173) yield an expression for firm $1 L$ 's profit anywhere along its reaction function, and in particular in equilibrium,

$$
\pi_{1 L}=\frac{1+\theta}{(1-\theta)(1+2 \theta)}\left(\bar{p}_{1 L}\right)^{2} .
$$

Corresponding relationships hold for the payoffs of other firms (for the entrant, subtracting off entry cost $K)$. obtains

(158) and (159) continue to hold; in addition, from (177) and (178), one

$$
\bar{p}_{3 L}=\bar{p}_{3 H}+\frac{c_{H}-c_{L}}{2} .
$$

Using (158), (159), and (180), reduce the system of equations of the reaction functions to a system of three equations in the low-cost firm prices,

$$
\left[(2+3 \theta) I_{3}-\theta J_{3} J_{3}^{\prime}\right]\left(\begin{array}{c}
\bar{p}_{1 L} \\
\bar{p}_{2 L} \\
\bar{p}_{3 L}
\end{array}\right)=(1-\theta) a_{L} J_{3}+\frac{\theta}{2}\left(\begin{array}{c}
u_{12}+u_{13} \\
u_{21}+u_{23} \\
u_{31}+u_{32}
\end{array}\right)\left(c_{H}-c_{L}\right) .
$$

In like manner, obtain a system of three equations in the high-cost firm prices,

$$
\left[(2+3 \theta) I_{3}-\theta J_{3} J_{3}^{\prime}\right]\left(\begin{array}{c}
\bar{p}_{1 H} \\
\bar{p}_{2 H} \\
\bar{p}_{3 H}
\end{array}\right)=(1-\theta) a_{H} J_{3}-\frac{\theta}{2}\left(\begin{array}{c}
v_{12}+v_{13} \\
v_{21}+v_{23} \\
v_{31}+v_{32}
\end{array}\right)\left(c_{H}-c_{L}\right) .
$$

Using the inverse

$$
\left[(2+3 \theta) I_{3}-\theta J_{3} J_{3}^{\prime}\right]^{-1}=\frac{1}{2+3 \theta}\left(I_{3}+\frac{\theta}{2} J_{3} J_{3}^{\prime}\right),
$$

solve the two subsystems of equations to obtain expressions for equilibrium prices

$$
\begin{aligned}
& \bar{p}_{1 L}=\frac{1}{2}(1-\theta) a_{L}+\frac{1}{2} \frac{\theta}{2+3 \theta}\left(u_{12}+u_{13}+\frac{\theta}{2} U\right)\left(c_{H}-c_{L}\right) \\
& \bar{p}_{2 L}=\frac{1}{2}(1-\theta) a_{L}+\frac{1}{2} \frac{\theta}{2+3 \theta}\left(u_{21}+u_{23}+\frac{\theta}{2} U\right)\left(c_{H}-c_{L}\right) \\
& \bar{p}_{3 L}=\frac{1}{2}(1-\theta) a_{L}+\frac{1}{2} \frac{\theta}{2+3 \theta}\left(u_{31}+u_{32}+\frac{\theta}{2} U\right)\left(c_{H}-c_{L}\right) \\
& \bar{p}_{1 H}=\frac{1}{2}(1-\theta) a_{H}-\frac{1}{2} \frac{\theta}{2+3 \theta}\left(v_{12}+v_{13}+\frac{\theta}{2} V\right)\left(c_{H}-c_{L}\right)
\end{aligned}
$$




$$
\begin{aligned}
& \bar{p}_{2 H}=\frac{1}{2}(1-\theta) a_{H}-\frac{1}{2} \frac{\theta}{2+3 \theta}\left(v_{21}+v_{23}+\frac{\theta}{2} V\right)\left(c_{H}-c_{L}\right) \\
& \bar{p}_{3 H}=\frac{1}{2}(1-\theta) a_{H}-\frac{1}{2} \frac{\theta}{2+3 \theta}\left(v_{31}+v_{32}+\frac{\theta}{2} V\right)\left(c_{H}-c_{L}\right),
\end{aligned}
$$

writing $U=u_{12}+u_{13}+u_{21}+u_{23}+u_{31}+u_{32}$ and $V=v_{12}+v_{13}+v_{21}+v_{23}+v_{31}+v_{32}$ for notational compactness.

\subsection{Pooling on $p_{L}$}

\subsubsection{Boundaries of Case 2}

The boundaries of case 2 are determined by the inequalities

$$
\begin{aligned}
& \frac{1+\theta}{(1-\theta)(1+2 \theta)}\left[\bar{p}_{3 L}\left(u_{12}, 0, u_{21}, 0, u_{31}, u_{32}\right)\right]^{2} \geq K \\
\geq & \frac{1+\theta}{(1-\theta)(1+2 \theta)}\left[\bar{p}_{3 H}\left(u_{12}, u_{13}, u_{21}, u_{23}, u_{31}, u_{32}\right)\right]^{2} .
\end{aligned}
$$

If the game is in case 2, a high-cost incumbent defects from the pooling equilibrium, revealing its cost type, and a high-cost entrant comes into the market, the high-cost entrant's payoff is

$$
\pi_{3 H}\left(u_{12}, u_{13}, 1, u_{23}, 1, u_{32}\right)=\frac{1+\theta}{(1-\theta)(1+2 \theta)}\left[\bar{p}_{3 H}\left(u_{12}, u_{13}, 1, u_{23} .1, u_{32}\right)\right]^{2}-K .
$$

If (191) is positive, the game is in case 2(a); otherwise, it is in case 2(b).

\subsubsection{Case 2}

Case 2(a) $\pi_{3 H}\left(u_{12}, u_{13}, 1, u_{23}, 1, u_{32}\right)>K \geq \pi_{3 H}\left(u_{12}, u_{13}, u_{21}, u_{23}, u_{31}, u_{32}\right) \quad 1 H$ pooling payoff:

$$
\pi_{1 H}\left(p_{L}\right)+u_{13} \pi_{1 H}\left(u_{12}, u_{21}\right)+v_{13} \pi_{1 H}\left(u_{12}, 0, u_{21}, 0, u_{31}, u_{32}\right)
$$

$1 H$ defection payoff:

$$
\pi_{1 H}^{b r}\left(p_{L}\right)+\pi_{1 H}\left(u_{12}, u_{13}, 1, u_{23}, 1, u_{32}\right)
$$

Condition for $1 H$ pooling:

$$
\begin{gathered}
u_{13}\left[\pi_{1 H}\left(u_{12}, 1\right)-\pi_{1 H}\left(u_{12}, u_{13}, 1, u_{23}, 1, u_{32}\right)\right] \geq \\
\pi_{1 H}^{b r}\left(p_{L}\right)-\pi_{1 H}\left(p_{L}\right)+u_{13}\left[\pi_{1 H}\left(u_{12}, 1\right)-\pi_{1 H}\left(u_{12}, u_{21}\right)\right] \\
+v_{13}\left[\pi_{1 H}\left(u_{12}, u_{13}, 1, u_{23}, 1, u_{32}\right)-\pi_{1 H}\left(u_{12}, 0, u_{21}, 0, u_{31}, u_{32}\right)\right]
\end{gathered}
$$


$1 L$ pooling payoff:

$$
\pi_{1 L}\left(p_{L}\right)+u_{13} \pi_{1 L}\left(u_{12}, u_{21}\right)+v_{13} \pi_{1 L}\left(u_{12}, 0, u_{21}, 0, u_{31}, u_{32}\right) .
$$

$1 L$ defection payoff:

$$
\pi_{1 L}\left(p_{L}\right)+\pi_{1 L}\left(u_{12}, u_{13}, 1, u_{23}, 1, u_{32}\right) .
$$

Condition for $1 L$ pooling:

$$
\begin{gathered}
u_{13}\left[\pi_{1 L}\left(u_{12}, 1\right)-\pi_{1 L}\left(u_{12}, u_{13}, 1, u_{23}, 1, u_{32}\right)\right] \geq u_{13}\left[\pi_{1 L}\left(u_{12}, 1\right)-\pi_{1 L}\left(u_{12}, u_{21}\right)\right] \\
+v_{13}\left[\pi_{1 L}\left(u_{12}, u_{13}, 1, u_{23}, 1, u_{32}\right)-\pi_{1 L}\left(u_{12}, 0, u_{21}, 0, u_{31}, u_{32}\right)\right]
\end{gathered}
$$

Case 2(b) $\pi_{3 H}\left(u_{12}, 0, u_{21}, 0, u_{31}, u_{32}\right)>\mathbf{K} \geq \pi_{3 H}\left(u_{12}, u_{13}, 1, u_{23}, 1, u_{32}\right) \quad 1 H$ pooling payoff:

$$
\pi_{1 H}\left(p_{L}\right)+u_{13} \pi_{1 H}\left(u_{12}, u_{21}\right)+v_{13} \pi_{1 H}\left(u_{12}, 0, u_{21}, 0, u_{31}, u_{32}\right)
$$

$1 H$ defection payoff:

$$
\pi_{1 H}^{b r}\left(p_{L}\right)+u_{13} \pi_{1 H}\left(u_{12}, 1\right)+v_{13} \pi_{1 H}\left(u_{12}, 0,1,0,1, u_{32}\right)
$$

Condition for $1 H$ pooling: $1 H$ will always wish to defect.

\subsubsection{Linear example, Case 2(a)}

\section{High-cost incumbents}

$$
\begin{gathered}
\pi_{1 H}\left(p_{L}\right)=\left[\bar{p}_{L}-\left(c_{H}-c_{L}\right)\right] \frac{(1-\theta) a_{L}+\theta \bar{p}_{L}-\bar{p}_{L}}{1-\theta^{2}} \\
=\left[\bar{p}_{L}-\left(c_{H}-c_{L}\right)\right] \frac{a_{H}-\theta a_{L}+\theta \bar{p}_{L}-\bar{p}_{1 H}^{b r}+\bar{p}_{1 H}^{b r}-\bar{p}_{L}+\left(a_{L}-a_{H}\right)}{1-\theta^{2}} \\
=\left[\bar{p}_{1 H}^{b r}-\left(\bar{p}_{1 H}^{b r}-\bar{p}_{L}+c_{H}-c_{L}\right)\right] \frac{\bar{p}_{1 H}^{b r}+\left[\bar{p}_{1 H}^{b r}-\bar{p}_{L}+c_{H}-c_{L}\right)}{1-\theta^{2}}
\end{gathered}
$$

(using $a_{H}-\theta a_{L}+\theta \bar{p}_{L}-\bar{p}_{1 H}^{b r}=\bar{p}_{1 H}^{b r}$ from the equation of $1 H$ 's reaction function)

$$
\begin{gathered}
=\frac{1}{1-\theta^{2}}\left(\bar{p}_{1 H}^{b r}\right)^{2}-\frac{1}{1-\theta^{2}}\left(\bar{p}_{1 H}^{b r}-\bar{p}_{L}+c_{H}-c_{L}\right)^{2} \\
=\pi_{1 H}^{b r}\left(p_{L}\right)-\frac{1}{4} \frac{1}{1-\theta^{2}}\left(c_{H}-c_{L}\right)^{2}
\end{gathered}
$$

(using the definition of $\bar{p}_{L}$ to evaluate the final term). Hence the first-period gain from defection is

$$
\pi_{1 H}^{b r}\left(p_{L}\right)-\pi_{1 H}\left(p_{L}\right)=\frac{1}{4} \frac{1}{1-\theta^{2}}\left(c_{H}-c_{L}\right)^{2}
$$


Firm $1 H$ 's second-period gain from revealing its cost type is positively proportional to the difference between its prices if it has and has not revealed its cost type. This is

$$
p_{1 H}\left(u_{12}, 1\right)-p_{1 H}\left(u_{12}, u_{21}\right)=\frac{\theta^{2}}{2} \frac{v_{21}}{4-\theta^{2}}\left(c_{H}-c_{L}\right)
$$

if the entrant has high cost and

$$
\begin{aligned}
& p_{1 H}\left(u_{12}, u_{13}, 1, u_{23}, 1, u_{32}\right)-p_{1 H}\left(u_{12}, 0, u_{21}, 0, u_{31}, u_{32}\right)= \\
& \frac{1}{2} \frac{\theta}{2+3 \theta}\left[u_{13}+\frac{\theta}{2}\left(u_{13}+v_{21}+u_{23}+v_{31}\right)\right]\left(c_{H}-c_{L}\right) \geq 0 .
\end{aligned}
$$

if the entrant has low cost.

Explicit evaluation of the entry deterrence term, the left-hand side of (194), is unrevealing.

Low-cost incumbents For firm $1 L$, the second-period cost revelation effects are positively proportional to the difference between prices in the different regimes. These are

$$
p_{1 L}\left(u_{12}, 1\right)-p_{1 L}\left(u_{12}, u_{21}\right)=\frac{\theta^{2}}{2} \frac{v_{21}}{4-\theta^{2}}\left(c_{H}-c_{L}\right) \geq 0
$$

and

$$
\begin{aligned}
& p_{1 L}\left(u_{12}, u_{13}, 1, u_{23}, 1, u_{32}\right)-p_{1 L}\left(u_{12}, 0, u_{21}, 0, u_{31}, u_{32}\right)= \\
& \frac{1}{2} \frac{\theta}{2+3 \theta}\left[u_{13}+\frac{\theta}{2}\left(u_{13}+u_{23}+v_{21}+v_{31}\right)\right]\left(c_{H}-c_{L}\right) \geq 0 .
\end{aligned}
$$

Explicit evaluation of the entry deterrence term, the left-hand side of (197), is unrevealing.

\subsubsection{Case 3}

Case 3(a) $\pi_{3 L}\left(u_{12}, 0,1,0,1, u_{32}\right)>K>\pi_{3 L}\left(u_{12}, 0, u_{21}, 0, u_{31}, u_{32}\right)$

$1 \mathrm{H}$ pooling payoff:

$$
\pi_{1 H}\left(p_{L}\right)+\pi_{1 H}\left(u_{12}, u_{21}\right)
$$

$1 H$ defection payoff:

$$
\pi_{1 H}^{b r}\left(p_{L}\right)+u_{13} \pi_{1 H}\left(u_{12}, 1\right)+v_{13} \pi_{1 H}\left(u_{12}, 0,1,0,1, u_{32}\right)
$$

Condition for $1 H$ pooling:

$$
\pi_{1 H}\left(u_{12}, u_{21}\right)-\pi_{1 H}\left(u_{12}, 1\right)+v_{13}\left[\pi_{1 H}\left(u_{12}, 1\right)-\pi_{1 H}\left(u_{12}, 0,1,0,1, u_{32}\right)\right] \geq
$$




$$
\pi_{1 H}^{b r}\left(p_{L}\right)-\pi_{1 H}\left(p_{L}\right)
$$

$1 L$ second-period pooling payoff:

$$
\pi_{1 L}\left(u_{12}, u_{21}\right)
$$

$1 L$ second-period defection payoff:

$$
u_{13} \pi_{1 L}\left(u_{12}, 1\right)+v_{13} \pi_{1 L}\left(u_{12}, 0,1,0,1, u_{32}\right)
$$

Condition for $1 L$ pooling:

$$
v_{13}\left[\pi_{1 L}^{b r}\left(p_{L}\right)-\pi_{1 L}\left(u_{12}, 0,1,0,1, u_{32}\right)\right] \geq \pi_{1 L}\left(u_{12}, 1\right)-\pi_{1 L}\left(u_{12}, u_{21}\right)
$$

Case 3(b) $K>\pi_{3 L}\left(u_{12}, 0,1,0,1, u_{32}\right)$

$1 \mathrm{H}$ pooling payoff:

$$
\pi_{1 H}\left(p_{L}\right)+\pi_{1 H}\left(u_{12}, u_{21}\right)
$$

$1 H$ defection payoff:

$$
\pi_{1 H}^{b r}\left(p_{L}\right)+\pi_{1 H}\left(u_{12}, 1\right)
$$

Condition for $1 H$ pooling: $1 H$ will always wish to defect.

\subsection{Pooling on $p_{H}$}

It can be a sequential equilibrium for price-setting firms to pool on high prices. In a certain sense, this equilibrium is dual to the high-output pooling equilibrium described for quantity-setting firms. But if pooling on a high price is an equilibrium, it is not a limit-pricing equilibrium: the profit to be gained by discouraging entry encourages firms to defect from high-price pooling behavior.

Let $p_{H}$ be the first-period Nash equilibrium price if both incumbents are known to have high cost. Suppose an alleged equilibrium strategy calls for firms to pool on $p_{H}$, and let out-of-equilibrium beliefs be such that if the entrant sees any price other than $p_{H}$, it infers that the defector has low cost.

For concreteness, let the game be in case 2 (if incumbents pool, a high-cost entrant will stay out of the market but a low-cost entrant will come into the market). Conditions for high-price pooling in the other cases can be analyzed in a similar manner.

To evaluate defection payoffs, case 2 must be divided into two subcases. In what I will call case $2(\mathrm{c})$, entry $\operatorname{cost} K$ is relatively small,

$$
\pi_{3 L}\left(u_{12}, 0,0,0,0, u_{32}\right)>K \geq \pi_{3 H}\left(u_{12}, u_{13}, u_{21}, u_{23}, u_{31}, u_{32}\right),
$$


and a low-cost entrant will come into the market in the second period if one incumbent has defected and revealed itself as having low cost. For larger values of $K$, in case $2(\mathrm{~d})$,

$$
\pi_{3 L}\left(u_{12}, 0, u_{21}, 0, u_{31}, u_{32}\right)>K \geq \pi_{3 L}\left(u_{12}, 0,0,0,0, u_{32}\right)
$$

a low-cost potential entrant will stay out of the market if it is known that once incumbent has low cost.

If incumbent $1 H$ pools on $p_{H}$, it earns its best -response payoff in the first period, and has expected second-period payoff

$$
u_{13} \pi_{1 H}\left(u_{12}, u_{21}\right)+v_{13} \pi_{1 H}\left(u_{12}, 0, u_{21}, 0, u_{31}, u_{32}\right) .
$$

If the game is in case $2(\mathrm{c})$, firm $1 H$ would never defect. To do so would reduce its first-period payoff. It would not alter the probability of entry. By convincing rivals that it had low cost, firm 1 would cause rivals to set lower prices in the second period, reducing its expected second-period payoff.

Now suppose the game falls in case 2(d). By defecting slightly from the high-price pooling equilibrium, firm $1 H$ slightly reduces its first-period payoff. Defection convinces rivals that it has low cost and causes a low-cost entrant to stay out of the market. Firm 1H's expected second-period defection payoff is

$$
\pi_{1 H}\left(u_{12}, 0\right)
$$

its best-response payoff if incumbent 2 believes incumbent 1 has low cost while incumbent 1 does not know incumbent 2's cost type.

Comparing (216) and (217), in case 2(d) a high-cost incumbent 1 will pool on high prices if

$$
\pi_{1 H}\left(u_{12}, u_{21}\right)-\pi_{1 H}\left(u_{12}, 0\right) \geq v_{13}\left[\pi_{1 H}\left(u_{12}, u_{21}\right)-\pi_{1 H}\left(u_{12}, 0, u_{21}, 0, u_{31}, u_{32}\right)\right] .
$$

The term on the left, lost profit due to pretending to have low cost. is a pure masquerade effect. The term on the right is the gain in profit if a low-cost. entrant stays out of the market, weighted by the prior probability that the entrant has low cost. If the profit lost by entry is great enough, and if the high-cost incumbent thinks it very unlikely that the potential entrant has low cost, then it will defect from the high-price pooling strategy.

Now consider the incentives of a low-cost firm 1 to pool on $p_{H}$. Its pooling payoff is

$$
\pi_{1 L}\left(p_{H}\right)+u_{13} \pi_{1 L}\left(u_{12}, u_{21}\right)+v_{13} \pi_{1 L}\left(u_{12}, 0, u_{21}, 0, u_{31}, u_{32}\right)
$$

Any defection by firm $1 L$ reveals it as a low-cost firm. This being the case, if $1 L$ defects, it will set a price that maximizes its first-period payoff. If 
the game is in case 2(c), defection does not affect the likelihood of entry. Firm $1 L$ 's defection payoff is

$$
\pi_{1 L}^{b r}\left(p_{H}\right)+u_{13} \pi_{1 L}\left(u_{12}, 0\right)+v_{13} \pi_{1 L}\left(u_{12}, 0,0,0,0, u_{32}\right) .
$$

The second term is firm $1 L$ 's payoff if the entrant has high cost and stays out of the market; the third term is firm $1 L$ 's payoff if the entrant has low cost and comes into the market. Each payoff is weighted by the appropriate prior probability, and each payoff reflects the fact that after defection firm 1 is known to have low cost.

Comparing (219) and (220), in case 2(c) a low-cost firm $1 L$ will pool on high prices if

$$
\begin{gathered}
u_{13}\left[\pi_{1 L}\left(u_{12}, u_{21}\right)-\pi_{1 L}\left(u_{12}, 0\right)\right] \\
+v_{13}\left[\pi_{1 L}\left(u_{12}, 0, u_{21}, 0, u_{31}, u_{32}\right)-\pi_{1 L}\left(u_{12}, 0,0,0,0, u_{32}\right)\right] \geq \pi_{1 L}^{b r}\left(p_{H}\right)-\pi_{1 L}\left(p_{H}\right) .
\end{gathered}
$$

The terms on the left are firm $1 L$ 's profit lost by revealing its cost type, in the event that entry does not and does occur, weighted by the appropriate prior probabilities. The term on the right is the first-period gain from defection. Firm $1 L$ will pool on high prices if cost revelation is sufficiently costly. But in case 2(c), entry limitation is not a factor in the low-cost incumbent's decision.

In case $2(\mathrm{~d})$, on the other hand, a consequence of firm $1 L$ 's defection is that a low-cost entrant will stay out of the market. Firm $1 L$ 's expected defection payoff is

$$
\pi_{1 L}^{b r}\left(p_{H}\right)+\pi_{1 L}\left(u_{12}, 0\right)
$$

Comparing (219) and (222), in case 2(d) firm $1 L$ will pool on high prices if

$$
\begin{gathered}
u_{13}\left[\pi_{1 L}\left(u_{12}, u_{21}\right)-\pi_{1 L}\left(u_{12}, 0\right)\right] \geq \\
\pi_{1 L}^{b r}\left(p_{H}\right)-\pi_{1 L}\left(p_{H}\right)+v_{13}\left[\pi_{1 L}\left(u_{12}, 0\right)-\pi_{1 L}\left(u_{12}, 0, u_{21}, 0, u_{31}, u_{32}\right)\right] .
\end{gathered}
$$

The term on the left is firm $1 L$ 's expected second-period lost profit due to cost-type revelation if the entrant has high cost and would have stayed out of the market in any event. The terms on the right are the first-period gain from defection and the expected second period gain from defection if the entrant has low cost and stays out of the market because it is known that firm 1 has low cost.

Condition (223) will fail if $v_{13}$ is sufficiently large -if firm $1 L$ thinks it very likely that the incumbent has low cost. The possibility of entry limitation is an incentive to defect from the high-price pooling equilibrium.

\subsection{Separating equilibrium: payoffs from entry}

For price-setting firms, the inequalities (64)

$$
\pi_{3 L}(1,0,1,0,1,1)>\pi_{3 L}(0,0,1,0,1,0)>\pi_{3 L}(0,0,0,0,0,0)
$$




$$
\geq \pi_{3 H}\left(1, u_{13}, 1, u_{23}, 1,1\right)>\pi_{3 H}\left(0, u_{13}, 1, u_{23}, 1,0\right)>\pi_{3 H}\left(0, u_{13}, 0, u_{23}, 0,0\right)
$$

can be verified by showing that the corresponding relationships hold for net prices. Evaluating (186) and (189) for alternative beliefs,

$$
\begin{gathered}
\bar{p}_{3 L}(1,0,1,0,1,1)=\frac{1}{2}(1-\theta) a_{L}+\frac{1+2 \theta}{2+3 \theta}\left(c_{H}-c_{L}\right) \\
\bar{p}_{3 L}(0,0,1,0,1,0)=\frac{1}{2}(1-\theta) a_{L}+\frac{1}{2} \frac{\theta}{2+3 \theta}(1+\theta)\left(c_{H}-c_{L}\right) \\
\bar{p}_{3 L}(0,0,0,0,0,0)=\frac{1}{2}(1-\theta) a_{L} \\
\bar{p}_{3 H}\left(1, u_{13}, 1, u_{23}, 1,1\right)=\frac{1}{2}(1-\theta) a_{H}-\frac{1}{4} \frac{\theta^{2}}{2+3 \theta}\left(v_{13}+v_{23}\right)\left(c_{H}-c_{L}\right) \\
\bar{p}_{3 H}\left(0, u_{13}, 1, u_{23}, 1,0\right)=\frac{1}{2}(1-\theta) a_{H}-\frac{1}{4} \frac{\theta}{2+3 \theta}\left[2+\left(2+v_{13}+v_{23}\right) \theta\right]\left(c_{H}-c_{L}\right) \\
\bar{p}_{3 H}\left(0, u_{13}, 0, u_{23}, 0,0\right)=\frac{1}{2}(1-\theta) a_{H}-\frac{1}{4} \frac{\theta}{2+3 \theta}\left[4+\left(4+v_{13}+v_{23}\right) \theta\right]\left(c_{H}-c_{L}\right)
\end{gathered}
$$

The inequalities (64) are satisfied.

\subsection{Separation by $\mathrm{L}$-firm price reduction}

Consider the follow collection of actions and beliefs:

(a) firms $1 L$ and $2 L$ set prices $p_{1 \lambda}>p_{1 L}$ and $p_{2 \lambda}>p_{2 L}$, respectively, in period 1 ;

(b) firms $1 H$ and $2 H$ set their best-response prices $p_{1 h}$ and $p_{2 h}$, respectively. in period 1 ;

(c) incumbents' cost types are revealed by observing first-period prices:

(d) the potential entrant comes into the market in the second period if it expects a positive second-period profit, net of entry cost:

(e) if the fact of entry does not reveal the entrant's cost type, incumbents carry forward prior beliefs from the first period to the second; all firms maximize expected profit in the second period;

If firm 1 sets any price other than $p_{1 \lambda}$ (firm 2 sets any price other than $p_{2 \lambda}$ ), rivals infer that it has high cost.

It is clear that the entrant maximizes its expected payoff by behaving as indicated, given that other players behave as indicated. 


\subsubsection{High-cost incumbents}

The inequalities (64) define the seven ranges of entry cost that must be considered to examine incumbents' incentives to separate. Firm 1H's separation and defection payoffs for the seven ranges, and the conditions for firm $1 \mathrm{H}$ to separate, are:

Case $\mathbf{S} 1 K>\pi_{3 L}(1,0,1,0,1,1)$

Separation payoff:

$$
\pi_{1 H}\left(p_{1 h}\right)+u_{12} \pi_{1 H}(1,1)+v_{12} \pi_{1 H}(0,1)
$$

Defection payoff:

$$
\pi_{1 H}\left(p_{1 \lambda}\right)+u_{12} \pi_{1 H}(1,0)+v_{12} \pi_{1 H}(0,0)
$$

Condition for $1 \mathrm{H}$ to separate:

By imitating a low-cost firm, firm $1 H$ reduces its first-period payoff. By convincing rivals that it has low cost, it induces them to set lower prices in the second period. This reduces firm $1 H$ 's second-period payoff. It follows that firm $1 H$ would always wish to separate.

Case S2 $\pi_{3 L}(1,0,1,0,1,1)>K \geq \pi_{3 L}(0,0,1,0,1,0)$

Separation payoff:

$$
\pi_{1 H}\left(p_{1 h}\right)+u_{12}\left[u_{13} \pi_{1 H}(1,1)+v_{13} \pi_{1 H}(1,0,1,0,1,1)\right]+v_{12} \pi_{1 H}(0,1)
$$

Defection payoff:

$$
\pi_{1 H}\left(p_{1 \lambda}\right)+u_{12} \pi_{1 H}(1,0)+v_{12} \pi_{1 H}(0,0)
$$

Condition for $1 H$ to separate:

$$
\begin{gathered}
\pi_{1 H}\left(p_{1 h}\right)-\pi_{1 H}\left(p_{1 \lambda}\right)+u_{12} u_{13}\left[\pi_{1 H}(1,1)-\pi_{1 H}(1,0)\right]+v_{12}\left[\pi_{1 H}(0,1)-\pi_{1 H}(0,0)\right] \\
\geq u_{12} v_{13}\left[\pi_{1 H}(1,0)-\pi_{1 H}(1,0,1,0,1,1)\right]
\end{gathered}
$$

Case S3 $\pi_{3 L}(0,0,1,0,1,0)>K \geq \pi_{3 L}(0,0,0,0,0,0)$

Separation payoff:

$$
\begin{gathered}
\pi_{1 H}\left(p_{1 h}\right)+u_{12}\left[u_{13} \pi_{1 H}(1,1)+v_{13} \pi_{1 H}(1,0,1,0,1,1)\right] \\
+v_{12}\left[u_{13} \pi_{1 H}(0,1)+v_{13} \pi_{1 H}(0,0,1,0,1,0)\right]
\end{gathered}
$$

Defection payoff:

$$
\pi_{1 H}\left(p_{1 \lambda}\right)+u_{12}\left[u_{13} \pi_{1 H}(1,0)+v_{13} \pi_{1 H}(1,0,0,0,0,1)\right]+v_{12} \pi_{1 H}(0,0)
$$


Condition for $1 H$ to separate:

$$
\begin{gathered}
\pi_{1 H}\left(p_{1 h}\right)-\pi_{1 H}\left(p_{1 \lambda}\right)+u_{12} u_{13}\left[\pi_{1 H}(1,1)-\pi_{1 H}(1,0)\right] \\
+u_{12} v_{13}\left[\pi_{1 H}(1,0,1,0,1,1)-\pi_{1 H}(1,0,0,0,0,1)\right]+v_{12} u_{13}\left[\pi_{1 H}(0,1)-\pi_{1 H}(0,0)\right] \\
\geq v_{12} v_{13}\left[\pi_{1 H}(0,0)-\pi_{1 H}(0,0,1,0,1,0)\right]
\end{gathered}
$$

Case S4 $\pi_{3 L}(0,0,0,0,0,0)>K \geq \pi_{3 H}\left(1, u_{13}, 1, u_{23}, 1,1\right)$ Separation payoff:

$$
\begin{gathered}
\pi_{1 H}\left(p_{1 h}\right)+u_{12}\left[u_{13} \pi_{1 H}(1,1)+v_{13} \pi_{1 H}(1,0,1,0,1,1)\right] \\
+v_{12}\left[u_{13} \pi_{1 H}(0,1)+v_{13} \pi_{1 H}(0,0,1,0,1.0)\right]
\end{gathered}
$$

Defection payoff:

$$
\begin{gathered}
\pi_{1 H}\left(p_{1 \lambda}\right)+u_{12}\left[u_{13} \pi_{1 H}(1,0)+v_{13} \pi_{1 H}(1,0,0,0.0,1)\right] \\
+v_{12}\left[u_{13} \pi_{1 H}(0,0)+v_{13} \pi_{1 H}(0,0,0,0,0,0)\right]
\end{gathered}
$$

Condition for $1 H$ to separate: by the same argument that was used for case $\mathrm{S} 1$, firm $1 H$ will always wish to separate.

Case S5 $\pi_{3 H}\left(1, u_{13}, 1, u_{23}, 1,1\right)>K \geq \pi_{3 H}\left(0, u_{13} .1 . u_{23}, 1,0\right)$ Separation payoff:

$$
\pi_{1 H}\left(p_{1 h}\right)+u_{12} \pi_{1 H}\left(1, u_{13}, 1, u_{23}, 1,1\right)+v_{12}\left[u_{13} \pi_{1 H}(0.1)+v_{13} \pi_{1 H}(0.0 .1,0,1,0)\right]
$$

Defection payoff:

$$
\begin{gathered}
\pi_{1 H}\left(p_{1 \lambda}\right)+u_{12}\left[u_{13} \pi_{1 H}(1,0)+v_{13} \pi_{1 H}(1,0,0,0.0,1)\right] \\
+v_{12}\left[u_{13} \pi_{1 H}(0,0)+v_{13} \pi_{1 H}(0,0,0,0,0,0)\right]
\end{gathered}
$$

Condition for $1 H$ to separate:

$$
\begin{gathered}
\pi_{1 H}\left(p_{1 h}\right)-\pi_{1 H}\left(p_{1 \lambda}\right)+u_{12} v_{13}\left[\pi_{1 H}\left(1, u_{13}, 1, u_{23}, 1,1\right)-\pi_{1 H}(1,0,0.0 .0 .1)\right](242) \\
+v_{12} u_{13}\left[\pi_{1 H}(0,1)-\pi_{1 H}(0,0)\right]+v_{12} v_{13}\left[\pi_{1 H}(0,0,1,0.1,0)-\pi_{1 H}(0.0 .0,0,0.0)\right] \\
\geq u_{12} u_{13}\left[\pi_{1 H}(1,0)-\pi_{1 H}\left(1, u_{13}, 1, u_{23}, 1,1\right)\right]
\end{gathered}
$$


Case S6 $\pi_{3 H}\left(0, u_{13}, 1, u_{23}, 1,0\right)>K \geq \pi_{3 H}\left(0, u_{13}, 0, u_{23}, 0,0\right)$

Separation payoff:

$$
\pi_{1 H}\left(p_{1 h}\right)+u_{12} \pi_{1 H}\left(1, u_{13}, 1, u_{23}, 1,1\right)+v_{12} \pi_{1 H}\left(0, u_{13}, 1, u_{23}, 1,0\right)
$$

Defection payoff:

$$
\pi_{1 H}\left(p_{1 \lambda}\right)+u_{12} \pi_{1 H}\left(1, u_{13}, 0, u_{23}, 0,1\right)+v_{12}\left[u_{13} \pi_{1 H}(0,0)+v_{13} \pi_{1 H}(0,0,0,0,0,0)\right]
$$

Condition for $1 H$ to separate:

$$
\begin{gathered}
\pi_{1 H}\left(p_{1 h}\right)-\pi_{1 H}\left(p_{1 \lambda}\right)+ \\
u_{12}\left[\pi_{1 H}\left(1, u_{13}, 1, u_{23}, 1,1\right)-\pi_{1 H}\left(1, u_{13}, 0, u_{23}, 0,1\right)\right] \\
+v_{12} v_{13}\left[\pi_{1 H}\left(0, u_{13}, 1, u_{23}, 1,0\right)-\pi_{1 H}(0,0,0,0,0,0)\right] \\
\geq v_{12} u_{13}\left[\pi_{1 H}(0,0)-\pi_{1 H}\left(0, u_{13}, 1, u_{23}, 1,0\right)\right]
\end{gathered}
$$

Case S7 $\pi_{3 H}\left(0, u_{13}, 0, u_{23}, 0,0\right)>K$

Separation payoff:

$\pi_{1 H}\left(p_{1 h}\right)+u_{12} \pi_{1 H}\left(1, u_{13}, 1, u_{23}, 1,1\right)+v_{12} \pi_{1 H}\left(0, u_{13}, 1, u_{23}, 1,0\right)$

Defection payoff:

$$
\pi_{1 H}\left(p_{1 \lambda}\right)+u_{12} \pi_{1 H}\left(1, u_{13}, 0, u_{23}, 0,1\right)+v_{12} \pi_{1 H}\left(0, u_{13}, 0, u_{23}, 0,0\right)
$$

Condition for $1 H$ to separate: by the same argument that was used for case $\mathrm{S} 1$, firm $1 H$ will always wish to separate.

In cases S1, S4, and S7, the entrant's decision is not affected by a highcost incumbent's first-period action, with the result that the possibility of entry deterrence does not affect the high-cost incumbent's incentives to separate. In the remaining cases, the possibility of deterring entry is an incentive for the high-cost incumbent to defect from separating behavior.

\subsubsection{Low-cost incumbents}

Case S1 $K>\pi_{3 L}(1,0,1,0,1,1)$

Separation payoff:

$$
\pi_{1 L}\left(p_{1 \lambda}, p_{2 \lambda}\right)+u_{12} \pi_{1 L}(1,0)+v_{12} \pi_{1 L}(0,0)
$$

Defection payoff:

$$
\pi_{1 L}^{b r}\left(p_{1 \lambda}, p_{2 \lambda}\right)+u_{12} \pi_{1 L}(1,1)+v_{12} \pi_{1 L}(0,1)
$$

If firm $1 L$ defects, it sets its best-response price in the first period, and leads firm 2 to believe that it has high cost. This leads firm 2 to set a higher price in the second period, which allows firm $1 L$ to set a higher price and earn a greater profit. Firm $1 L$ earns a greater profit in both periods if it defects if the game is in case S1, and will never be willing to separate. 
Case S2 $\pi_{3 L}(1,0,1,0,1,1)>K \geq \pi_{3 L}(0,0,1,0,1,0)$

Separation payoff:

$$
\pi_{1 L}\left(p_{1 \lambda}, p_{2 \lambda}\right)+u_{12} \pi_{1 L}(1,0)+v_{12} \pi_{1 L}(0.0)
$$

Defection payoff:

$$
\pi_{1 L}^{b r}\left(p_{1 \lambda}, p_{2 \lambda}\right)+u_{12}\left[u_{13} \pi_{1 L}(1,1)+v_{13} \pi_{1 L}(1,0,1,0,1,1)\right]+v_{12} \pi_{1 L}(0,1)
$$

Condition for $1 L$ to separate:

$$
\begin{gathered}
u_{12} v_{13}\left[\pi_{1 L}(1,0)-\pi_{1 L}(1,0,1,0,1,1)\right] \geq \pi_{1 L}^{b r}\left(p_{1 \lambda}, p_{2 \lambda}\right)-\pi_{1 L}\left(p_{1 \lambda}, p_{2 \lambda}\right) \\
+u_{12} u_{13}\left[\pi_{1 L}(1,1)-\pi_{1 L}(1,0)\right]+v_{12}\left[\pi_{1 L}(0,1)-\pi_{1 L}(0,0)\right]
\end{gathered}
$$

Case S3 $\pi_{3 L}(0,0,1,0,1,0)>K \geq \pi_{3 L}(0,0,0,0,0.0)$

Separation payoff:

$$
\pi_{1 L}\left(p_{1 \lambda}, p_{2 \lambda}\right)+u_{12}\left[u_{13} \pi_{1 L}(1,0)+v_{13} \pi_{1 L}(1,0,0,0.0 .1)\right]+v_{12} \pi_{1 / .}(0.0)
$$

Defection payoff:

$$
\begin{gathered}
\pi_{1 L}^{b r}\left(p_{1 \lambda}, p_{2 \lambda}\right)+u_{12}\left[u_{13} \pi_{1 L}(1.1)+v_{13} \pi_{1 L}(1.0 .1 .0 .1 .1)\right] \\
+v_{12}\left[u_{13} \pi_{1 L}(0,1)+v_{13} \pi_{1 L}(0.0,1.0 .1 .0)\right]
\end{gathered}
$$

Condition for $1 L$ to separate:

$$
\begin{gathered}
v_{12} v_{13}\left[\pi_{1 L}(0,0)-\pi_{1 L}(0,0,1,0,1,0)\right] \geq \pi_{1 L}\left(p_{1 \lambda}, p_{2 \lambda}\right)-\pi_{1 L}\left(p_{1 \lambda} \cdot p_{2 \lambda}\right) \\
+u_{12} u_{13}\left[\pi_{1 L}(1,1)-\pi_{1 L}(1,0)\right]+u_{12} v_{13}\left[\pi_{1 L}(1,0,1,0,1,1)-\pi_{1 L}(1.0 .0 .0 .0 .1)\right] \\
+v_{12} u_{13}\left[\pi_{1 L}(0,1)-\pi_{1 L}(0,0)\right]
\end{gathered}
$$

Case S4 $\pi_{3 L}(0,0,0,0,0,0)>K \geq \pi_{3 H}\left(1, u_{13}, 1, u_{23} \cdot 1.1\right)$

Separation payoff:

$$
\begin{gathered}
\pi_{1 L}\left(p_{1 \lambda}, p_{2 \lambda}\right)+u_{12}\left[u_{13} \pi_{1 L}(1,0)+v_{13} \pi_{1 L}(1,0.0 .0 .(0.1)]\right. \\
+v_{12}\left[u_{13} \pi_{1 L}(0,0)+v_{13} \pi_{1 L}(0,0,0,0,0.0)\right]
\end{gathered}
$$

Defection payoff:

$$
\begin{gathered}
\pi_{1 L}\left(p_{1 \lambda}, p_{2 \lambda}\right)+u_{12}\left[u_{13} \pi_{1 L}(1.1)+v_{13} \pi_{1 L}(1.0,1.0 .1 .1)\right] \\
+v_{12}\left[u_{13} \pi_{1 L}(0,1)+v_{13} \pi_{1 L}(0,0,1,0,1.0)\right]
\end{gathered}
$$

Condition for $1 L$ to separate: by the same argument that was used for case $\mathrm{S} 1$, firm $1 L$ will always wish to defect from separating behavior. 
Case S5 $\pi_{3 H}\left(1, u_{13}, 1, u_{23}, 1,1\right)>K \geq \pi_{3 H}\left(0, u_{13}, 1, u_{23}, 1,0\right)$

Separation payoff:

$$
\begin{gathered}
\pi_{1 L}\left(p_{1 \lambda}, p_{2 \lambda}\right)+u_{12}\left[u_{13} \pi_{1 L}(1,0)+v_{13} \pi_{1 L}(1,0,0,0,0,1)\right] \\
+v_{12}\left[u_{13} \pi_{1 L}(0,0)+v_{13} \pi_{1 L}(0,0,0,0,0,0)\right]
\end{gathered}
$$

Defection payoff:

$$
\begin{aligned}
& \pi_{1 L}^{b r}\left(p_{1 \lambda}, p_{2 \lambda}\right)+u_{12} \pi_{1 L}\left(1, u_{13}, 1, u_{23}, 1,1\right) \\
& +v_{12}\left[u_{13} \pi_{1 L}(0,1)+v_{13} \pi_{1 L}(0,0,1,0,1,0)\right]
\end{aligned}
$$

Condition for $1 L$ to separate:

$$
\begin{gathered}
u_{12} u_{13}\left[\pi_{1 L}(1,0)-\pi_{1 L}\left(1, u_{13}, 1, u_{23}, 1,1\right)\right] \geq \pi_{1 L}^{b r}\left(p_{1 \lambda}, p_{2 \lambda}\right)-\pi_{1 L}\left(p_{1 \lambda}, p_{2 \lambda}\right) \\
+u_{12} v_{13}\left[\pi_{1 L}\left(1, u_{13}, 1, u_{23}, 1,1\right)-\pi_{1 L}(1,0,0,0,0,1)\right] \\
+v_{12} u_{13}\left[\pi_{1 L}(0,1)-\pi_{1 L}(0,0)\right]+v_{12} v_{13}\left[\pi_{1 L}(0,0,1,0,1,0)-\pi_{1 L}(0,0,0,0,0,0)\right]
\end{gathered}
$$

Case S6 $\pi_{3 H}\left(0, u_{13}, 1, u_{23}, 1,0\right)>K \geq \pi_{3 H}\left(0, u_{13}, 0, u_{23}, 0,0\right)$

Separation payoff:

$$
\begin{aligned}
& \pi_{1 L}\left(p_{1 \lambda}, p_{2 \lambda}\right)+u_{12} \pi_{1 L}\left(1, u_{13}, 0, u_{23}, 0,1\right) \\
& +v_{12}\left[u_{13} \pi_{1 L}(0,0)+v_{13} \pi_{1 L}(0,0,0,0,0,0)\right]
\end{aligned}
$$

Defection payoff:

$$
\pi_{1 L}^{b r}\left(p_{1 \lambda}, p_{2 \lambda}\right)+u_{12} \pi_{1 L}\left(1, u_{13}, 1, u_{23}, 1,1\right)+v_{12} \pi_{1 L}\left(0, u_{13}, 1, u_{23}, 1,0\right)
$$

Condition for $1 L$ to separate:

$$
v_{12} u_{13}\left[\pi_{1 L}(0,0)-\pi_{1 L}\left(0, u_{13}, 1, u_{23}, 1,0\right)\right] \geq
$$

$\pi_{1 L}^{b r}\left(p_{1 \lambda}, p_{2 \lambda}\right)-\pi_{1 L}\left(p_{1 \lambda}, p_{2 \lambda}\right)+u_{12}\left[\pi_{1 L}\left(1, u_{13}, 1, u_{23}, 1,1\right)-\pi_{1 L}\left(1, u_{13}, 0, u_{23}, 0,1\right)\right]$

$$
+v_{12} v_{13}\left[\pi_{1 L}\left(0, u_{13}, 1, u_{23}, 1,0\right)-\pi_{1 L}(0,0,0,0,0,0)\right]
$$

Case S7 $\pi_{3 H}\left(0, u_{13}, 0, u_{23}, 0,0\right)>K$

Separation payoff:

$$
\pi_{1 L}\left(p_{1 \lambda}, p_{2 \lambda}\right)+u_{12} \pi_{1 L}\left(1, u_{13}, 0, u_{23}, 0,1\right)+v_{12} \pi_{1 L}\left(0, u_{13}, 0, u_{23}, 0,0\right)
$$

Defection payoff:

$$
\pi_{1 L}^{b r}\left(p_{1 \lambda}, p_{2 \lambda}\right)+u_{12} \pi_{1 L}\left(1, u_{13}, 1, u_{23}, 1,1\right)+v_{12} \pi_{1 L}\left(0, u_{13}, 1, u_{23}, 1,0\right)
$$

Condition for $1 L$ to separate: by the same argument that was used for case $\mathrm{S} 1$, firm $1 L$ will always wish to defect from separating behavior. 


\section{Separation by L-firm price reduction: resumé}

A low-cost incumbent will never be willing to separate if entry costs and prior beliefs place the game in case S1, S4, or S7. A low-cost ircumbent may be willing to separate in remaining cases. If it is willing to separate, it is because the expected lost profit from the entry that would following defection (pretending to have high cost) outweighs expected gains from inducing rivals to set higher prices in the second period. If low-cost incumbents are willing to separate, their motivation is to limit entry. For high-cost incumbents, however, the expected profit to be gained by deterring entry is an incentive to defect from the separating strategy.

\subsection{Separation on Nash duopoly prices}

This is the case considered in the text.

\subsubsection{High-cost incumbents}

Case S1 $K>\pi_{3 L}(1,0,1,0,1,1)$

Separation payoff:

$$
\pi_{1 H}\left(u_{12}, u_{21}\right)+u_{12} \pi_{1 H}(1,1)+v_{12} \pi_{1 H}(0.1)
$$

Defection payoff:

$$
\pi_{1 H}\left(p_{1 L}\right)+u_{12} \pi_{1 H}(1,0)+v_{12} \pi_{1 H}(0,0)
$$

By imitating a low-cost firm, firm $1 H$ reduces its first-period payoff. By convincing rivals that it has low cost, it induces them to set lower prices in the second period. This reduces firm $1 H$ 's second-period payoff. It follows that firm $1 H$ would always wish to separate.

Case S2 $\pi_{3 L}(1,0,1,0,1,1)>K \geq \pi_{3 L}(0,0,1,0,1,0)$

Separation payoff:

$$
\pi_{1 H}\left(u_{12}, u_{21}\right)+u_{12}\left[u_{13} \pi_{1 H}(1,1)+v_{13} \pi_{1 H}(1,0,1,0,1,1)\right]+v_{12} \pi_{1 H}(0,1)
$$

Defection payoff:

$$
\pi_{1 H}\left(p_{1 L}\right)+u_{12} \pi_{1 H}(1,0)+v_{12} \pi_{1 H}(0,0)
$$

Condition for $1 H$ to separate:

$$
\begin{gathered}
\pi_{1 H}\left(u_{12}, u_{21}\right)-\pi_{1 H}\left(p_{1 L}\right)+u_{12} u_{13}\left[\pi_{1 H}(1,1)-\pi_{1 H}(1,0)\right] \\
+v_{12}\left[\pi_{1 H}(0,1)-\pi_{1 H}(0,0)\right] \geq u_{12} v_{13}\left[\pi_{1 H}(1,0)-\pi_{1 H}(1,0,1,0,1,1)\right]
\end{gathered}
$$


Case S3 $\pi_{3 L}(0,0,1,0,1,0)>K \geq \pi_{3 L}(0,0,0,0,0,0)$

Separation payoff:

$$
\begin{gathered}
\pi_{1 H}\left(u_{12}, u_{21}\right)+u_{12}\left[u_{13} \pi_{1 H}(1,1)+v_{13} \pi_{1 H}(1,0,1,0,1,1)\right] \\
+v_{12}\left[u_{13} \pi_{1 H}(0,1)+v_{13} \pi_{1 H}(0,0,1,0,1,0)\right]
\end{gathered}
$$

Defection payoff:

$$
\pi_{1 H}\left(p_{1 L}\right)+u_{12}\left[u_{13} \pi_{1 H}(1,0)+v_{13} \pi_{1 H}(1,0,0,0,0,1)\right]+v_{12} \pi_{1 H}(0,0)
$$

Condition for $1 \mathrm{H}$ to separate:

$$
\begin{gathered}
\pi_{1 H}\left(u_{12}, u_{21}\right)-\pi_{1 H}\left(p_{1 L}\right)+u_{12} u_{13}\left[\pi_{1 H}(1,1)-\pi_{1 H}(1,0)\right] \\
+u_{12} v_{13}\left[\pi_{1 H}(1,0,1,0,1,1)-\pi_{1 H}(1,0,0,0,0,1)\right]+v_{12} u_{13}\left[\pi_{1 H}(0,1)-\pi_{1 H}(0,0)\right] \\
\geq v_{12} v_{13}\left[\pi_{1 H}(0,0)-\pi_{1 H}(0,0,1,0,1,0)\right]
\end{gathered}
$$

Case $\mathbf{S} 4 \pi_{3 L}(0,0,0,0,0,0)>K \geq \pi_{3 H}\left(1, u_{13}, 1, u_{23}, 1,1\right)$ Separation payoff:

$$
\begin{gathered}
\pi_{1 H}\left(u_{12}, u_{21}\right)+u_{12}\left[u_{13} \pi_{1 H}(1,1)+v_{13} \pi_{1 H}(1,0,1,0,1,1)\right] \\
+v_{12}\left[u_{13} \pi_{1 H}(0,1)+v_{13} \pi_{1 H}(0,0,1,0,1,0)\right]
\end{gathered}
$$

Defection payoff:

$$
\begin{gathered}
\pi_{1 H}\left(p_{1 L}\right)+u_{12}\left[u_{13} \pi_{1 H}(1,0)+v_{13} \pi_{1 H}(1,0,0,0,0,1)\right] \\
+v_{12}\left[u_{13} \pi_{1 H}(0,0)+v_{13} \pi_{1 H}(0,0,0,0,0,0)\right]
\end{gathered}
$$

Condition for $1 H$ to separate: by the same argument that was used for case $\mathrm{S} 1$, firm $1 H$ will always wish to separate.

Case S5 $\pi_{3 H}\left(1, u_{13}, 1, u_{23}, 1,1\right)>K \geq \pi_{3 H}\left(0, u_{13}, 1, u_{23}, 1,0\right)$ Separation payoff:

$$
\begin{aligned}
& \pi_{1 H}\left(u_{12}, u_{21}\right)+u_{12} \pi_{1 H}\left(1, u_{13}, 1, u_{23}, 1,1\right) \\
+ & v_{12}\left[u_{13} \pi_{1 H}(0,1)+v_{13} \pi_{1 H}(0,0,1,0,1,0)\right]
\end{aligned}
$$

Defection payoff:

$$
\begin{gathered}
\pi_{1 H}\left(p_{1 L}\right)+u_{12}\left[u_{13} \pi_{1 H}(1,0)+v_{13} \pi_{1 H}(1,0,0,0,0,1)\right] \\
+v_{12}\left[u_{13} \pi_{1 H}(0,0)+v_{13} \pi_{1 H}(0,0,0,0,0,0)\right]
\end{gathered}
$$

Condition for $1 H$ to separate:

$$
\begin{gathered}
\pi_{1 H}\left(u_{12}, u_{21}\right)-\pi_{1 H}\left(p_{1 L}\right)+u_{12} v_{13}\left[\pi_{1 H}\left(1, u_{13}, 1, u_{23}, 1,1\right)-\pi_{1 H}(1,0,0,0,0,1)\right] \\
+v_{12} u_{13}\left[\pi_{1 H}(0,1)-\pi_{1 H}(0,0)\right]+v_{12} v_{13}\left[\pi_{1 H}(0,0,1,0,1,0)-\pi_{1 H}(0,0,0,0,0,0)\right] \\
\geq u_{12} u_{13}\left[\pi_{1 H}(1,0)-\pi_{1 H}\left(1, u_{13}, 1, u_{23}, 1,1\right)\right]
\end{gathered}
$$


Case S6 $\pi_{3 H}\left(0, u_{13}, 1, u_{23}, 1,0\right)>K \geq \pi_{3 H}\left(0, u_{13}, 0, u_{23}, 0,0\right)$

Separation payoff:

$$
\pi_{1 H}\left(u_{12}, u_{21}\right)+u_{12} \pi_{1 H}\left(1, u_{13}, 1, u_{23}, 1,1\right)+v_{12} \pi_{1 H}\left(0, u_{13}, 1, u_{23}, 1,0\right)
$$

Defection payoff:

$$
\pi_{1 H}\left(p_{1 L}\right)+u_{12} \pi_{1 H}\left(1, u_{13}, 0, u_{23}, 0,1\right)+v_{12}\left[u_{13} \pi_{1 H}(0,0)+v_{13} \pi_{1 H}(0,0,0,0,0,0)\right]
$$

Condition for $1 H$ to separate:

$$
\begin{gathered}
\pi_{1 H}\left(u_{12}, u_{21}\right)-\pi_{1 H}\left(p_{1 L}\right)+ \\
u_{12}\left[\pi_{1 H}\left(1, u_{13}, 1, u_{23}, 1,1\right)-\pi_{1 H}\left(1, u_{13}, 0, u_{23}, 0,1\right)\right] \\
+v_{12} v_{13}\left[\pi_{1 H}\left(0, u_{13}, 1, u_{23}, 1,0\right)-\pi_{1 H}(0,0,0,0,0,0)\right] \\
\geq v_{12} u_{13}\left[\pi_{1 H}(0,0)-\pi_{1 H}\left(0, u_{13}, 1, u_{23}, 1,0\right)\right]
\end{gathered}
$$

Case S7 $\pi_{3 H}\left(0, u_{13}, 0, u_{23}, 0,0\right)>K$

Separation payoff:

$$
\pi_{1 H}\left(u_{12}, u_{21}\right)+u_{12} \pi_{1 H}\left(1, u_{13}, 1, u_{23}, 1,1\right)+v_{12} \pi_{1 H}\left(0, u_{13}, 1, u_{23}, 1,0\right)
$$

Defection payoff:

$$
\pi_{1 H}\left(p_{1 L}\right)+u_{12} \pi_{1 H}\left(1, u_{13}, 0, u_{23}, 0,1\right)+v_{12} \pi_{1 H}\left(0, u_{13}, 0, u_{23}, 0,0\right)
$$

Condition for $1 H$ to separate: by the same argument that was used for case $\mathrm{S} 1$, firm $1 H$ will always wish to separate.

\subsubsection{Low-cost incumbents}

Given the assumed nature of beliefs about disequilibrium actions, a minimal deviation from $p_{1 L}$ convinces rivals that the offending firm has high cost. Incentives to defect essentially depend on a comparison of second period payoffs.

Case S1 $K>\pi_{3 L}(1,0,1,0,1,1)$

Separation payoff:

$$
u_{12} \pi_{1 L}(1,0)+v_{12} \pi_{1 L}(0,0)
$$

Defection payoff:

$$
u_{12} \pi_{1 L}(1,1)+v_{12} \pi_{1 L}(0,1)
$$

If firm $1 L$ defects, it leads firm 2 to believe that it has high cost. This leads firm 2 to set a higher price in the second period, which allows firm $1 L$ to set a higher price and earn a greater profit. Firm $1 L$ will not wish to separate in case $\mathrm{S} 1$. 
Case S2 $\pi_{3 L}(1,0,1,0,1,1)>K \geq \pi_{3 L}(0,0,1,0,1,0)$

Separation payoff:

$$
u_{12} \pi_{1 L}(1,0)+v_{12} \pi_{1 L}(0,0)
$$

Defection payoff:

$$
u_{12}\left[u_{13} \pi_{1 L}(1,1)+v_{13} \pi_{1 L}(1,0,1,0,1,1)\right]+v_{12} \pi_{1 L}(0,1)
$$

Condition for $1 L$ to separate:

$$
\begin{gathered}
u_{12} v_{13}\left[\pi_{1 L}(1,0)-\pi_{1 L}(1,0,1,0,1,1)\right] \geq \\
+u_{12} u_{13}\left[\pi_{1 L}(1,1)-\pi_{1 L}(1,0)\right]+v_{12}\left[\pi_{1 L}(0,1)-\pi_{1 L}(0,0)\right]
\end{gathered}
$$

Case S3 $\pi_{3 L}(0,0,1,0,1,0)>K \geq \pi_{3 L}(0,0,0,0,0,0)$

Separation payoff:

$$
u_{12}\left[u_{13} \pi_{1 L}(1,0)+v_{13} \pi_{1 L}(1,0,0,0,0,1)\right]+v_{12} \pi_{1 L}(0,0)
$$

Defection payoff:

$$
\begin{aligned}
& u_{12}\left[u_{13} \pi_{1 L}(1,1)+v_{13} \pi_{1 L}(1,0,1,0,1,1)\right] \\
+ & v_{12}\left[u_{13} \pi_{1 L}(0,1)+v_{13} \pi_{1 L}(0,0,1,0,1,0)\right]
\end{aligned}
$$

Condition for $1 L$ to separate:

$$
\begin{gathered}
v_{12} v_{13}\left[\pi_{1 L}(0,0)-\pi_{1 L}(0,0,1,0,1,0)\right] \geq \\
+u_{12} u_{13}\left[\pi_{1 L}(1,1)-\pi_{1 L}(1,0)\right]+u_{12} v_{13}\left[\pi_{1 L}(1,0,1,0,1,1)-\pi_{1 L}(1,0,0,0,0,1)\right] \\
+v_{12} u_{13}\left[\pi_{1 L}(0,1)-\pi_{1 L}(0,0)\right]
\end{gathered}
$$

Case $\mathbf{S} 4 \pi_{3 L}(0,0,0,0,0,0)>K \geq \pi_{3 H}\left(1, u_{13}, 1, u_{23}, 1,1\right)$

Separation payoff:

$$
\begin{gathered}
u_{12}\left[u_{13} \pi_{1 L}(1,0)+v_{13} \pi_{1 L}(1,0,0,0,0,1)\right] \\
+v_{12}\left[u_{13} \pi_{1 L}(0,0)+v_{13} \pi_{1 L}(0,0,0,0,0,0)\right]
\end{gathered}
$$

Defection payoff:

$$
\begin{aligned}
& u_{12}\left[u_{13} \pi_{1 L}(1,1)+v_{13} \pi_{1 L}(1,0,1,0,1,1)\right] \\
+ & v_{12}\left[u_{13} \pi_{1 L}(0,1)+v_{13} \pi_{1 L}(0,0,1,0,1,0)\right]
\end{aligned}
$$

By the same argument that was used for case $\mathrm{S} 1$, firm $1 L$ will not wish to separate in case S4. 
Case S5 $\pi_{3 H}\left(1, u_{13}, 1, u_{23}, 1,1\right)>K \geq \pi_{3 H}\left(0, u_{13}, 1, u_{23}, 1.0\right)$ Separation payoff:

$$
\begin{gathered}
u_{12}\left[u_{13} \pi_{1 L}(1,0)+v_{13} \pi_{1 L}(1,0,0,0,0,1)\right] \\
+v_{12}\left[u_{13} \pi_{1 L}(0,0)+v_{13} \pi_{1 L}(0,0,0,0,0,0)\right]
\end{gathered}
$$

Defection payoff:

$u_{12} \pi_{1 L}\left(1, u_{13}, 1, u_{23}, 1,1\right)+v_{12}\left[u_{13} \pi_{1 L}(0,1)+v_{13} \pi_{1 L}(0,0,1,0.1,0)\right]$

Condition for $1 L$ to separate:

$$
\begin{gathered}
u_{12} u_{13}\left[\pi_{1 L}(1,0)-\pi_{1 L}\left(1, u_{13}, 1, u_{23}, 1,1\right)\right] \geq \\
+u_{12} v_{13}\left[\pi_{1 L}\left(1, u_{13}, 1, u_{23}, 1,1\right)-\pi_{1 L}(1,0.0 .0 .0 .1)\right]
\end{gathered}
$$$$
+v_{12} u_{13}\left[\pi_{1 L}(0,1)-\pi_{1 L}(0,0)\right]+v_{12} v_{13}\left[\pi_{1 L}(0,0,1,0,1.0)-\pi_{1 L}(0.0 .0,0,0,0)\right]
$$

Case S6 $\pi_{3 H}\left(0, u_{13}, 1, u_{23}, 1,0\right)>K \geq \pi_{3 H}\left(0, u_{13}, 0, u_{23},(0,0)\right.$

Separation payoff:

$$
u_{12} \pi_{1 L}\left(1, u_{13}, 0, u_{23}, 0,1\right)+v_{12}\left[u_{13} \pi_{1 L}(0,0)+v_{13} \pi_{1 L}(0.0 .0 .0 .0 .0)\right]
$$

Defection payoff:

$$
u_{12} \pi_{1 L}\left(1, u_{13}, 1, u_{23}, 1,1\right)+v_{12} \pi_{1 L}\left(0, u_{13} \cdot 1 . u_{23} \cdot 1.0\right)
$$

Condition for $1 L$ to separate:

$$
\begin{gathered}
v_{12} u_{13}\left[\pi_{1 L}(0,0)-\pi_{1 L}\left(0, u_{13}, 1, u_{23}, 1,0\right)\right] \geq \\
u_{12}\left[\pi_{1 L}\left(1, u_{13}, 1, u_{23}, 1,1\right)-\pi_{1 L}\left(1, u_{13}, 0, u_{23.3} .0 .1\right)\right] \\
+v_{12} v_{13}\left[\pi_{1 L}\left(0, u_{13}, 1, u_{23}, 1,0\right)-\pi_{1 L}(0.0 .0 .0 .0 .(0)]\right.
\end{gathered}
$$

Case S7 $\pi_{3 H}\left(0, u_{13}, 0, u_{23}, 0,0\right)>K$

Separation payoff:

$$
\pi_{1 L}\left(p_{1 \lambda}, p_{2 \lambda}\right)+u_{12} \pi_{1 L}\left(1, u_{13}, 0, u_{23}, 0,1\right)+v_{12} \pi_{1 L}\left(0, u_{13}, 0 . u_{23}, 0.0\right)
$$

Defection payoff:

$$
\pi_{1 L}^{b r}\left(p_{1 \lambda}, p_{2 \lambda}\right)+u_{12} \pi_{1 L}\left(1, u_{13}, 1, u_{23}, 1,1\right)+v_{12} \pi_{1 L}\left(0, u_{13}, 1 . u_{23} .1 .0\right)
$$

By the same argument that was used for case S1. firm $1 L$ will not wish to separate in case $\mathrm{S} 7$. 
Separation on Nash duopoly prices: resumé A low-cost incumbent will not be willing to separate if entry costs and prior beliefs place the game in case $\mathrm{S} 1, \mathrm{~S} 4$, or S7. A low-cost incumbent may be willing to separate in remaining cases. If it is willing to separate, it is because the expected lost profit from the entry that would following defection (pretending to have high cost) outweighs expected gains from inducing rivals to set higher prices in the second period. If low-cost incumbents are willing to separate, their motivation is to limit entry.

For high-cost incumbents, however, the expected profit to be gained by deterring entry is an incentive to defect from the separating strategy.

\subsubsection{Linear example, case S2}

The condition for firm $1 H$ to separate, reproduced here for convenience, is

$$
\begin{gathered}
\pi_{1 H}\left(u_{12}, u_{21}\right)-\pi_{1 H}\left(p_{1 L}\right)+u_{12} u_{13}\left[\pi_{1 H}(1,1)-\pi_{1 H}(1,0)\right] \\
+v_{12}\left[\pi_{1 H}(0,1)-\pi_{1 H}(0,0)\right] \geq u_{12} v_{13}\left[\pi_{1 H}(1,0)-\pi_{1 H}(1,0,1,0,1,1)\right] .
\end{gathered}
$$

Firm $1 H$ 's payoff in the one-period game with only own cost type known is

$$
\pi_{1 H}\left(u_{12}, u_{21}\right)=\frac{1}{1-\theta^{2}}\left(\bar{p}_{1 H}\right)^{2} .
$$

If instead of separating firm $1 H$ masquerades as firm $1 L$, its payoff is

$$
\begin{gathered}
\pi_{1 H}\left(p_{1 L}\right)=\left(\bar{p}_{1 L}+c_{L}-c_{H}\right) \frac{a_{L}-u_{12} \theta a_{H}-v_{12} \theta a_{L}+u_{12} \theta \bar{p}_{2 H}+v_{12} \theta \bar{p}_{2 L}-\bar{p}_{1 L}}{1-\theta^{2}} \\
=\left[\bar{p}_{1 H}+\frac{c_{H}-c_{L}}{2}-\left(c_{H}-c_{L}\right)\right] \frac{a_{L}-u_{12} \theta a_{H}-v_{12} \theta a_{L}+u_{12} \theta \bar{p}_{2 H}+v_{12} \theta \bar{p}_{2 L}-\bar{p}_{1 L}}{1-\theta^{2}} \\
\text { (making use of }(158)) \quad=\left(\bar{p}_{1 H}-\frac{c_{H}-c_{L}}{2}\right) \times \\
\frac{c_{H}-c_{L}+\bar{p}_{1 H}-\bar{p}_{1 L}+\left[(1-\theta) a_{H}-v_{12} \theta\left(a_{L}-a_{H}\right)+u_{12} \theta \bar{p}_{2 H}+v_{12} \theta \bar{p}_{2 L}-\bar{p}_{1 L}\right]}{1-\theta^{2}} \\
=\left(\bar{p}_{1 H}-\frac{c_{H}-c_{L}}{2}\right) \frac{c_{H}-c_{L}+\bar{p}_{1 H}-\bar{p}_{1 L}+\bar{p}_{1 H}}{1-\theta^{2}}
\end{gathered}
$$

(using the equation of firm $1 H$ 's reaction function)

$$
\begin{gathered}
=\frac{1}{1-\theta^{2}}\left(\bar{p}_{1 H}-\frac{c_{H}-c_{L}}{2}\right)\left(\bar{p}_{1 H}+\frac{c_{H}-c_{L}}{2}\right) \\
=\frac{1}{1-\theta^{2}}\left(\bar{p}_{1 H}\right)^{2}-\frac{1}{4} \frac{1}{1-\theta^{2}}\left(c_{H}-c_{L}\right)^{2} \\
=\pi_{1 H}\left(u_{12}, u_{21}\right)-\frac{1}{4} \frac{1}{1-\theta^{2}}\left(c_{H}-c_{L}\right)^{2} .
\end{gathered}
$$


Hence

$$
\pi_{1 H}\left(u_{12}, u_{21}\right)-\pi_{1 H}\left(p_{1 L}\right)=\frac{1}{4} \frac{1}{1-\theta^{2}}\left(c_{H}-c_{L}\right)^{2} .
$$

Expressions for the other elements of the stability condition are

$$
\begin{aligned}
& \pi_{1 H}(1,1)-\pi_{1 H}(1,0)=\frac{1}{1-\theta^{2}}\left\{\left[\bar{p}_{1 H}(1,1)\right]^{2}-\left[\bar{p}_{1 H}(1,0)\right]^{2}\right\} \\
= & \frac{\theta^{2}}{\left(1-\theta^{2}\right)\left(4-\theta^{2}\right)}\left[\frac{1-\theta}{2-\theta} a_{H}-\frac{1}{4} \frac{\theta^{2}}{4-\theta^{2}}\left(c_{H}-c_{L}\right)\right]\left(c_{H}-c_{L}\right) \\
& \pi_{1 H}(0,1)-\pi_{1 H}(0,0)=\frac{1}{1-\theta^{2}}\left\{\left[\bar{p}_{1 H}(0,1)\right]^{2}-\left[\bar{p}_{1 H}(0,0)\right]^{2}\right\} \\
= & \frac{\theta^{2}}{\left(1-\theta^{2}\right)\left(4-\theta^{2}\right)}\left[\frac{1-\theta}{2-\theta} a_{H}-\frac{\theta}{4} \frac{4+\theta}{4-\theta^{2}}\left(c_{H}-c_{L}\right)\right]\left(c_{H}-c_{L}\right) \\
= & \frac{1}{1-\theta^{2}}\left[\bar{p}_{1 H}(0,1)\right]^{2}-\frac{1+\theta}{(1-\theta)(1+2 \theta)}\left[\bar{p}_{1 H}(1,0.1 .0 .1 .1)\right]^{2} .
\end{aligned}
$$

This can be evaluated using (164) and (187); the result is not informative. 


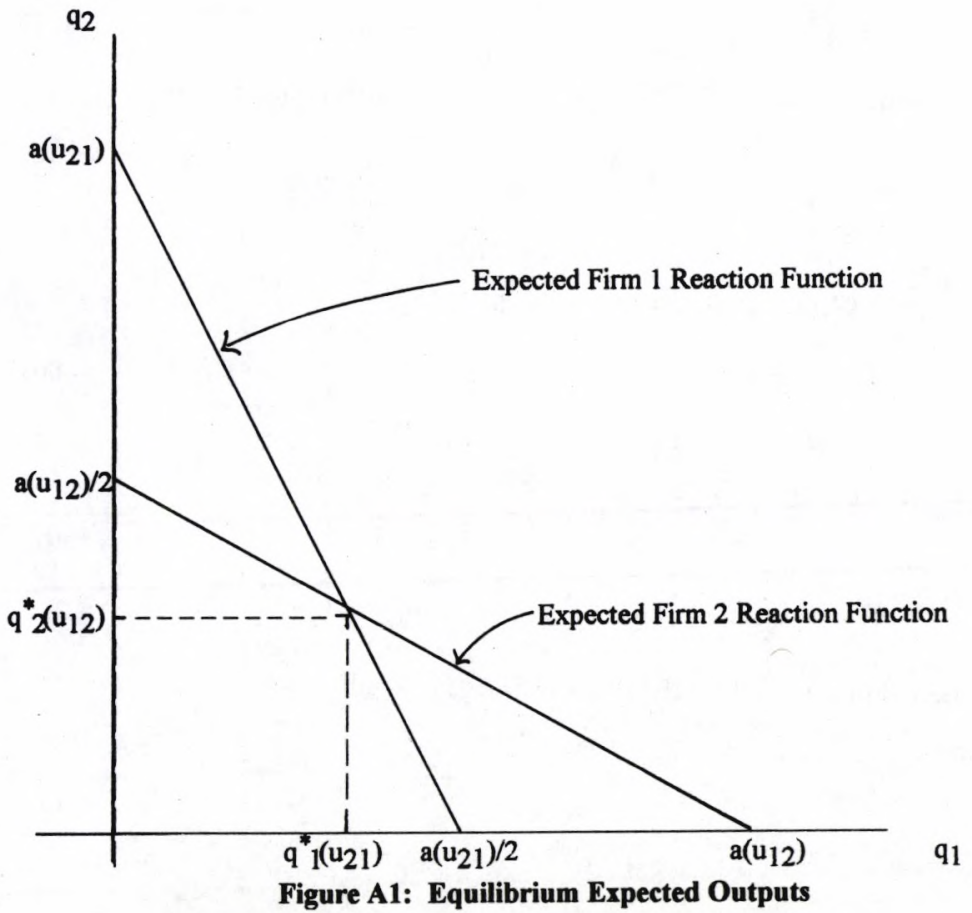




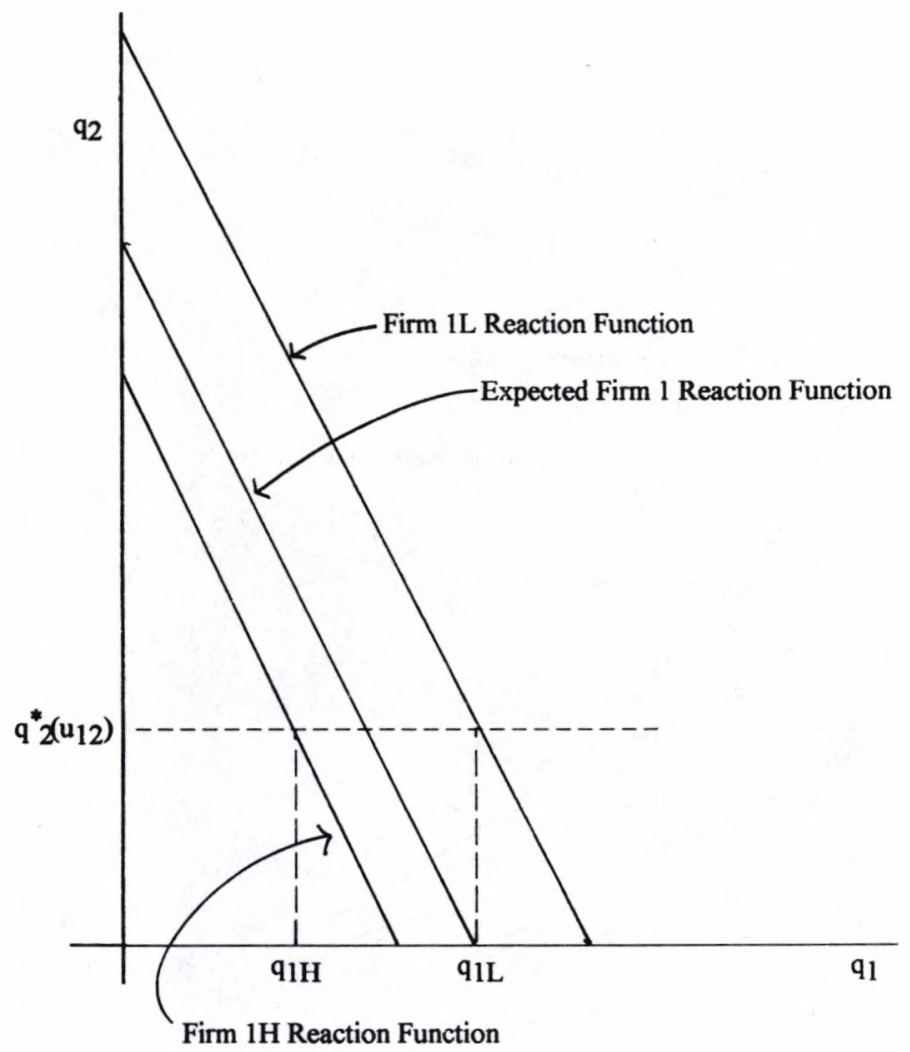

Figure A2: Equilibrium Outputs, Firm 1L and Firm 1H 


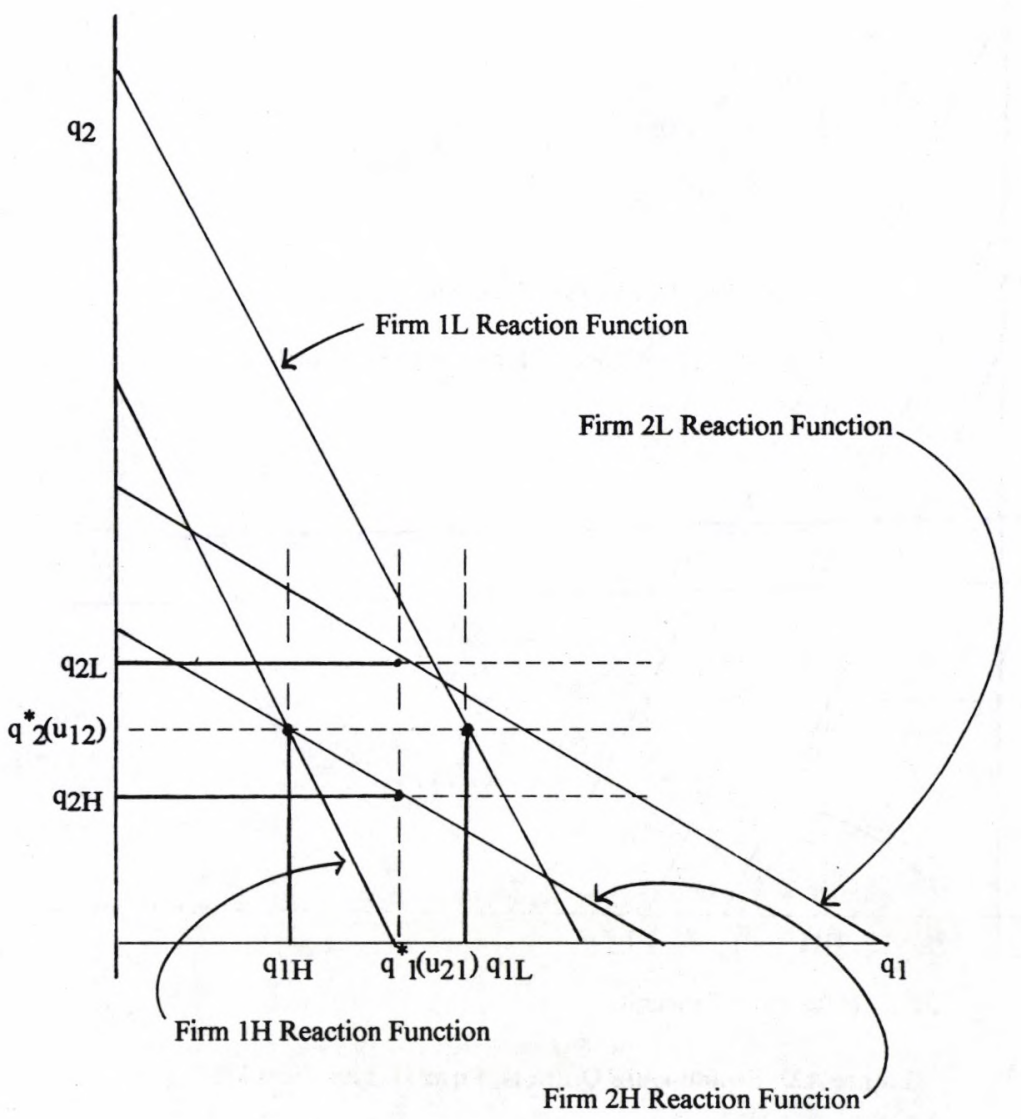

Figure A3: Equilibrium Outputs, Firms 1L, 1H, 2L, 2H 


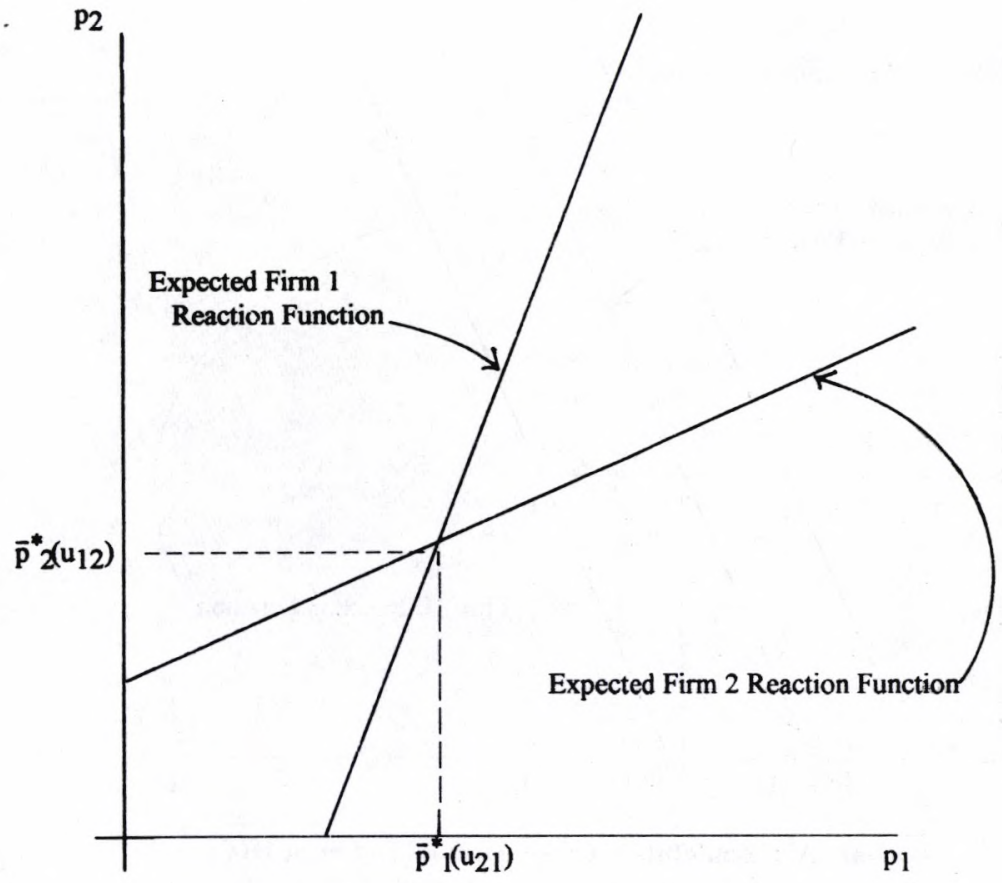

Figure A4: Equilibrium Expected Prices 


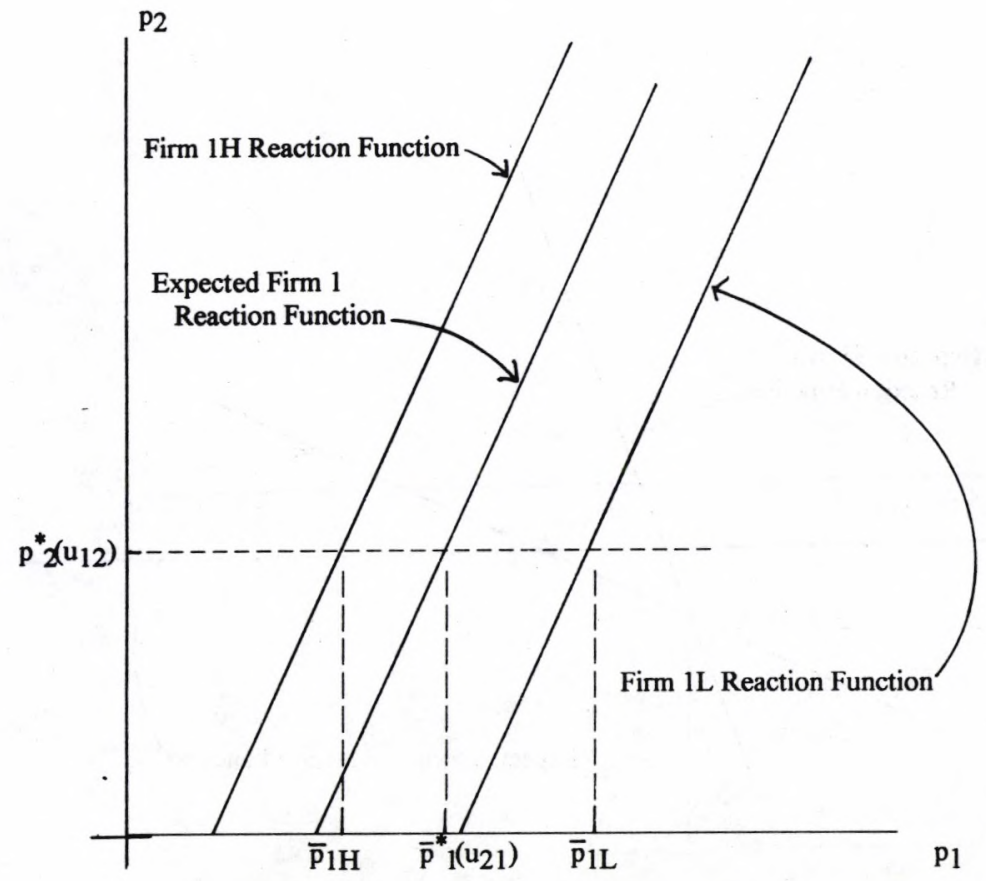

Figure A5: Equilibrium Prices, Firm 1L and Firm 1H 


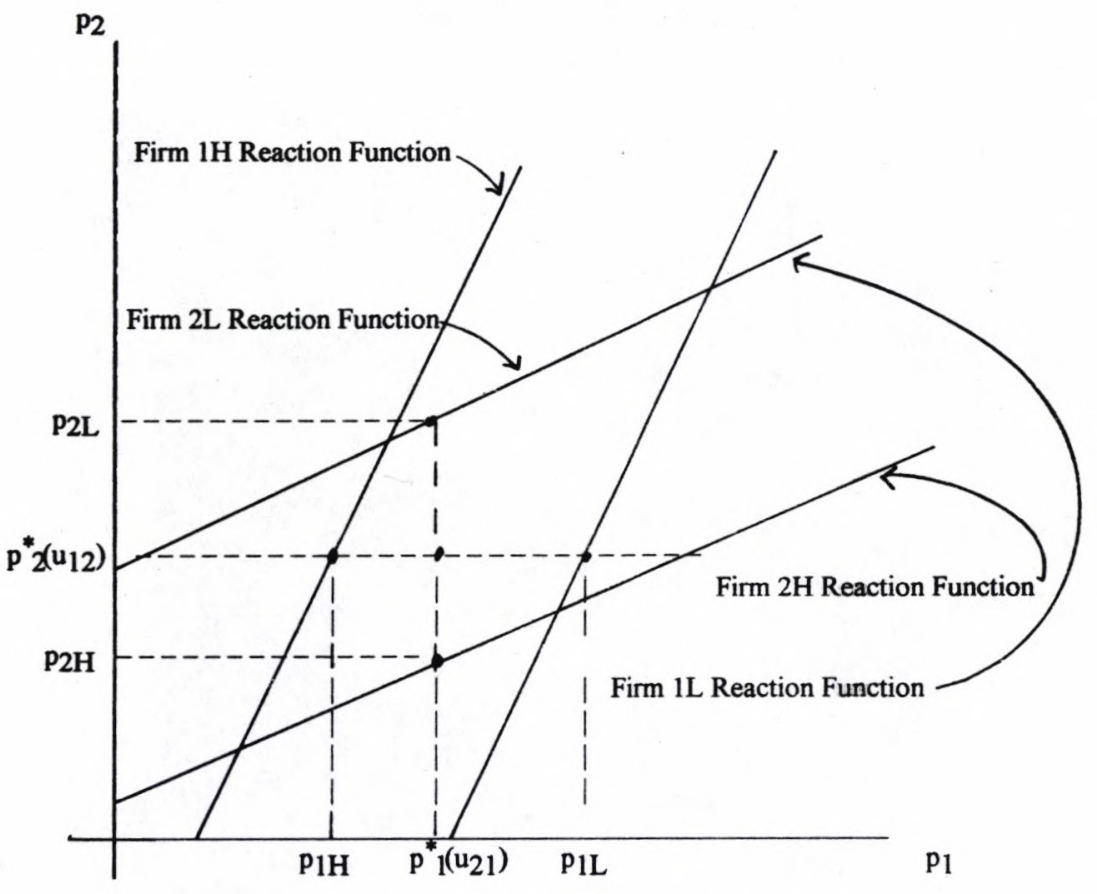

Figure A6: Equilibrium Prices, Firms 1L, 1H, 2L, 2H 


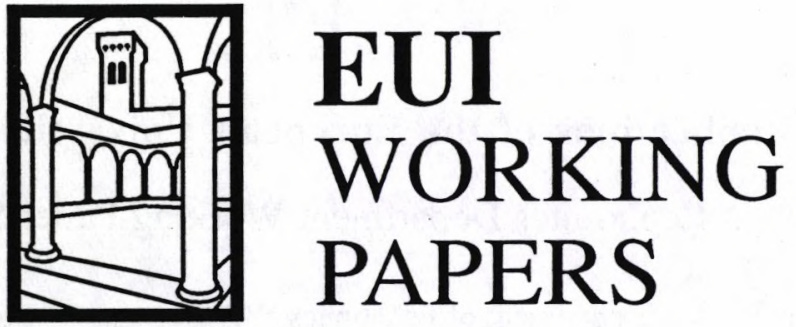

EUI Working Papers are published and distributed by the European University Institute, Florence

Copies can be obtained free of charge

- depending on the availability of stocks - from:

The Publications Officer

European University Institute

Badia Fiesolana

I-50016 San Domenico di Fiesole (FI)

Italy 


\section{嗞 \\ Publications of the European University Institute}

Economics Department Working Paper Series

To

Department of Economics WP

European University Institute

Badia Fiesolana

I-50016 San Domenico di Fiesole (FI)

Italy

From

Name

Address.

(Please print)

$\square$ Please enter/confirm my name on EUI Economics Dept. Mailing List

$\square$ Please send me a complete list of EUI Working Papers

$\square$ Please send me a complete list of EUI book publications

$\square$ Please send me the EUI brochure Academic Year 1994/95

Please send me the following EUI ECO Working Paper(s):

No, Author

Title:

No, Author

Title:

No, Author

Title:

No, Author

Title:

Date 


\section{Working Papers of the Department of Economics Published since 1993}

ECO No. 93/1

Carlo GRILLENZONI

Forecasting Unstable and Non-Stationary Time Series

ECO No. 93/2

Carlo GRILLENZONI

Multilinear Models for Nonlinear Time

Series

ECO No. 93/3

Ronald M. HARSTAD/Louis PHLIPS

Futures Market Contracting When You

Don't Know Who the Optimists Are

ECO No. 93/4

Alan KIRMAN/Louis PHLIPS

Empirical Studies of Product Markets

ECO No. 93/5

Grayham E. MIZON

Empirical Analysis of Time Series:

Illustrations with Simulated Data

ECO No. 93/6

Tilman EHRBECK

Optimally Combining Individual

Forecasts From Panel Data

ECO NO. 93/7

Víctor GÓMEZ/Agustín MARAVALL Initializing the Kalman Filter with Incompletely Specified Initial Conditions

ECO No. 93/8

Frederic PALOMINO

Informed Speculation: Small Markets

Against Large Markets

ECO NO. 93/9

Stephen MARTIN

Beyond Prices Versus Quantities

ECO No. 93/10

José María LABEAGA/Angel LÓPEZ

A Flexible Demand System and VAT

Simulations from Spanish Microdata

ECO No. 93/11

Maozu LU/Grayham E. MIZON

The Encompassing Principle and

Specification Tests
ECO No. 93/12

Louis PHLIPS/Peter MØLLGAARD

Oil Stocks as a Squeeze Preventing

Mechanism: Is Self-Regulation Possible?

ECO No. 93/13

Pieter HASEKAMP

Disinflation Policy and Credibility: The

Role of Conventions

ECO No. 93/14

Louis PHLIPS

Price Leadership and Conscious

Parallelism: A Survey

ECO No. 93/15

Agustín MARAVALL

Short-Term Analysis of Macroeconomic Time Series

ECO No. 93/16

Philip Hans FRANSES/Niels

HALDRUP

The Effects of Additive Outliers on Tests for Unit Roots and Cointegration

ECO No. 93/17

Fabio CANOVA/Jane MARRINAN

Predicting Excess Returns in Financial Markets

ECO No. 93/18

Iñigo HERGUERA

Exchange Rate Fluctuations, Market

Structure and the Pass-through

Relationship

ECO No. 93/19

Agustín MARAVALL

Use and Misuse of Unobserved

Components in Economic Forecasting

ECO No. 93/20

Torben HOLVAD/Jens Leth

HOUGAARD

Measuring Technical Input Efficiency for

Similar Production Units:

A Survey of the Non-Parametric

Approach 
ECO No. 93/21

Stephen MARTIN/Louis PHLIPS

Product Differentiation, Market Structure and Exchange Rate Passthrough

ECO No 93/22

F. CANOVA/M. FINN/A. R. PAGAN

Evaluating a Real Business Cycle Model

ECO No 93/23

Fabio CANOVA

Statistical Inference in Calibrated Models

ECO No 93/24

Gilles TEYSSIËRE

Matching Processes in the Labour Market in Marseilles. An Econometric Study

ECO No 93/25

Fabio CANOVA

Sources and Propagation of International

Business Cycles: Common Shocks or

Transmission?

ECO No. 93/26

Marco BECHT/Carlos RAMÍREZ

Financial Capitalism in Pre-World War I

Germany: The Role of the Universal

Banks in the Financing of German

Mining Companies 1906-1912

ECO No. 93/27

Isabelle MARET

Two Parametric Models of Demand,

Structure of Market Demand from

Heterogeneity

ECO No. 93/28

Stephen MARTIN

Vertical Product Differentiation, Intra-

industry Trade, and Infant Industry

Protection

ECO No. 93/29

J. Humberto LOPEZ

Testing for Unit Roots with the k-th

Autocorrelation Coefficient

ECO No. 93/30

Paola VALBONESI

Modelling Interactions Between State and

Private Sector in a "Previously" Centrally

Planned Economy
ECO No. 93/31

Enrique ALBEROLA ILA/J. Humberto LOPEZ/Vicente ORTS RIOS

An Application of the Kalman Filter to the Spanish Experience in a Target Zone (1989-92)

ECO No. 93/32

Fabio CANOVA/Morten O. RAVN

International Consumption Risk Sharing

ECO No. 93/33

Morten Overgaard RAVN

International Business Cycles: How much can Standard Theory Account for?

ECO No. 93/34

Agustín MARAVALL

Unobserved Components in Economic

Time Series

ECO No. 93/35

Sheila MARNIE/John

MICKLEWRIGHT

"Poverty in Pre-Reform Uzbekistan:

What do Official Data Really Reveal?'

ECO No. 93/36

Torben HOLVAD/Jens Leth

HOUGAARD

Measuring Technical Input Efficiency for

Similar Production Units:

80 Danish Hospitals

ECO No. 93/37

Grayham E. MIZON

A Simple Message for Autocorrelation

Correctors: DON'T

ECO No. 93/38

Barbara BOEHNLEIN

The Impact of Product Differentiation on Collusive Equilibria and Multimarket

Contact

ECO No. 93/39

H. Peter MØLLGAARD

Bargaining and Efficiency in a

Speculative Forward Market

洸洸 
ECO No. 94/1

Robert WALDMANN

Cooperatives With Privately Optimal

Price Indexed Debt Increase Membership

When Demand Increases

ECO No. 94/2

Tilman EHRBECK/Robert

WALDMANN

Can Forecasters' Motives Explain

Rejection of the Rational Expectations

Hypothesis?

ECO No. 94/3

Alessandra PELLONI

Public Policy in a Two Sector Model of

Endogenous Growth

ECO No. 94/4

David F. HENDRY

On the Interactions of Unit Roots and

Exogeneity

ECO No. 94/5

Bernadette GOVAERTS/David F. HENDRY/Jean-François RICHARD

Encompassing in Stationary Linear

Dynamic Models

ECO No. 94/6

Luigi ER.MINL/Dongkoo CHANG

Testing the Joint Hypothesis of Rationality and Neutrality under Seasonal Cointegration: The Case of Korea

ECO No. 94/7

Gabriele FIORENTINI/Agustín

MARAVALL

Unobserved Components in ARCH

Models: An Application to Seasonal

Adjustment

\section{ECO No. 94/8}

Niels HALDRUP/Mark SALMON

Polynomially Cointegrated Systems and their Representations: A Synthesis

ECO No. 94/9

Mariusz TAMBORSKI

Currency Option Pricing with Stochastic

Interest Rates and Transaction Costs:

A Theoretical Model

ECO No. 94/10

Mariusz TAMBORSKI

Are Standard Deviations Implied in

Currency Option Prices Good Predictors

of Future Exchange Rate Volatility?
ECO No. 94/11

John MICKLEWRIGHT/Gyula NAGY

How Does the Hungarian Unemployment Insurance System Really Work?

ECO No. 94/12

Frank CRITCHLEY/Paul MARRIOTT/Mark SALMON

An Elementary Account of Amari's

Expected Geometry

ECO No. 94/13

Domenico Junior MARCHETTI

Procyclical Productivity, Externalities and Labor Hoarding: A Reexamination of Evidence from U.S. Manufacturing

ECO No. 94/14

Giovanni NERO

A Structural Model of Intra-European

Airline Competition

ECO No. 94/15

Stephen MARTIN

Oligopoly Limit Pricing: Strategic

Substitutes, Strategic Complements 


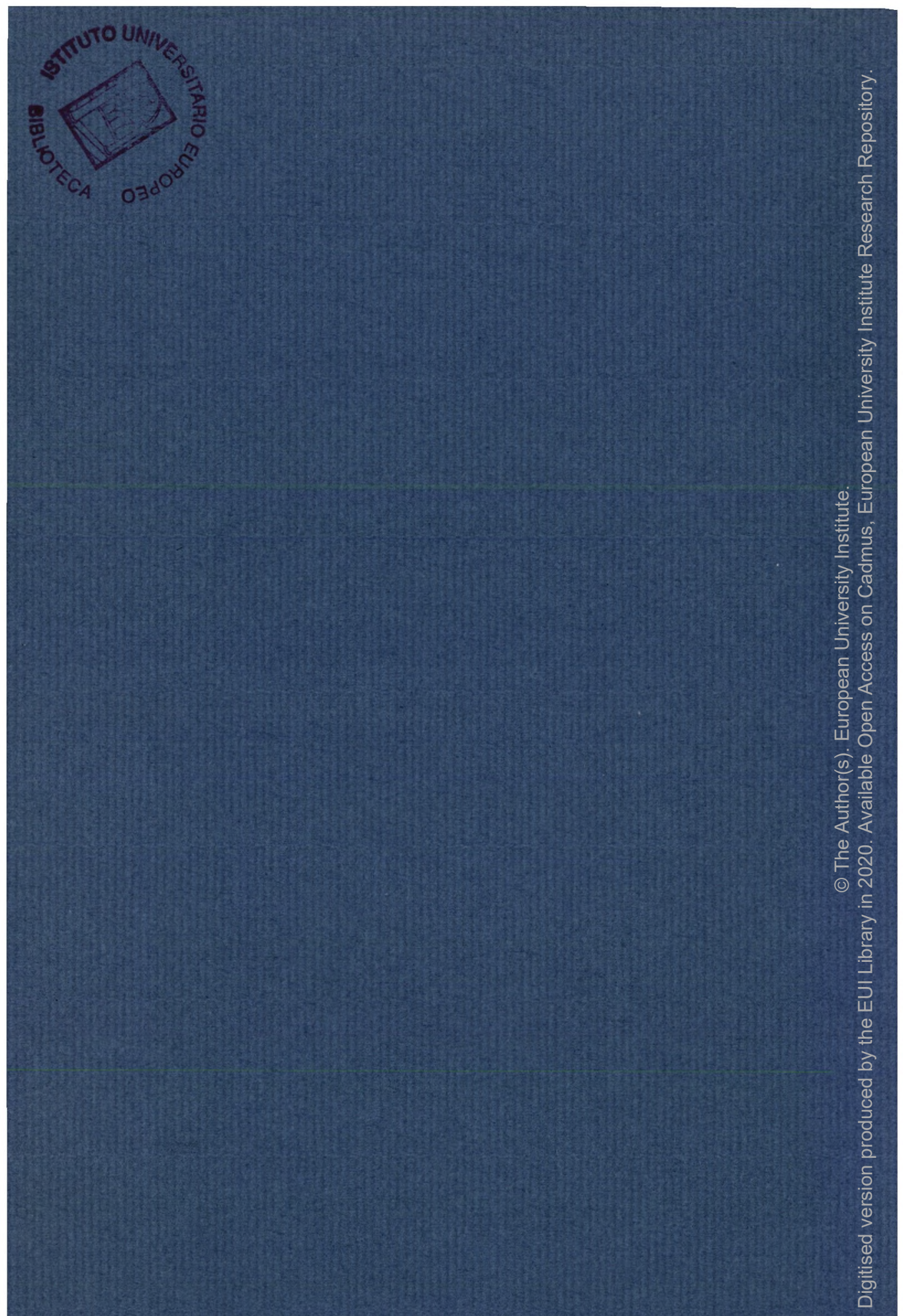

